\title{
On the shoulders of giants: uncovering key themes of organizational unlearning research in mainstream management journals
}

\author{
Shubham Sharma ${ }^{1}$. Usha Lenka ${ }^{1}$ i
}

Received: 18 May 2020 / Accepted: 13 August 2021 / Published online: 2 September 2021

(c) The Author(s), under exclusive licence to Springer-Verlag GmbH Germany, part of Springer Nature 2021

\begin{abstract}
Unlearning has evinced immense traction and opportunity in debates pertaining to organizational learning, innovation, management of change, knowledge management, and new product development, to name but a few. Provided the diversity and expansiveness of the phenomenon, past studies have undertaken both narrative and systematic reviews to synthesize the field of organizational unlearning (OU). Although highly commendable and enlightening, these scholarly efforts would be augmented by contemplating the share of leading management journals towards furthering the research on unlearning. Moreover, a systematic comprehension of the research themes of OU can be instrumental in representing the intellectual structure of the field. For this purpose, we undertake a combination of bibliometric and thematic analysis to identify critical trends that have helped shape unlearning research. The results discern the main scientific actors (articles, authors, journals, universities), research design, and dimensions of OU. In addition, eight clusters of unlearning along with underlying theoretical perspectives are analyzed, which may help scholars integrate the development of one domain to another, formulate pertinent research questions related to OU, and encourage interdisciplinary research.
\end{abstract}

Keywords Organizational unlearning · Organizational learning · Bibliometrics · Leading management journals · Co-occurrence analysis · Thematic analysis · VOSviewer

Shubham Sharma

shubham.mgmt@gmail.com

Usha Lenka

usha.lenka@ms.iitr.ac.in; ushalenka@gmail.com

1 Department of Management Studies, Indian Institute of Technology Roorkee, Roorkee,

Uttarakhand, India 


\section{Introduction}

Not long ago, organizations were often attributed to conservatism, stability, and aversion to change (Drucker 1999). For this reason, although indispensable, learning in organizations was considered serendipitous, sporadic, and antithetical to the spirit of organizing. Learning, on the one hand, promotes experimentation, variety, and disorganization. On the other hand, organizing opposes variety and instability (Contu et al. 2003; Weick and Westley 1996). But this view about organizations quickly changed, given that organizations are operating in a volatile, uncertain, complex, and ambiguous environment. This means that organizations have to become destabilizers and continuously innovate and change (Drucker 1999; Starbuck 1983). Furthermore, organizations cannot circumvent learning; otherwise, that leads to the repetition of mistakes, insensitivity to the stakeholders' cues, and commitment of valuable resources to the areas of nonresults.

However, as organizations continue to learn new knowledge, behaviors, and practices, it may be that a portion of that knowledge becomes obsolete and ineffective due to continuous changes in the external environment (Hedberg 1981). In such a case, organizations must be capable of discarding established knowledge, practices, values, and/or behaviors that have become redundant and inhibit the acquisition of new knowledge and behaviors (Becker 2018; Nystrom and Starbuck 1984). This practice of discarding obsolete knowledge and/or behaviors is known as organizational unlearning (henceforth $\mathrm{OU}$ ) and is crucial to maintaining organizational viability and competitiveness (Hedberg 1981; Tsang 2017). In this regard, it is essential to note that unlearning is a conscious and deliberate attempt to eliminate obsolete and misleading knowledge. Thus, OU is different from passive forgetting, defined as an inadvertent or accidental loss of knowledge due to its disuse, failure to capture new knowledge, memory decay, or personnel turnover (Argote 2013; Easterby-Smith and Lyles 2011; Martin de Holan et al. 2004).

Since the publication of the seminal book chapter of Hedberg (1981), How Organizations Learn and Unlearn, there has been a recent surge of interest in studying the phenomenon of OU among academicians, researchers, and practitioners from diverse theoretical and empirical backgrounds. Most of the earlier studies focused on unlearning in crisis management (Hedberg et al. 1976; Nystrom and Starbuck 1984; Sheaffer and Mano-Negrin 2003; Snihur 2018; Starbuck and Hedberg 1977). Some studies regard OU as a prerequisite to learning new knowledge and behaviors (Bettis and Prahalad 1995; Hamel 1991; Hedberg 1981; Starbuck 1996). While this debate on whether unlearning is a prerequisite for learning is still prevalent, several emerging aspects, including the mechanism of unlearning (Azmi 2008; Cegarra-Navarro and Wensley 2019; Zhao et al. 2013), differences between unlearning and accidental forgetting (CegarraNavarro et al. 2014a, b; Fernandez and Sune 2009; Martin de Holan and Phillips 2004a, b; Martin de Holan et al. 2004; Tsang and Zahra 2008), unlearning as a catalyst of change (Akgün et al. 2007a; Azmi 2008), innovation (Becker 2008, 
2010; Mariano and Casey 2015; Rebernik and Širec 2007), and knowledge transfer in multinational enterprises (Tsang 2008, 2017; Wang et al. 2017; Yildiz and Fey 2010; Zahra et al. 2011), have begun to receive increased attention. A plethora of other studies have also explored the relationship of unlearning with topics like new product development (Akgün et al. 2006, 2007b; Lyu et al. 2020), environmental knowledge (Martelo-Landroguez et al. 2018), and quality of health care (Cegarra-Navarro et al. 2011; Cegarra-Navarro et al. 2014a, b; Rushmer and Davies 2004). Overall, these efforts endeavor to "loosening up unlearning and forgetting's enclosed system and connecting the field to other research streams such as change management, innovation, learning" (Klammer and Gueldenberg 2019: p. 874). Therefore, although the knowledge base of unlearning has proliferated by virtue of its linkage to other concepts, yet it has evolved in a fragmented manner, and it is difficult to capture the entire gamut of OU.

Provided the diversity and fragmentation of the phenomenon and in an attempt to synthesize the existing body of knowledge, scholars have undertaken traditional and systematic reviews of the unlearning literature. A systematic review is different from a traditional review in the sense that the former provides a systematic, transparent, and replicable means for gathering, synthesizing, and appraising the results of previous studies on a specific topic (Gomes et al. 2016; Tranfield et al. 2003). On the one hand, the review articles on unlearning by Azmi (2008), Becker (2005), and Tsang and Zahra (2008) fall into the traditional review category. On the other hand, Hislop et al. (2014), Howells and Scholderer (2016), and Klammer and Gueldenberg (2019) reviews on unlearning can be placed in the systematic review category. ${ }^{1}$

Although both the categories of review articles have provided an invaluable contribution to the existing state of knowledge and helped advance our understanding of unlearning research, several shortcomings are evident. First, none of the previous studies have systematically addressed the key themes or research clusters that have helped shape the unlearning research. Unlearning has been associated with multiple concepts like organizational learning (henceforth OL), innovation, and organizational transformation. Subsequently, these reviews have not facilitated the integration of unlearning with the aforementioned research domains and have also precluded researchers to 'leverage developments from one domain to another' domain (Raghuram et al. 2019: p. 309). Second, none of the studies have reported the contribution of leading management journals vis-à-vis unlearning, i.e., authors' characteristics, collaboration network amongst authors, methodological issues applied in unlearning research, dimensions of unlearning and analyzing the most influential articles, books, and book chapters of unlearning.

Given these conditions, this study aims to extend and complement the previous reviews while simultaneously providing a qualitative and quantitative view of leading trends of unlearning research. For this, we restrict our focus to the contribution of leading business and management journals publishing on unlearning over 43 years (1976-2019). This is in line with the justification of Locke and GoldenBiddle (1997), Sergeeva and Andreeva (2016), and Gomes et al. (2016) that

\footnotetext{
${ }^{1}$ A summary of these reviews on unlearning is presented in Appendix 1 (Table 18).
} 
mainstream journals represent 'a proxy for academic scholarship' by constituting a rigorous review process, publishing only the highest quality manuscript, and providing an accurate view of the topic (Sergeeva and Andreeva 2016: p. 243). This study incorporates bibliometric procedures to analyze the leading trends and map the key research themes of unlearning in mainstream management journals. Bibliometric procedures yield both the quantitative description of leading trends (main authors, journals, documents, and institutions) as well as provide a meticulous view of the qualitative content (prominent themes of unlearning research) of a concept (Ferreira et al. 2014; Gaviria-Marin et al. 2019; Mas-Tur et al. 2020). This study explicitly incorporates bibliometric methods like citation analysis (Garfield 1972) to report the leading trends of unlearning research. A co-citation analysis (Small et al. 1973) is used to identify linkages among influential articles of OU, and co-occurrence of keyword analysis (Callon et al. 1991) is used to present the main research themes of OU. For this reason, bibliometric analysis is preferred over other classical tools of literature review (traditional reviews, scoping studies, systematic review, and integrative literature review) as far as this study is concerned.

This study contributes to the unlearning literature in several ways. First, it establishes the leading business and management journals' contribution as outlets for publishing research on unlearning. This will help the researchers to select the right journal and prepare their manuscripts per the targeted journal's scope. Second, it analyzes the characteristics of leading authors and institutions that publish research on unlearning. This may help the other researchers working in the field of unlearning to collaborate with these leading scholars. It also provides budding researchers to undertake their doctoral and post-doctoral research under the mentorship of these researchers. Third, this study analyzes the subject matter of the most influential studies on unlearning carried out during the last 43 years. This analysis will help establish the intellectual core of unlearning, whereby future works can extend or even improve the interpretation of previous studies. Fourth, this study proposes an integrative framework of unlearning based on prominent themes of OU, uncovers the primary theoretical lenses operative in each theme, and identifies theme-wise research gaps that can be used as a starting point for future research.

The rest of the article proceeds as follows. First, Sect. 2 explains the fundamentals of unlearning like origin, evolution, definition, and subject matter of OU. Then, Sect. 3 presents the methodology used in this study to systematically search unlearning articles, select leading management journals, and perform bibliometric analysis. Next, Sect. 4 shows the results of bibliometric analysis. Finally, Sect. 5 discusses the findings and their implications for future theoretical and empirical research of OU.

\section{Foundations of organizational unlearning}

\subsection{Origin and development}

Thorough knowledge of the origin, changes, and development of unlearning since its inception is necessary to gauge the future of research. One effective way to achieve this objective is to divide the progress of research into different periods as 


\section{ORGANIZATIONAL UNLEARNING}

\section{PROGRESS IN LEADING MANAGEMENT JOURNALS}

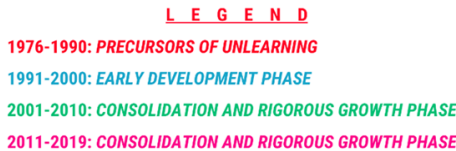

2011-2019: CONSOLIDATION AND RIGOROUS GROWTH PHASE

\section{PHASE 1: 1976-1990}

1976: First research paper on OU Camping on Seesaws...appears in Administrative Science Quarterly. 1981: Bo Hedberg's book chapter How Organizations Learn and Unlearn appears in Paul Nystrom and William Starbuck's book Handbook of Organizational Design. 1989: Klein's opposition to the need for unlearning is published.

1991: Unlearning is an important element of organizational learning (Huber, 1991). 1996: Special issue of unlearning published in International Journal of Technology Management. 2000: One of the seven major contributions to the field of organizational learning (Easterby Smith et al., 2000)

\begin{tabular}{|l|l}
\hline PHASE 4: 2011-2019 & forgetting (Martin de Holan and Phillips, 2004). \\
& 2004: Unlearning can be wiping or deep unlearning \\
& (Rushmer and Davies, 2004). \\
& 2008: First review article of unlearning \\
& "Organizational unlearning" published in Human \\
& Relations (Tsang and Zahra, 2008). \\
2011: Journal of Management Inquiry publish & 2009: Chokr's book Unlearning or How Not to Be \\
dialog section on unlearning. & Governed published.
\end{tabular}

two special issues on unlearning

2018: One of the thematic track in IFKAD 2018

conference held in Delft, Netherlands.

2019: First systematic review of organizational

unlearning published by Klammer and

Gueldenberg (2019) in Journal of Knowledge Management.

\section{PHASE 3: 2001-2010}

2004: Organizational unlearning is a part of forgetting (Martin de Holan and Phillips, 2004) : Unlearning can be wiping or deep unlearning Rushmer and Davies, 2004). 2008: First review article of unlearning Relations (Tsang and Zahra, 2008). Governed published.

Fig. 1 Timeline infographic of organizational unlearning (1976-2019). There are three distinct phases in organizational unlearning research. The 1976-1990 time period can be labeled as Precursors of Unlearning, 1991-2000 is characterized by Early Development, and the year 2000 onwards has witnessed the Consolidation and Rigorous phase of unlearning research

(1) precursors or initiation of unlearning (1976-1990), (2) early development phase (1991-2000), and (3) consolidation and rigorous growth phase (2000 onwards). Similar phases have also been proposed by Furrer et al. (2008), Gaviria-Marin et al. (2019), and Serenko (2013). For instance, Gaviria-Marin et al. (2019) divided the development of knowledge management based on the first (the 1960s), second (1990s), third (2000s), and fourth-generation (2010 onwards). Figure 1 shows the timeline of OU covering each of the three phases.

Unlearning first appeared in the writings of educational reformists like Dewey (1938) and Toffler (1971). For instance, Toffler (1971) believed that due to the increased pace of mechanization and industrialization, the obsolescence rate of knowledge has also increased and that 'today's 'fact' becomes tomorrow's 'misinformation"” (Toffler 1971: p. 414). Therefore, to improve learning efficiency, future schools must be cautious not to overload students with information but instigate a 
tendency to understand the relevance of new ideas and revitalize them by discarding obsolete ones (Dewey 1938; Toffler 1971). This view of unlearning is regaining currency among the academic community lately with the writings of Antonacopoulou (2009), Chokr (2009), and Brook et al. (2016).

Unlearning in organizational studies started with the study of Hedberg and associates to study Swedish firms struggling to avoid bankruptcy due to changes in the external environment and failure to pay sufficient attention to the evolution of its environment (Hedberg et al. 1976; Nystrom and Starbuck 1984; Starbuck 2017; Starbuck and Hedberg 1977). In such a case, past learning compels organizations to reinforce the success formulas embedded as organizational routines (Fiol and Lyles 1985; Levitt and March 1988). This stage of overlooking the intensity of crisis is called weathering the storm and consumes a substantial portion of an organization's financial and non-financial resources (Hedberg et al. 1976). Finally, when managers realize that threats have become inexorable, they take desperate measures to challenge organizations' status quo. These measures constitute the second stage, popularly called organizational unlearning. However, unlearning involves an umpteen number of challenges and resistance from individuals because it signifies a profound departure from the status quo. Nevertheless, the efficiency of unlearning is a prerequisite for the third stage of rediscovery and regeneration (Hedberg et al. 1976).

\subsection{Definitions and subject matter}

Table 1 presents a chronological outline of various definitions of unlearning prevalent during four different phases-1976-1990, 1991-2000, 2001-2010, and 2011present. Most definitions attribute a unified connotation to unlearning, i.e., it is an intentional process, whereby organizations question, identify and discard obsolete knowledge (Easterby-Smith and Lyles 2011; Hedberg 1981; Klein 1989; Martin de Holan et al. 2004; Zhao et al. 2013), routines (Akgün et al. 2006; Matsuo 2018; Tsang 2008; Tsang and Zahra 2008), beliefs (Baker and Sinkula 1999; Hislop et al. 2014), or behaviors (Hamel 1991; Becker 2010) in order to acquire new knowledge and behaviors (Becker 2010; Cegarra-Navarro et al. 2011). Moreover, unlearning definitions fall into either one of the two categories, namely, process-oriented and outcome-oriented. The process-oriented definition emphasizes how organizations discard their obsolete knowledge and behaviors (Baker and Sinkula 1999; Easterby-Smith and Lyles 2011; Matsuo 2018). The outcome-oriented definitions are more concerned about the consequences of unlearning. Such consequences include acquiring new knowledge and behaviors, relearning, and adaptation (Becker 2010; Hedberg 1981; Wang et al. 2019). Conclusively, the outcome-oriented definitions of unlearning are relatively broader in scope than the process-oriented definitions. However, outcome-oriented definitions are often criticized because of their inability to separate the process of learning/relearning from unlearning, a subject matter beyond the scope of the present study (see Sharma and Lenka 2019; Wang et al. 2019). This classification is in line with Wang et al. (2019), where they proposed two perspectives of unlearning: (i) elimination of outdated routines and (ii) learning/ relearning. The first perspective emphasizes the process orientation, and the second 


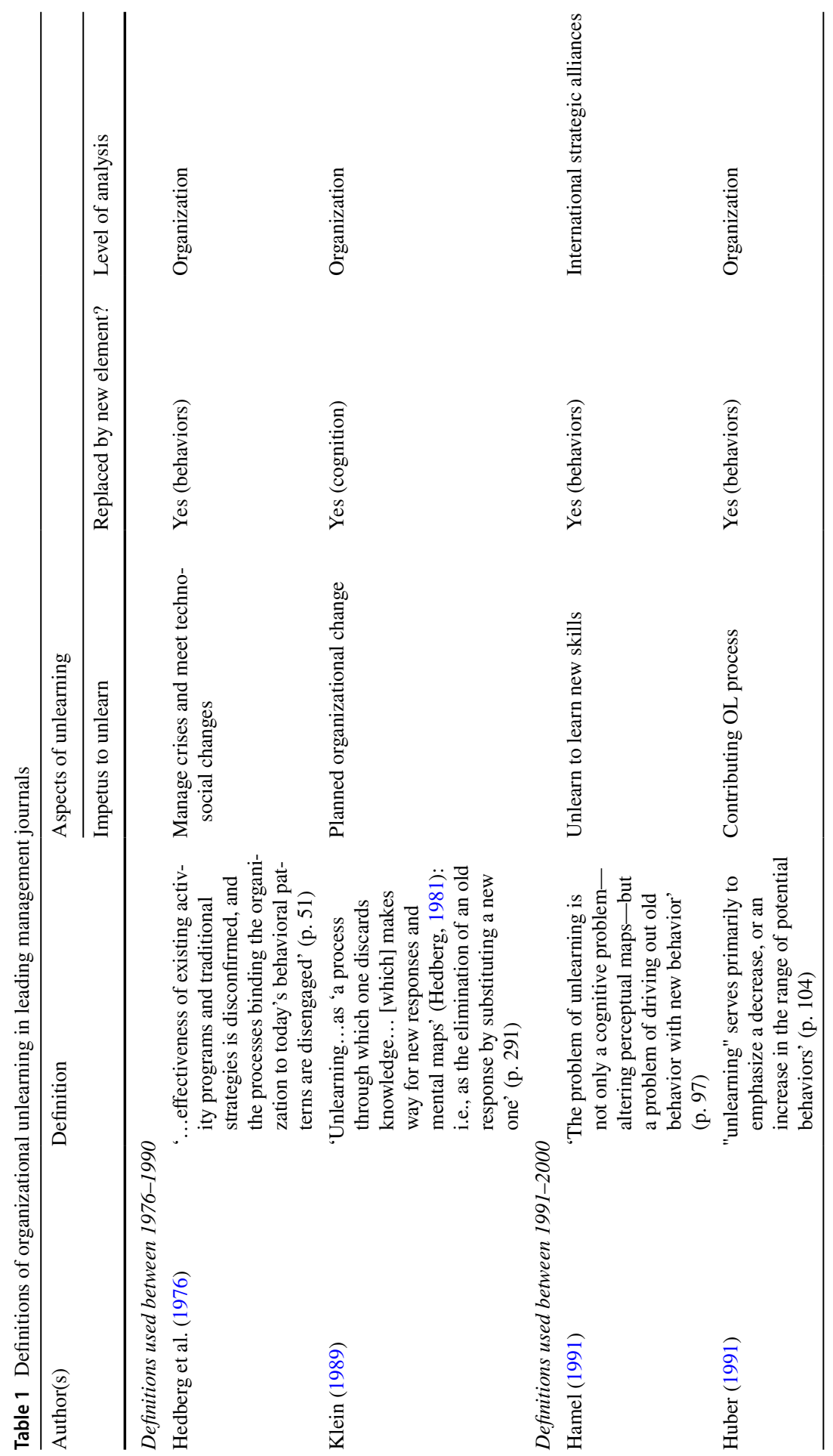




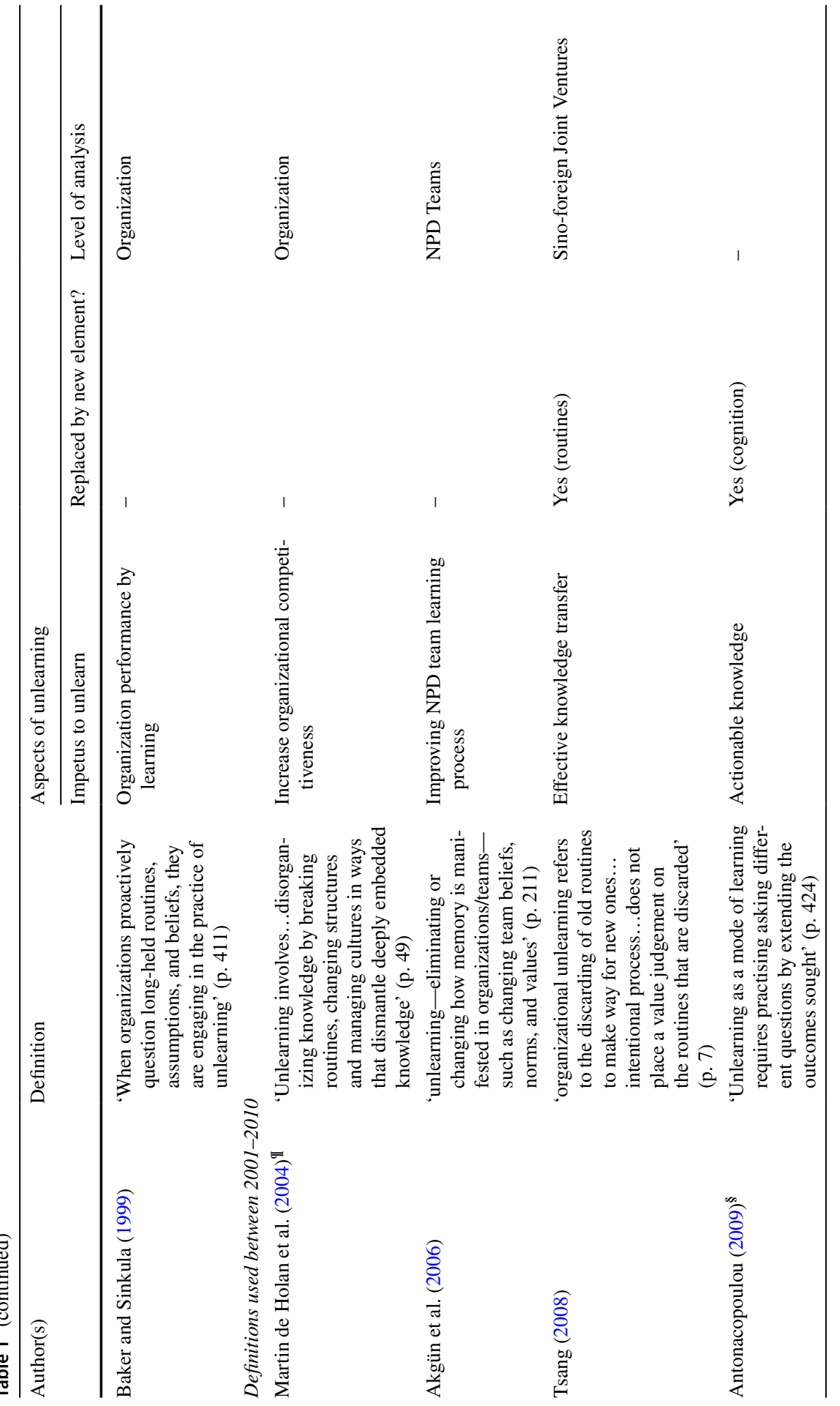




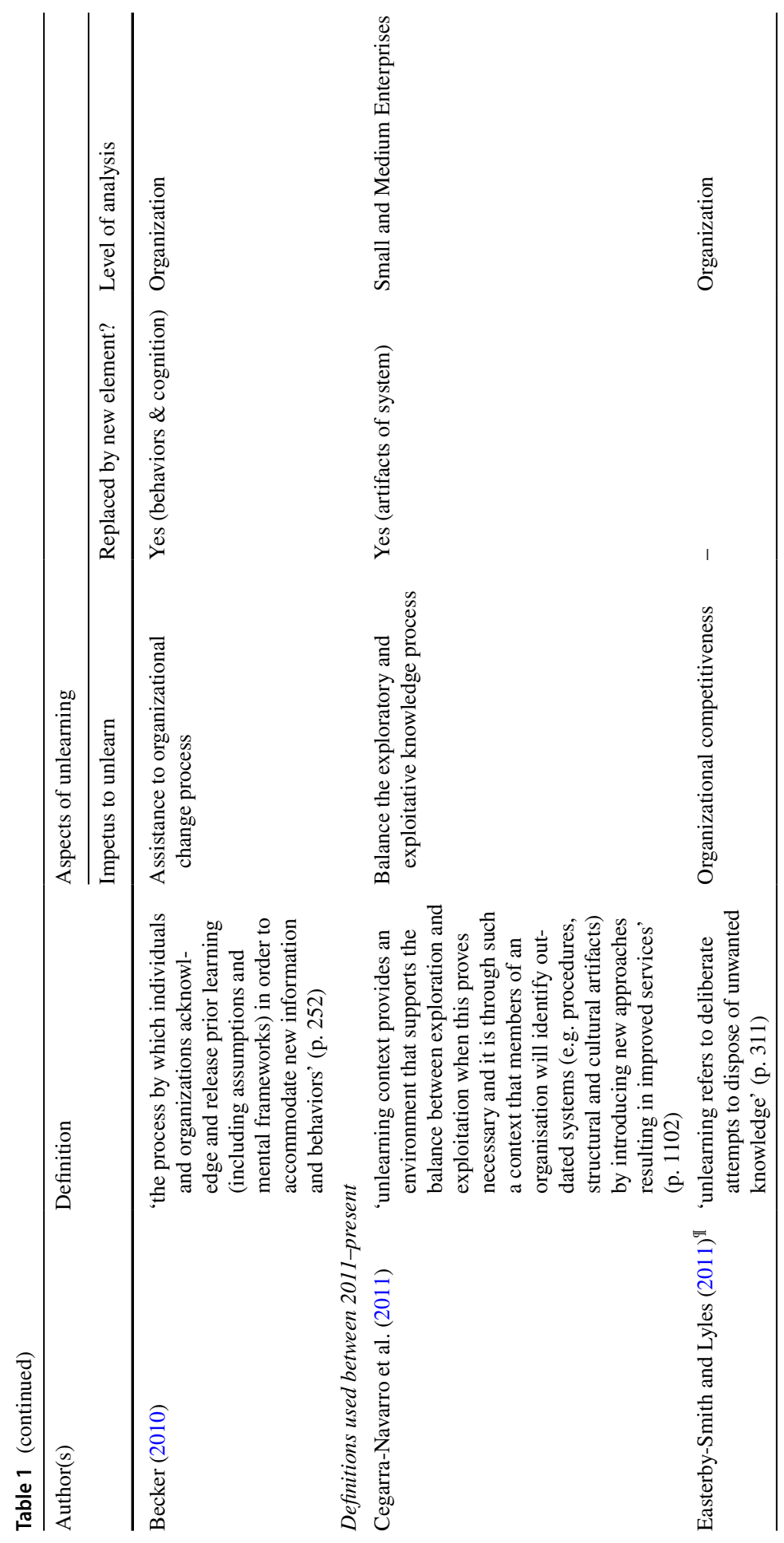




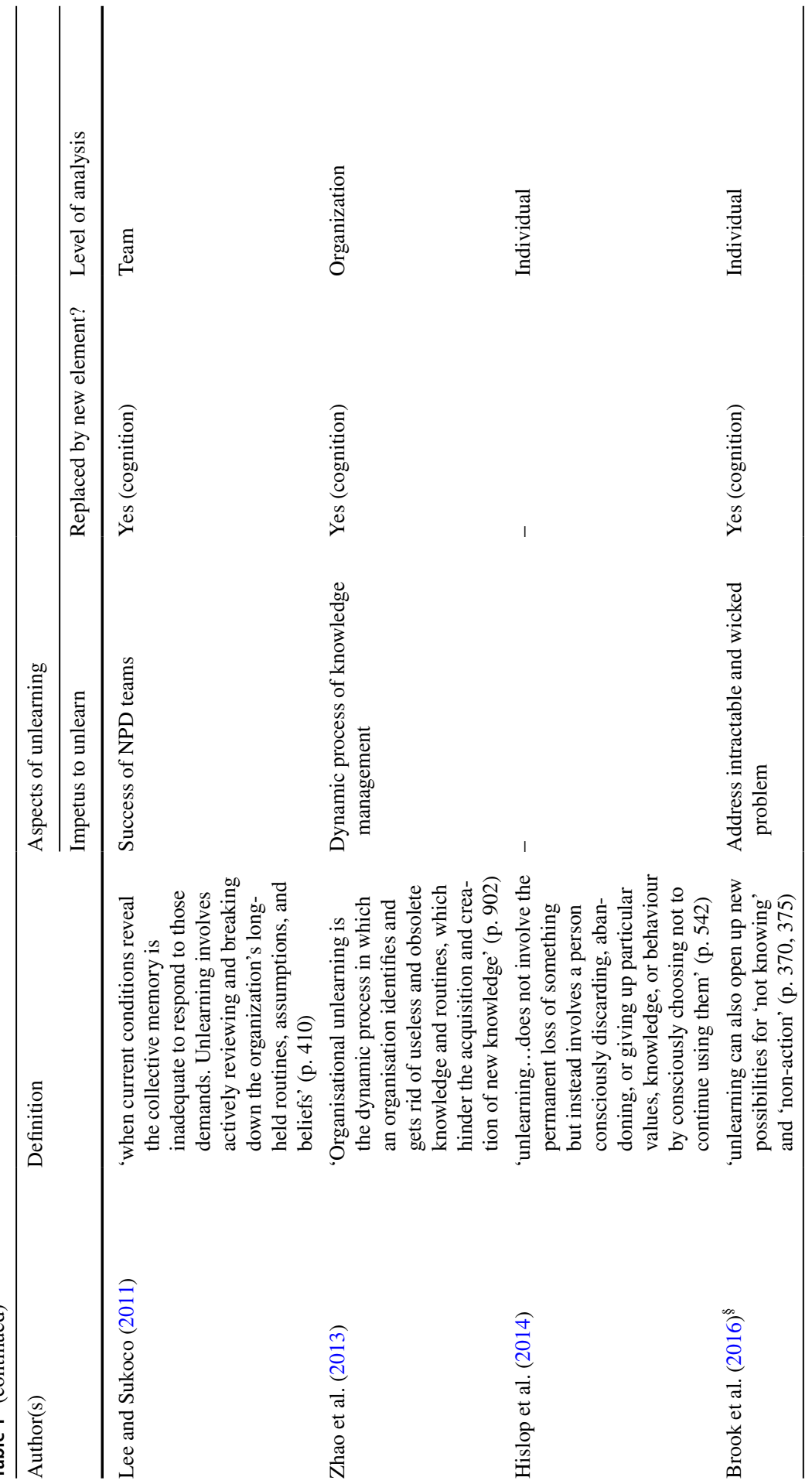




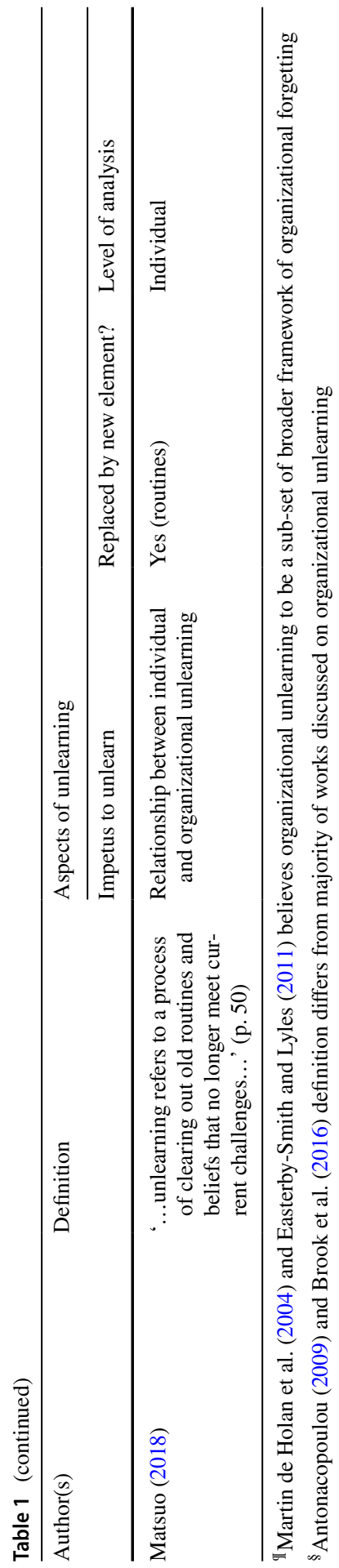


perspective is more inclined towards the outcome of unlearning, i.e., acquisition of new learning/relearning. However, our approach is different from Wang et al. (2019) because the impetus to unlearn cannot be restricted to learning/relearning, nor is relearning the ultimate objective of unlearning (Sharma and Lenka 2019). Firms unlearn to manage a crisis (Sheaffer and Mano-Negrin 2003; Snihur 2018), change (Becker 2010) and increase organizational effectiveness (Easterby-Smith and Lyles 2011). The definitions enumerated in Table 1 provide a mixture of both perspectives, and it is impossible to chalk out a distinct phase, wherein we can state that a particular orientation was more dominant than the other orientation.

In addition, Table 1 also enlists the triggers of the unlearning process, level of analysis (individual, group, or organization), and element that replaces the discarded element (knowledge, routines, habits, mental models, or behaviors). This allows us to compare the conceptualization of unlearning in organizational studies according to various phases of evolution. Despite a certain degree of homogeneity in definitions, unlearning underwent certain changes during construct development. ${ }^{2}$ Especially during the initial phase (1976-2000), unlearning was considered synonymous or even subsumable under other constructs. For instance, Huber (1991) considered unlearning conceptually subsumable under OL. Organizations unlearned existing knowledge to learn new knowledge, thereby creating a sequential cycle of learning-unlearning-relearning. It became a truism that "unlearning must precede the learning of new behaviors" (Hedberg 1981: p. 58), and "learning cannot occur until after there has been unlearning" (Starbuck 1996: p. 726). However, Tsang (2008) empirically refuted this argument by showing that "organizational learning and unlearning are distinct processes" that can happen at different times (p. 19). Organizations can unlearn knowledge without the subsequent acquisition of new knowledge.

Moreover, unlearning is a distinct type of organizational change process (Tsang 2008). But this created a hindrance in the development of OU because "questions that purport to address unlearning actually target aspects of general change conditions and processes instead of actual unlearning" (Cegarra-Navarro and Wensley 2019: p. 70). Therefore, an alternate approach to catalyze the unlearning process (awareness, relinquish, and relearning) is to develop an unlearning context (CegarraNavarro and Sánchez-Polo 2008). The unlearning context consists of examination of lens fitting, change in individual habits, and consolidation of emergent understandings. Examination of lens fitting refers to structures and processes that allow individuals to question the current habits and consider alternate information; change in individual habits allows groups to recognize the need for changing existing habits; consolidation of emergent understandings helps organizations to implement new knowledge and routines.

Finally, since OU was introduced by Hedberg (1981) in organizational studies after reviewing the psychological literature, certain psychological concepts appear to be synonymous with unlearning. For example, Klein (1989) argues that the

\footnotetext{
${ }^{2}$ We thank an anonymous reviewer for this insightful suggestion to examine other concepts that were used synonymously with unlearning.
} 


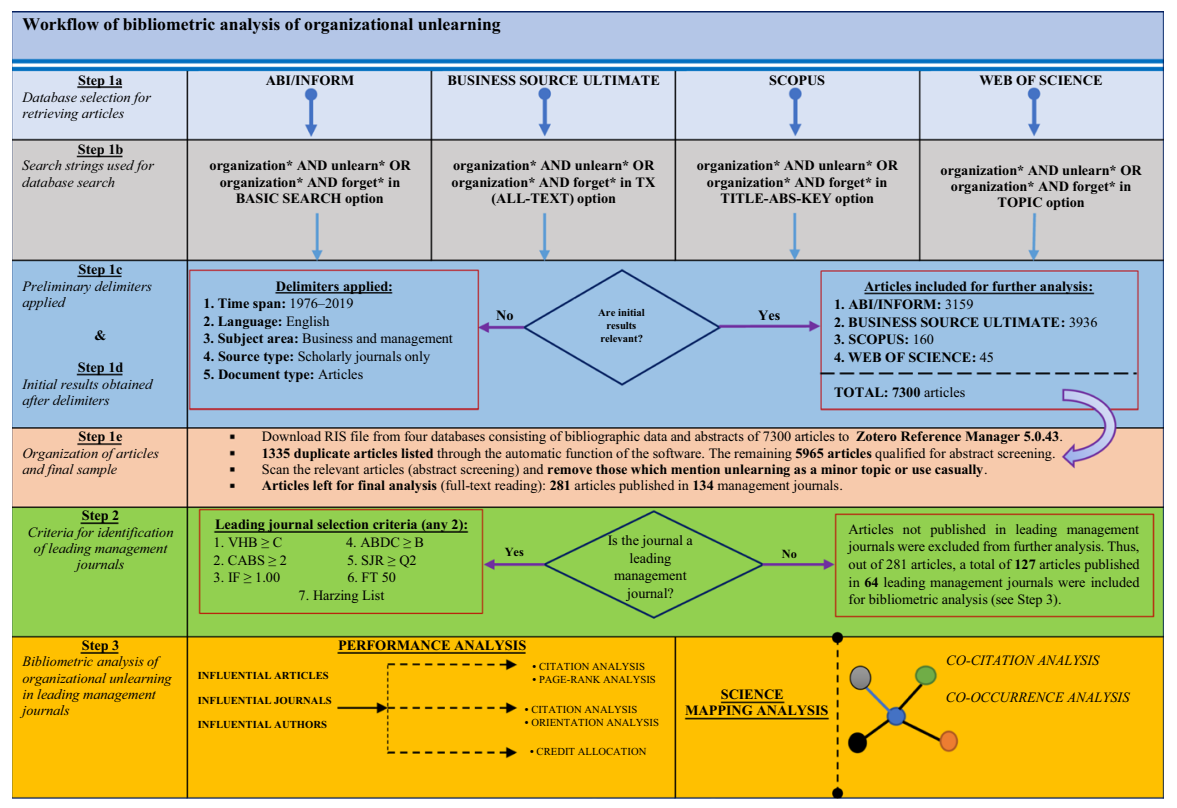

Fig. 2 Workflow of bibliometric analysis of organizational unlearning in leading management journals

unlearning model is a replica of extinction (removal of undesirable knowledge from individuals through dissuasion), replacement (dissemination of new knowledge as an alternative to existing knowledge), exorcism (purging individuals that are unable to change), and salvation (replacing current managers with external and visionary managers). Based on similar reasoning, Howells and Scholderer (2016) assert that unlearning is covered by other psychological concepts like extinction, inhibition (new learning hampers the recall of old learning and vice versa), and suppression (elimination of negative thoughts and emotions).

\section{Methodology}

This section describes a four-step methodology to review and assimilate the intellectual structure of OU. The first step involves the database search strategy to retrieve and organize articles of OU for further analysis. This is accomplished using a systematic literature review technique. The second step is used to ascertain the effectiveness of the database search strategy using sensitivity and precision tests. The third step includes the methodology for selecting leading management journals of OU. The final step involves utilizing various bibliometric techniques (citation analysis, co-citation analysis, and co-occurrence of keyword analysis) to present the leading trends of unlearning research and visualize the main themes of OU.

Figure 2 provides a schematic framework of the research design adopted for this study. This figure sequentially describes the database selection process, choice of search strings or keywords for database search, use of delimiters, and organization 
of articles. It also deals with the selection of leading management journals and bibliometric analysis.

\subsection{Database search strategy}

First, a systematic methodology for conducting a literature survey was followed (Tranfield et al. 2003; Rhaiem and Amara 2019). For this purpose, four different databases, namely ABI/INFORM (EBSCOhost), Business Source Ultimate (ProQuest), Scopus (Elsevier), and Web of Science (Clarivate Analytics), were searched for relevant literature of OU. The selection of these databases was made because researchers working in the multidisciplinary fields-including management and organization studies - generally recommend searching several databases to locate research articles on a given area of inquiry (Hislop et al. 2014). In addition, searching more than one database preempts the possibility of missing out on unique articles relevant to a systematic review (Lawrence 2008). Hence, we used the following combination of keywords (organization* AND unlearn* OR organization* AND forget*) in the BASIC SEARCH option of ABI/INFORM Collection, ALL-TEXT (TX) tab of Business Source Ultimate, TOPIC tab of Web of Science, and TITLEABSTRACT-KEYWORD (TITLE-ABS-KEY) option of Scopus. "Organization*," "unlearn*," and "forget*" are wild-card search strategy terms, where a database recall (number of articles returned) includes all forms of semantics like organizational, organizations, unlearning, unlearnt, unlearns, forgets, forgetting, etc. (Klammer and Gueldenberg 2019; Rhaiem and Amara 2019). Furthermore, the time range for the literature search was set to 1976-2019 because the seminal article of OU (Hedberg et al. 1976) was published in Administrative Science Quarterly (ASQ).

The results of all four databases were processed with the following delimiters: (a) the corpus of source type was restricted to scholarly journals and hence, dissertations and theses, newspapers, magazines, trade journals, reports, and working papers were excluded; (b) document type was restricted to journal articles only, and we did not include conference papers, books, book chapters, editorials, letters, and short surveys; (c) subject area of articles was limited to 'business,' 'management,' and 'accounting' categories and we excluded articles published in 'engineering,' 'decision sciences,' 'computer science,' 'psychology,' and 'medicine'; (d) language of articles was restricted to 'English.' This process of database search with four delimiters resulted in 7300 articles (160 in Scopus, 3159 in ABI/INFORM, 3936 in Business Source Ultimate, and 45 in Web of Science). For the initial selection of articles based on abstract screening, the RIS (Research Information System) file consisting of bibliographic information and abstracts included in a particular database was downloaded from four databases, respectively. Next, the RIS files were imported to Zotero Reference Manager 5.0.43, a software package facilitating the organization of bibliographic material (title, year of publication, authors, journals, pagination details, references, and digital object identifier details). We referred to the database again for abstract screening for articles whose abstract was missing in the RIS file. The software listed 1335 duplicate articles. Subsequently, we read the abstracts of the remaining 5965 documents, and based on abstract screening, 281 articles were 
selected for a full-text review. This filtering process led to a dataset of 281 articles published in 134 business and management journals. The dataset included only those articles that talked about unlearning as a central topic or a means to achieve any other process or objective. Finally, after the full-text read of 281 articles, 45 articles were not relevant to the current analysis because they were not related to unlearning/forgetting in organization studies.

To ascertain the effectiveness of the database search strategy, sensitivity and precision index of all four databases is reported in the following subsection.

\subsection{Sensitivity and precision index of database search strategy}

The next step pertains to the calculation of precision and sensitivity indices of the database search. Both are important indicators for measuring the performance of a bibliographic database search. The methodology for calculating precision and sensitivity is taken from systematic reviews conducted in the medical field (Watson and Richardson 1999; Wieland and Dickersin 2005). Precision means the ratio of true to false positives or the total number of relevant articles identified by the database divided by the total number of both relevant (true positives) and irrelevant (false positives) articles identified by a particular database search (Watson and Richardson 1999). Sensitivity refers to the ratio of the total number of relevant articles found in a specific database (say, ABI/INFORM) to the total number of relevant articles included in all databases.

The sensitivity and precision values for each database, i.e., ABI/INFORM, Scopus, Web of Science, and Business Source Ultimate was computed. Table 2 shows an inverse relationship between sensitivity and precision because if a database identifies many false positives, it lowers the precision index of that database (Watson and Richardson 1999). For example, the precision index of Business Source Ultimate database search is merely 3 percent due to many false-positive results, but its sensitivity index is around 45 percent due to a sufficient number of relevant results derived from the current search strategy. We also observe that the Scopus search provided a balanced value of sensitivity (30.63 percent) and precision (17.44 percent) index. This implies that the Scopus database search did not include many false-positive results of unlearning and forgetting, and its representation of true positive articles vis-à-vis other databases is also substantial.

\subsection{Selection of leading management journals}

Since this study is aimed to review the domain of OU in leading management journals only, a quality threshold index was applied to 134 journals. To ensure quality and maximum coverage of articles, we included journals that qualified at least two of the seven major journal ranking frameworks. The first three are derived from Bouncken et al. (2015). In addition, with the advent of new ranking frameworks, journals were subjected to an additional four criteria. These are listed below: 


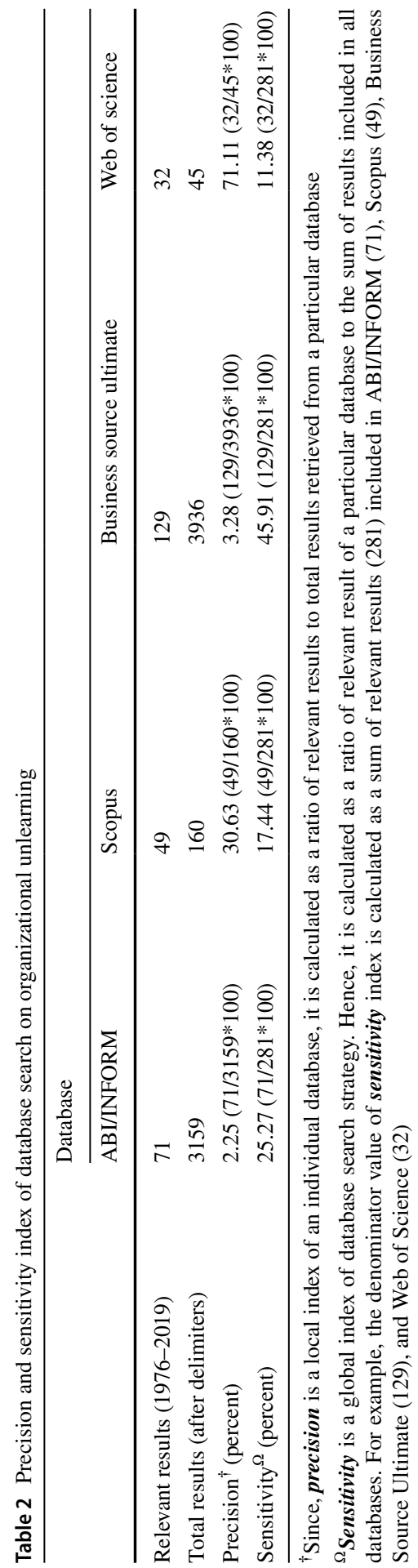


1. The German Academic Association for Business Research (VHB) "Jourqual 3" with the cut-off of $\geq \mathrm{C}$ [range $\mathrm{A}+, \mathrm{A}, \mathrm{B}, \mathrm{C}, \mathrm{D}]$.

2. The Chartered British Association of Business Schools (CABS) "Academic Journal Quality Guide 2018" with the cut-off of $\geq 2$ [range 4*, 4, 3, 2, 1].

3. The Thomson Reuters "Journal Citation Reports (JCR) Impact Factors" with a cut-off of $\geq 1.000$.

4. Australian Business Deans Council's (ABDC) "ABDC Journal Quality List" (include $\mathrm{A}^{*}$ to $\mathrm{B}$ journals) [range $\mathrm{A} *, \mathrm{~A}, \mathrm{~B}, \mathrm{C}$ ].

5. Financial Times top 50 journals.

6. Anne-Wil Harzing's "Harzing Journal Quality List" (59th Edition).

7. SCImago Journal Ranking "SJR Score” for 2017 (include Q1 and Q2 journals).

The results are presented in Table 3, where the relevant score of seven criteria is coded and mentioned against respective journals. Out of 134 journals, only 64 journals qualified at least two criteria and were included for bibliometric analysis.

Following this, a final dataset of 127 articles $^{3}$ published in 64 leading management journals was selected. These articles were divided according to the timeline proposed in Fig. 1: 1976-1990 (6 articles), 1991-2000 (20 articles), 2001-2010 (36 articles), and 2011-2019 (65 articles). Subsequently, these 127 articles were subjected to bibliometric analysis.

\subsection{Bibliometric methods}

Bibliometrics refers to the application of various statistical and mathematical techniques to analyze and measure the qualitative and quantitative changes in an area of inquiry (Durieux and Gevenois 2010; Kraus et al. 2014). Such an analysis is helpful to explore, organize, and analyze a vast amount of data; allow integration of past, present, and future research; measure the impact and prestige of documents published in scientific journals; make decisions regarding appointment, promotions and funding of researcher or research group by the organization; determine geographic erosion or growth of research in a nation; and optimize research policy (Durieux and Gevenois 2010; Ferreira et al. 2019; Gaviria-Marín et al. 2019).

The science of bibliometrics is expressed through various bibliometric indicators and is defined as 'measures referring to the scientific impact and/or quantity of scientific publications' (Vinkler 1988: p. 241; Mas-Tur et al. 2020). Borgman and Furner (2002) propose two types of bibliometric indicators: evaluative and relational bibliometric indicators. Evaluative bibliometrics seeks to measure and compare publications' impact using benchmark like citations received by a particular scientific actor. Contrarily, relational bibliometrics highlights the relationship between scientific actors in a discipline. Evaluative bibliometrics uses the same indicators as performance analysis or quality/quantity indicators. We employed the

\footnotetext{
${ }^{3}$ A list of 127 articles included for bibliometric analysis is available in Appendix 1 (Table 19)
} 
Table 3 Methodology for selection of leading management journals for review

\begin{tabular}{|c|c|c|c|c|c|c|c|}
\hline \multirow[b]{2}{*}{ Journal } & \multicolumn{5}{|c|}{ Criteria for Inclusion of Journal $^{\ddagger}$} & \multirow[b]{2}{*}{$\mathrm{SJR}^{\wedge}$} & \multirow[b]{2}{*}{$\begin{array}{c}\text { Harzing } \\
\text { List }\end{array}$} \\
\hline & $\mathrm{VHB}^{\Omega}$ & $\mathbf{A B S}^{\S}$ & $\mathbf{J C R}^{\dagger}$ & $\mathrm{ABDC}^{\pi}$ & FT 50 & & \\
\hline \multicolumn{8}{|l|}{ Academy of Management Executive ${ }^{\ddagger}$} \\
\hline Academy of Management Journal & At + & 4* & 7.525 & $\mathrm{~A}^{*}$ & & 01 & \\
\hline Academy of Management Learning and Education & & & 3.274 & $\mathrm{~A}^{*}$ & & Q1 & \\
\hline Administrative Science Quarterly & $\mathrm{A}+$ & 4* & 8.024 & $\mathrm{~A}^{*}$ & & 01 & \\
\hline Auditing & B & 3 & 2.108 & $\mathbf{A}^{*}$ & & 01 & \\
\hline Baltic Journal of Management & C & & 1.469 & & & Q2 & \\
\hline British Journal of Management & B & 4 & 3.023 & A & & 01 & \\
\hline Business Horizons & C & 2 & 2.828 & & & Q1 & \\
\hline California Management Review & B & 3 & 3.909 & $\mathrm{~A}$ & & 01 & \\
\hline Creativity and Innovation Management & C & 2 & 2.015 & & & Q2 & \\
\hline European Business Review & & 2 & & B & & 01 & \\
\hline European Journal of Innovation Management & C & & 1.793 & & & Q2 & \\
\hline European Management Journal & B & 2 & 2.985 & B & & Q1 & \\
\hline European Management Review & B & 3 & 1.600 & & & 02 & \\
\hline Harvard Business Review & C & 3 & 5.691 & A & & Q2 & \\
\hline Human Relations & B & 4 & 3.367 & $\mathbf{A}^{*}$ & & Q1 & \\
\hline Human Resource Development Quarterly & & 2 & 3.000 & B & & Q1 & \\
\hline Human Resource Management & B & 4 & 2.476 & $\mathrm{~A}^{*}$ & & Q1 & \\
\hline Human Resource Management Journal & B & 4 & 3.816 & $\mathrm{~A}$ & & Q1 & \\
\hline IEEE Transactions on Engineering Management & B & 3 & 2.784 & A & & 01 & \\
\hline Industrial and Corporate Change & B & 3 & 1.981 & A & & 01 & \\
\hline Industrial Marketing Management & B & 3 & 4.779 & $\mathbf{A}^{*}$ & & Q1 & \\
\hline International Journal of Human Resource Management & B & 3 & 3.040 & A & & Q1 & \\
\hline International Journal of Information Management & C & 2 & & $\mathbf{A}$ & & Q1 & \\
\hline International Journal of Innovation Management & B & 2 & & B & & Q2 & \\
\hline International Journal of Production Economics & B & 3 & 5.134 & $\mathrm{~A}$ & & Q1 & \\
\hline International Journal of Production Research & $\mathrm{B}$ & 3 & 4.577 & $\mathrm{~A}$ & & 01 & \\
\hline International Journal of Technology Management & $\mathrm{C}$ & 2 & 1.348 & B & & Q2 & \\
\hline Journal of the Academy of Marketing Science & $\mathbf{A}$ & $4^{*}$ & 9.360 & & & Q1 & \\
\hline Journal of Business Research & $\bar{B}$ & 3 & 4.028 & A & & Q1 & \\
\hline Journal of Contingencies and Crisis Management & & & 1.977 & & & Q2 & \\
\hline \multicolumn{8}{|l|}{ Journal of European Industrial Training ${ }^{\ddagger}$} \\
\hline Journal of Evolutionary Economics & & 2 & 1.433 & A & & 01 & \\
\hline Journal of International Business Studies & $\mathbf{A}$ & 4* & 9.158 & $\mathrm{~A}^{*}$ & & 01 & \\
\hline Journal of International Entrepreneurship & C & & & & & 01 & \\
\hline Journal of Knowledge Management & $\mathrm{C}$ & 2 & 4.604 & $\mathbf{A}$ & & Q1 & \\
\hline Journal of Management & A & $4^{*}$ & 8.852 & $\mathbf{A}^{*}$ & & 01 & \\
\hline Journal of Management Inquiry & B & 3 & 1.986 & A & & Q1 & \\
\hline Journal of Management Studies & $\mathrm{A}$ & 4 & 5.839 & $\mathrm{~A}^{*}$ & & Q1 & \\
\hline Journal of the Operational Research Society & $\bar{B}$ & 3 & 2.175 & & & Q1 & \\
\hline Journal of Organizational Change Management & & 2 & 1.185 & B & & Q2 & \\
\hline Knowledge Management Research \& Practice & & & 1.485 & $\mathbf{A}$ & & Q2 & \\
\hline Knowledge and Process Management & & & & $\bar{B}$ & & 02 & \\
\hline Kybernetes & & & 1.754 & & & Q2 & \\
\hline Long Range Planning & B & 3 & 3.363 & A & & Q1 & \\
\hline Management Decision & $\mathrm{C}$ & 2 & 1.963 & $\bar{B}$ & & 01 & \\
\hline Management International Review & B & 3 & 2.689 & $\bar{A}$ & & 01 & \\
\hline Management Learning & B & 3 & 1.935 & A & & 02 & \\
\hline Management Science & $\overline{\mathrm{A}+}$ & $4^{*}$ & 4.219 & $\overline{A^{*}}$ & & Q1 & \\
\hline Manufacturing \& Service Operations Management & A & 3 & 4.281 & $\mathbf{A}^{*}$ & & 01 & \\
\hline Marketing Science & At & $4^{*}$ & 3.019 & $\mathbf{A}^{*}$ & & 01 & \\
\hline MIT Sloan Management Review & $\mathrm{C}$ & 3 & 2.196 & A & & Q1 & \\
\hline Organizational Dynamics & C & 2 & 1.397 & A & & Q2 & \\
\hline Organization Science & $\overline{A+}$ & $4^{*}$ & 3.257 & $\mathrm{~A}^{*}$ & & Q1 & \\
\hline$R \& D$ Management & & & 2.908 & A & & & \\
\hline Scandinavian Journal of Management & B & 2 & 1.415 & B & & Q2 & \\
\hline Strategic Management Journal & $\mathbf{A}$ & $4^{*}$ & 5.572 & $\mathbf{A}^{*}$ & & Q1 & \\
\hline Strategic Organization & B & 4 & 3.109 & $\mathrm{~A}$ & & Q1 & \\
\hline Sustainability & C & & 2.592 & & & Q2 & \\
\hline Technological Forecasting and Social Change & B & 3 & 3.815 & A & & & \\
\hline Technovation & $\bar{C}$ & 3 & 5.729 & A & & 01 & \\
\hline The Journal of Product Innovation Management & A & 4 & 3.781 & $\mathrm{~A}^{*}$ & & Q1 & \\
\hline Thunderbird International Business Review & C & 2 & & B & & 01 & \\
\hline The TQM Journal & & & & B & & 01 & \\
\hline
\end{tabular}

For inclusion in further review, a journal needs to satisfy at least two of the seven criteria. Although the Journal of European Industrial Training qualifies only one criterion, it is renamed as European Journal of Training \& Development that satisfies more than two criteria. Similarly, Academy of Management Executive does not qualify any criterion, it is renamed to Academy of Management Perspectives that satisfies more than two criteria

${ }^{\Omega}$ For inclusion in the review, a cut off rating for a journal was set to at least C. Source VHB's JOUR- 
Table 3 (continued)

QUAL 3

${ }^{\S}$ For inclusion in the review, a journal needed to have at least a rating of 2. Source CABS' AJG 2018

${ }^{\dagger}$ Indicates the Impact Factor (IF) of 2018. Only journals with IF $\geq 1.000$ could qualify for review. Source: InCites Journal Citation Reports, Web of Science

IFor further review, a journal must have a rating of at least B. Source: ABDC's Journal Quality List, 2016

${ }^{\wedge}$ For further review, a journal must be placed in at least Quartile 2. Source SCImago Journal Ranking, 2018

number of publications to assess the most productive scientific actors. Additionally, we use total citations to determine the most influential scientific actors of OU.

Moving to relational bibliometrics, this paper utilizes co-citation analysis (Small et al. 1973) to establish the structural relationship among the published works of OU. Co-citation occurs when another publication jointly cites two or more documents. By citing a common set of documents in a bibliography, a researcher attempts to "establish connections between two or more references that have been published in the past" (Raghuram et al. 2019: p. 310). Subsequently, as more and more articles cite these two references jointly, it not only signals a close relationship between these co-cited articles but also highlights their importance individually to the specific research field (Ferreira et al. 2019). Co-citation analysis is used to map the intellectual structure of literature, identify fundamental articles of a research field, examine the evolution of particular literature, and evoke transdisciplinary research by synthesizing knowledge across several academic disciplines (Raghuram et al. 2019).

This paper also visualizes the key research themes of unlearning by using the $\mathrm{co}$ occurrence of keyword analysis (Callon et al. 1991). The co-occurrence of keyword analysis is based on the premises of co-occurrence or co-absence of keywords. Two keywords, $a$ and $b$, co-occur if used together in the same article (Callon et al. 1991). It is based on the following assumptions (Liu et al. 2012):

- The authors of the scientific article select their keywords carefully and judiciously,

- The keywords provide an adequate and reliable description of the paper's content,

- The use of two keywords in a paper suggests that the author is proposing a relationship between the two or more concepts,

- If enough authors recognize the same relationship between keywords, it can be called a significant relationship.

The above-mentioned techniques of relational bibliometrics, i.e., co-citation analysis and co-occurrence of keyword analysis, are performed using a freely available computer program, VOSviewer (van Eck and Waltman 2010). VOSviewer uses bibliographical information to produce a network diagram to map the relationship between key ideas, concepts, and problems. In this paper, 
the co-occurrence of keywords analysis identifies the most often used keywords and the key research themes in OU literature. Prior studies have used co-occurrence analysis to detect the evolution of a concept and how such development has led to new research topics by identifying the prominent research clusters (Liu et al. 2012; Ronda-Pupo and Guerras-Martin 2012).

\section{Results}

In the following subsections, we report the bibliometric results of 127 articles on OU published in leading management journals from 1976 to 2019. The results are divided into eleven sub-sections that broadly cover the performance analysis of documents, authors, and institutions/universities using citation analysis. In addition, with the help of co-citation analysis, we visualize the structural relationship among published works of unlearning and present an overview of the main themes of OU using the co-occurrence of keyword analysis.

\subsection{Source and nature of articles}

Table 4 shows that Management Learning $(M L)$ is the main source of OU articles ( $n=12$ articles), followed by Journal of Knowledge Management (JKM) with six articles, Human Resource Development Quarterly, Human Relations (HR), Journal of Management Inquiry (JMI) with five articles each, Journal of Business Research (JBR), Journal of Organizational Change Management (JOCM), and Organizational Dynamics (OD) with four articles each. Out of 64 journals reviewed, a total of 37 journals (57.81 percent) contributed only one article on unlearning.

Around 45 percent of articles published in leading management journals were empirical, i.e., they adopted a qualitative or quantitative method of inquiry to validate theoretical propositions. Approximately 27.56 percent of articles critically examined the extant literature and theories to propose a conceptual framework of unlearning in organizations. The top three sources for empirical articles on unlearning were JBR (7.02 percent), Management Decision (5.26 percent), and Management International Review (5.26 percent). The top three sources for conceptual articles were JMI (13.79 percent), HR (10.34 percent), and Journal of Management Studies (10.34 percent).

\subsection{Citation analysis}

Citation analysis is based on the proposition that the impact of a scientific actor can be measured by the number of citations received by an author, a document, an 


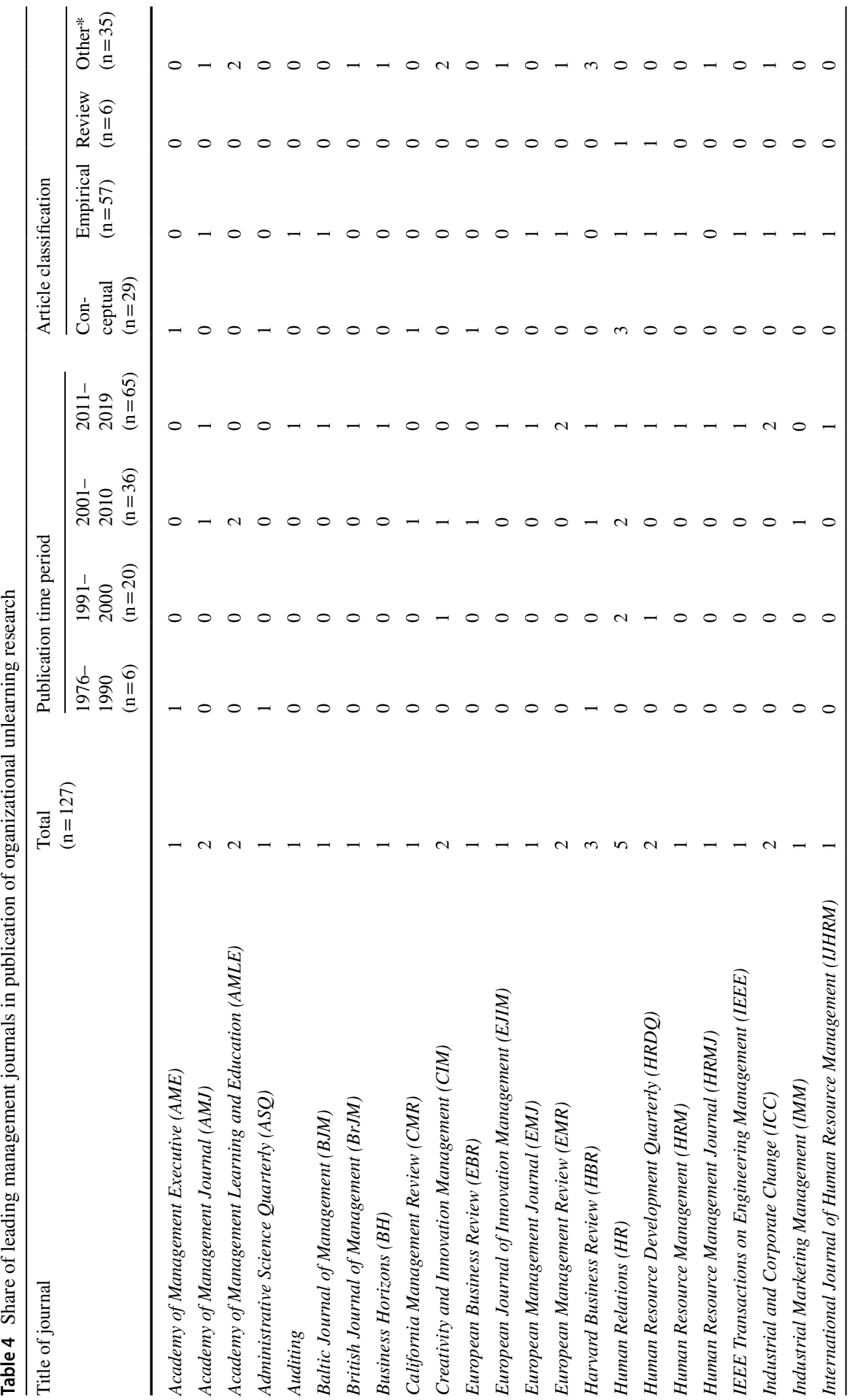




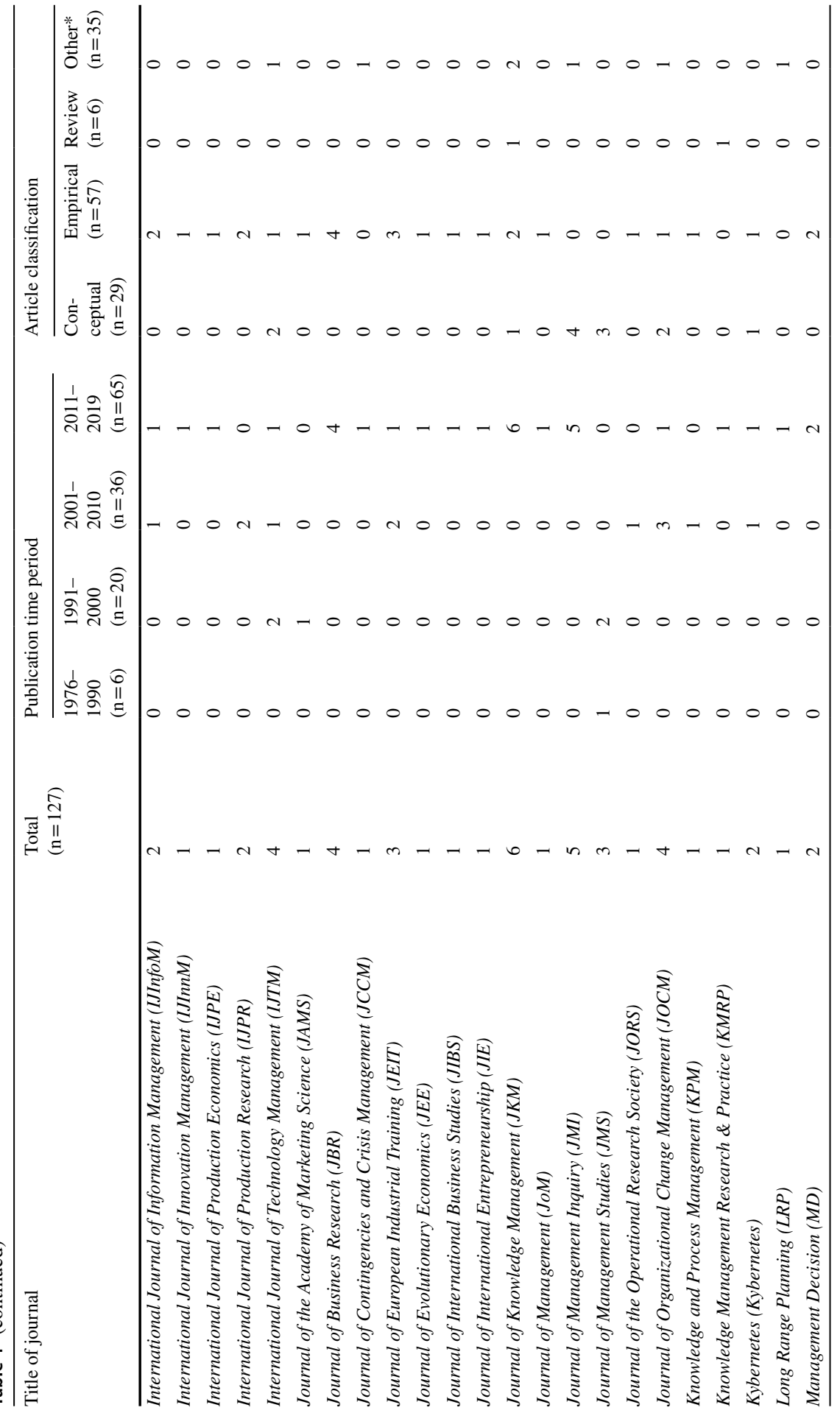




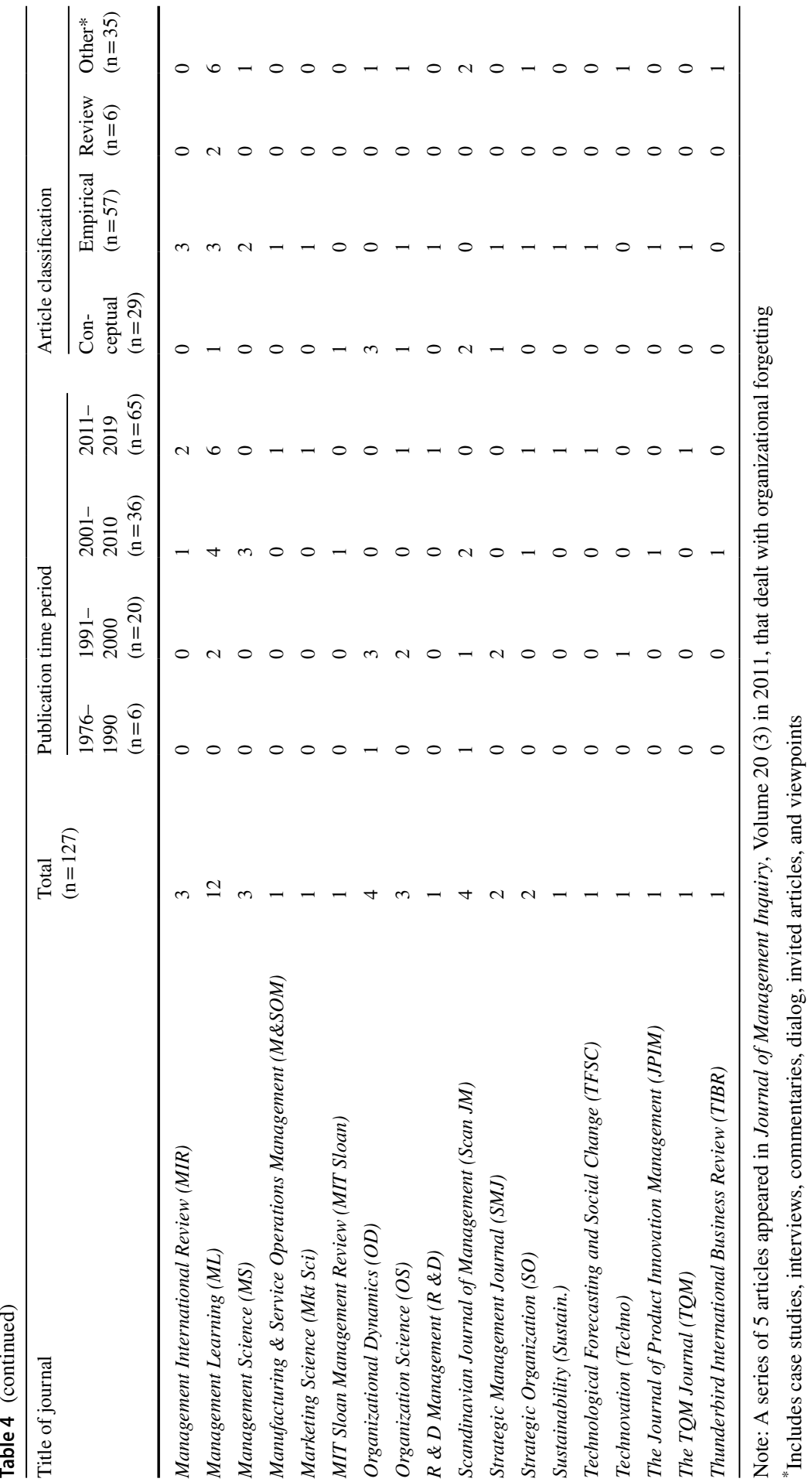




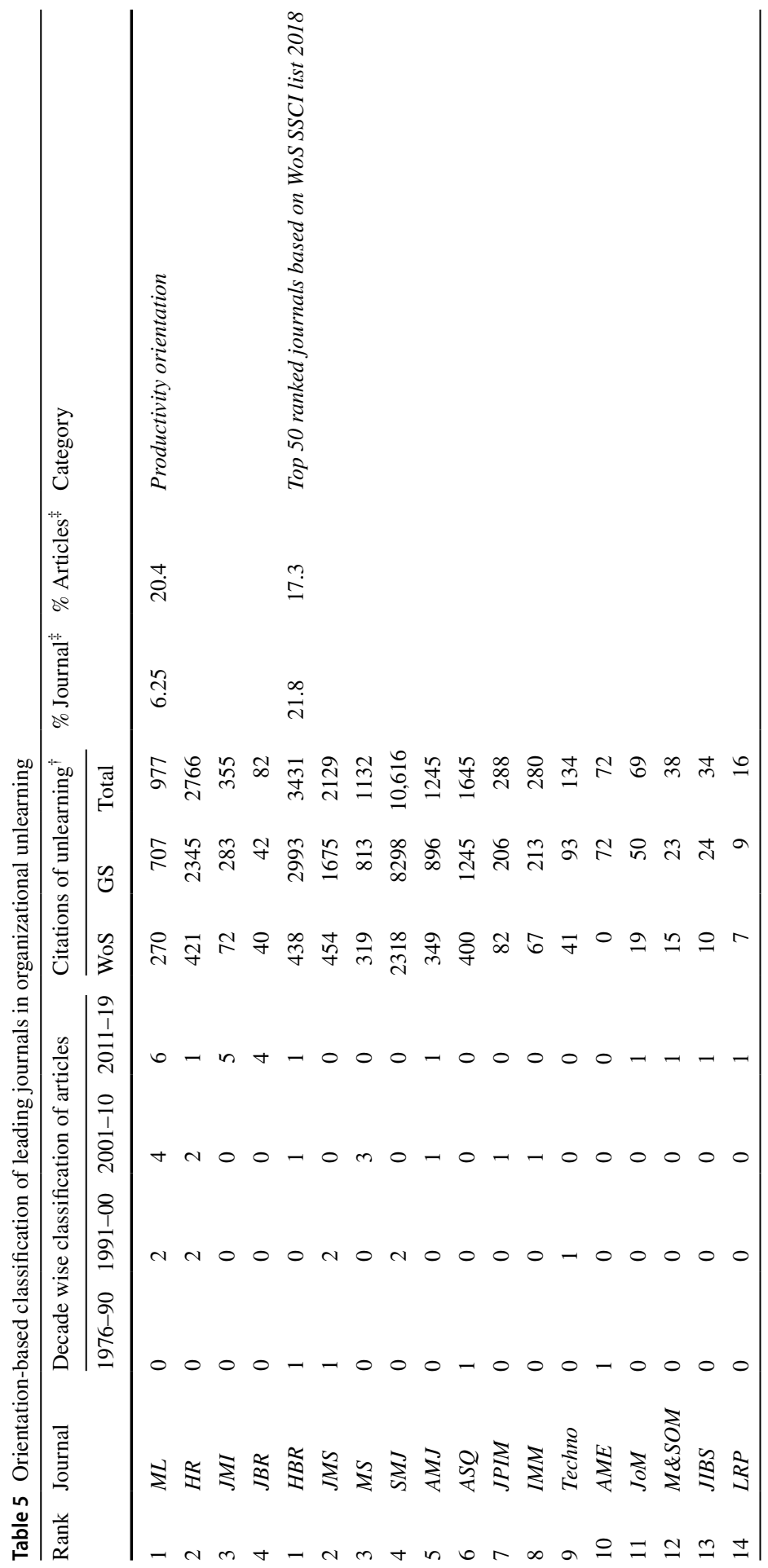




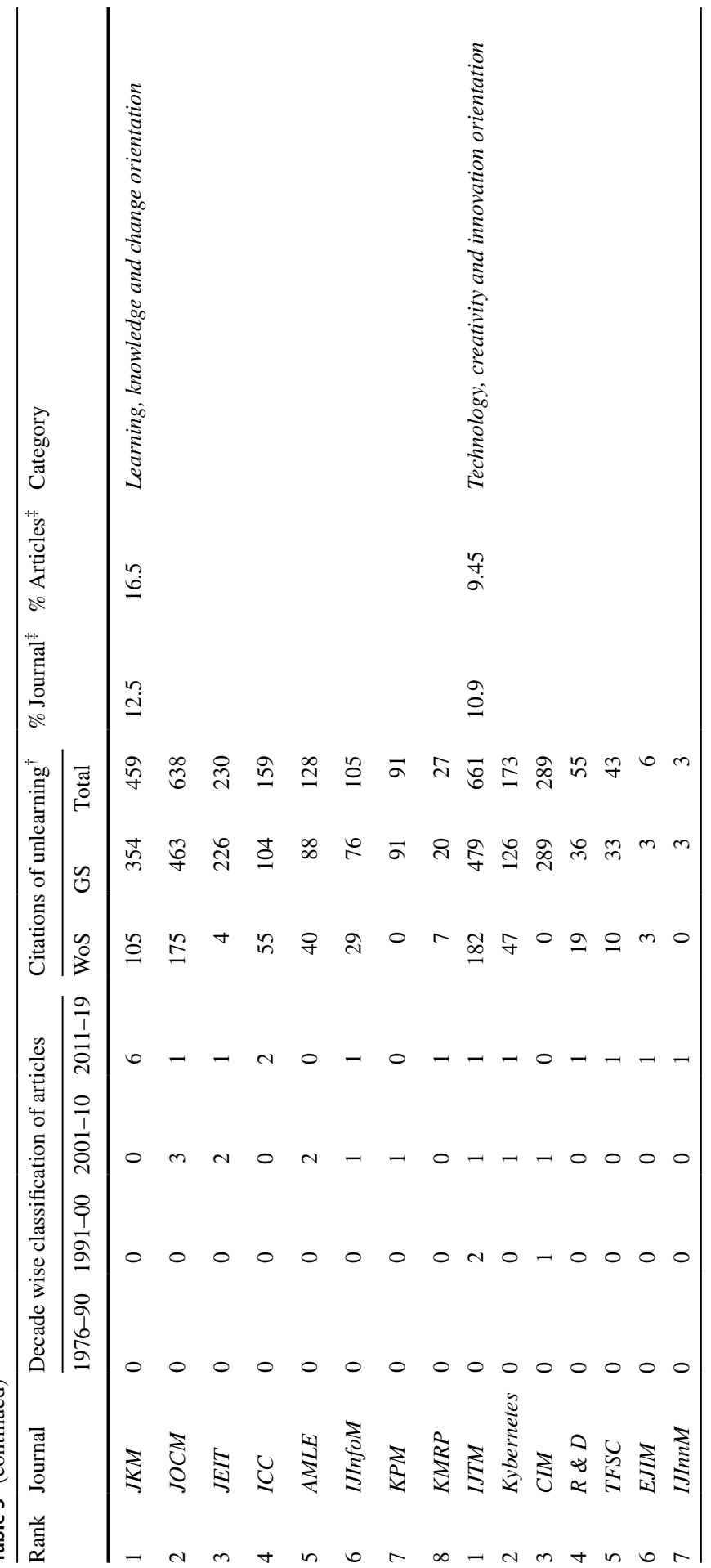




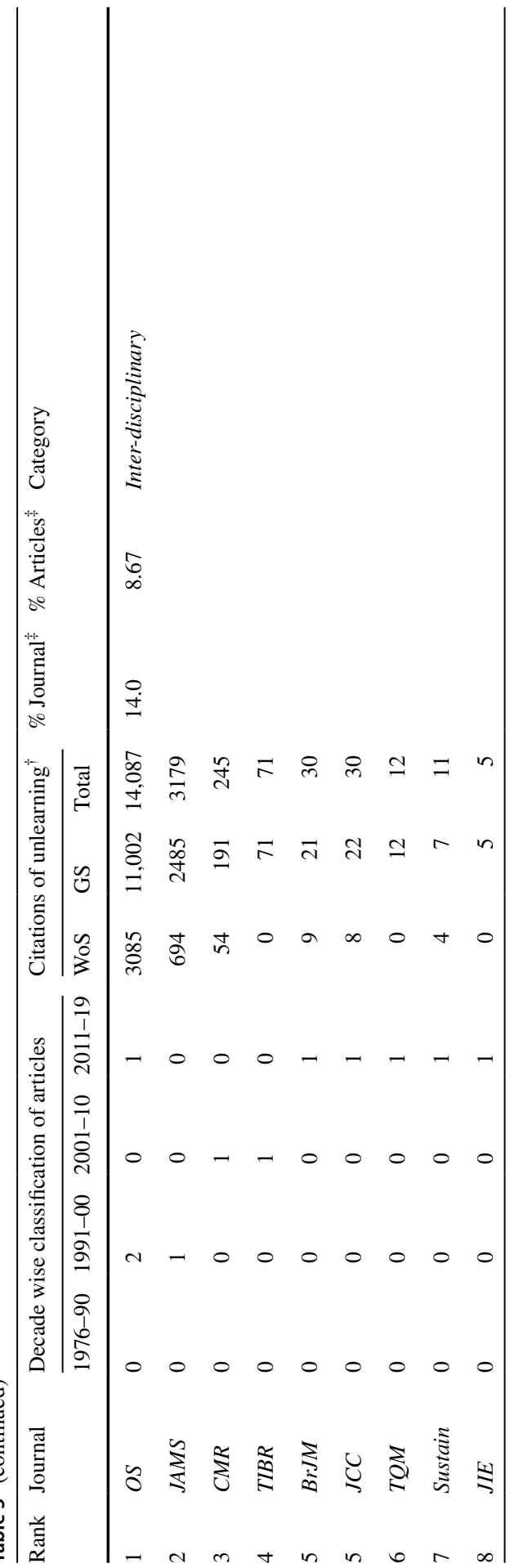




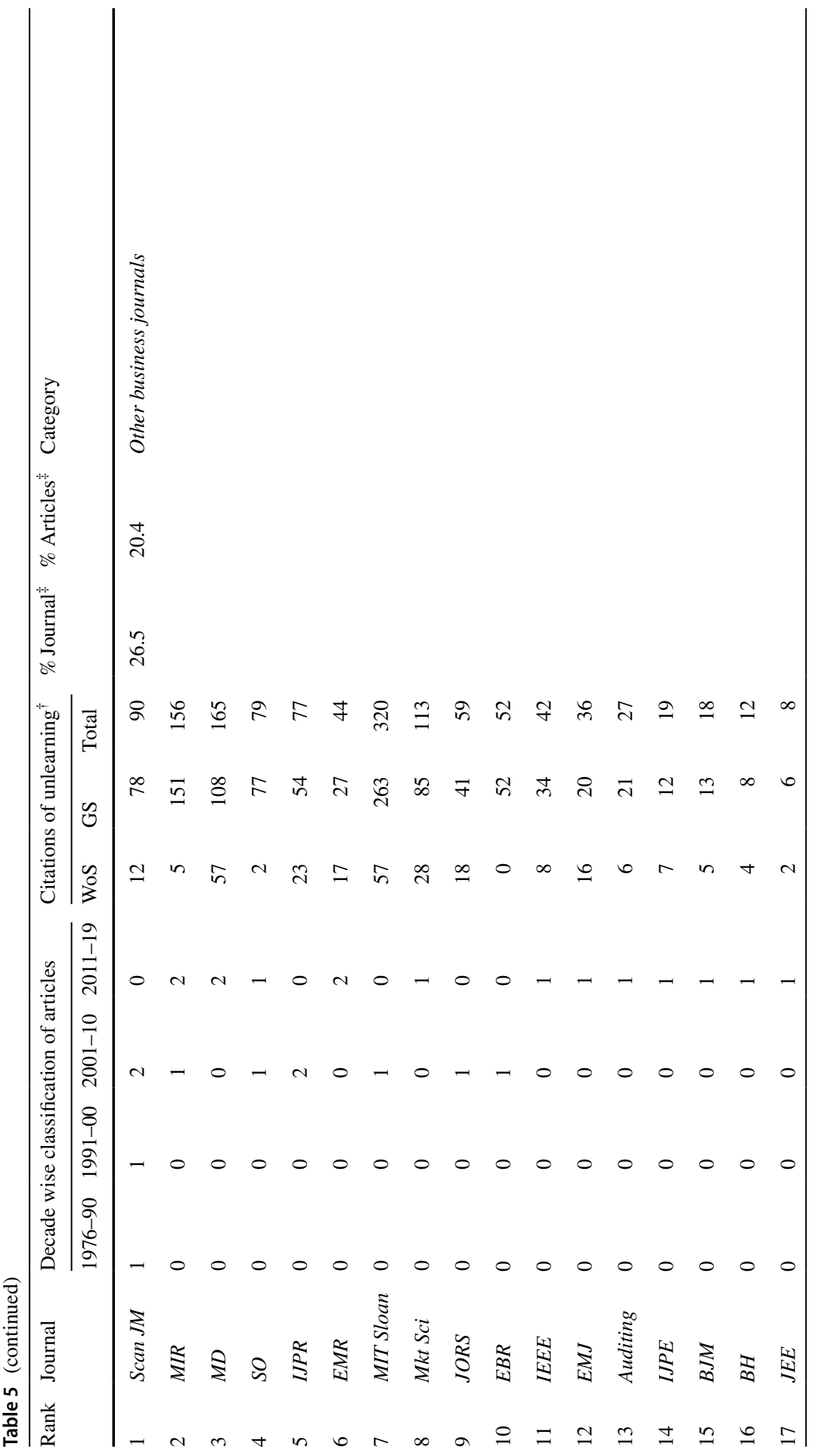




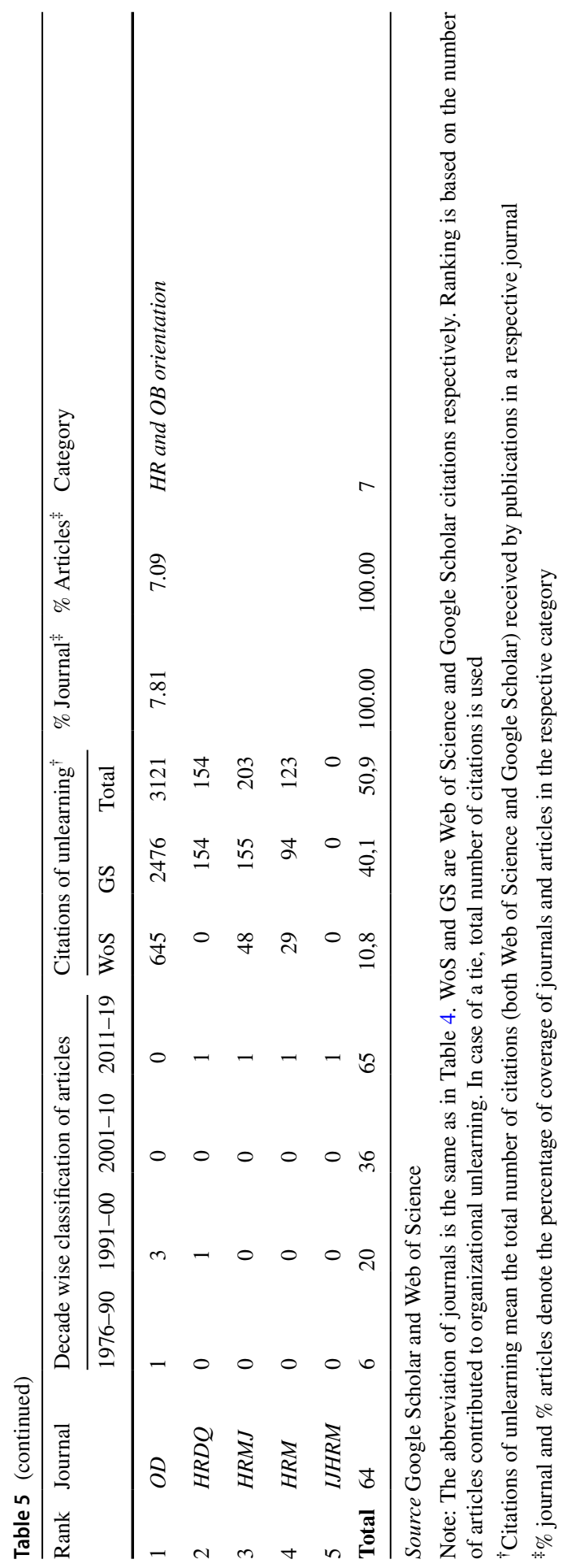


institution, or a journal (Garfield 1972). The following sub-sections report the citation analysis of journals, articles, books, and book chapters.

\subsubsection{Of journals}

Table 5 reports the evolution of 64 journals based on productivity (total number of articles) and influence (total number of citations). Since the nature, aims, and scope of these journals are quite diverging, consistent with Gaviria-Marín et al. (2019), we have attempted to classify them into specific categories. This allows a common ground to compare journals that share a similar orientation.

The first category is based on productivity. It includes four journals ( $M L, H R$, $J M I$, and $J B R$ ) and published 20.47 percent of unlearning articles. The second category includes articles published in the top-50 journals of the Web of Science Social Science Citation Index (SSCI) list of 2018. These journals have published 17.32 percent of all OU articles. The third category includes journals covering learning, knowledge, and change management. Surprisingly, these have only published 16.53 percent of all OU articles, even though unlearning is closely associated with this orientation. The fourth group includes journals with a focus on technology, creativity, and innovation orientation. This category has published 9.45 percent of all OU articles and represents 10.94 percent of all leading journals. Finally, another group of journals covers human resources and organizational behavior (HR/OB) orientation. It includes journals like OD, International Journal of Human Resource Management (IJHRM), and Human Resource Development Quarterly (HRDQ) and published 7.09 percent of all articles on OU. In this way, we divided leading journals into seven categories according to different orientations.

From a micro-perspective, in the group of most productive journals, i.e., journals publishing the highest number of articles on unlearning, $M L, H R$, and $J M I$ stands out as being exclusively dedicated to the field. $H R$ appears as the most influential journal with 2766 citations, according to the Scopus and Web of Science database. Among the top-50 ranked journals in SSCI, Strategic Management Journal is the most influential journal with 10,616 citations. It is also the second most influential journal across all categories. $J K M$ has published the highest number of unlearning articles (6 articles) with 459 citations among learning, knowledge, and change-oriented journals. All six articles of the journal appeared during the 2011-19 period. Finally, among HR/OB-oriented journals, only $O D$ has received more than 1000 citations (3121 cites) from other studies. This is because the articles in IJHRM and $H R D Q$ were published in 2018, and it takes time to receive citations from other studies (Wang 2013).

\subsubsection{Of influential articles}

Table 6 divides the most-cited articles on unlearning published in the leading management journals into two broad categories: (a) titles having 'unlearning' related keywords and (b) titles not having 'unlearning' related keywords, but elucidate upon unlearning substantially. This is because the second category of articles deal with multi-dimensional topics and has a higher probability of getting cited. However, the 


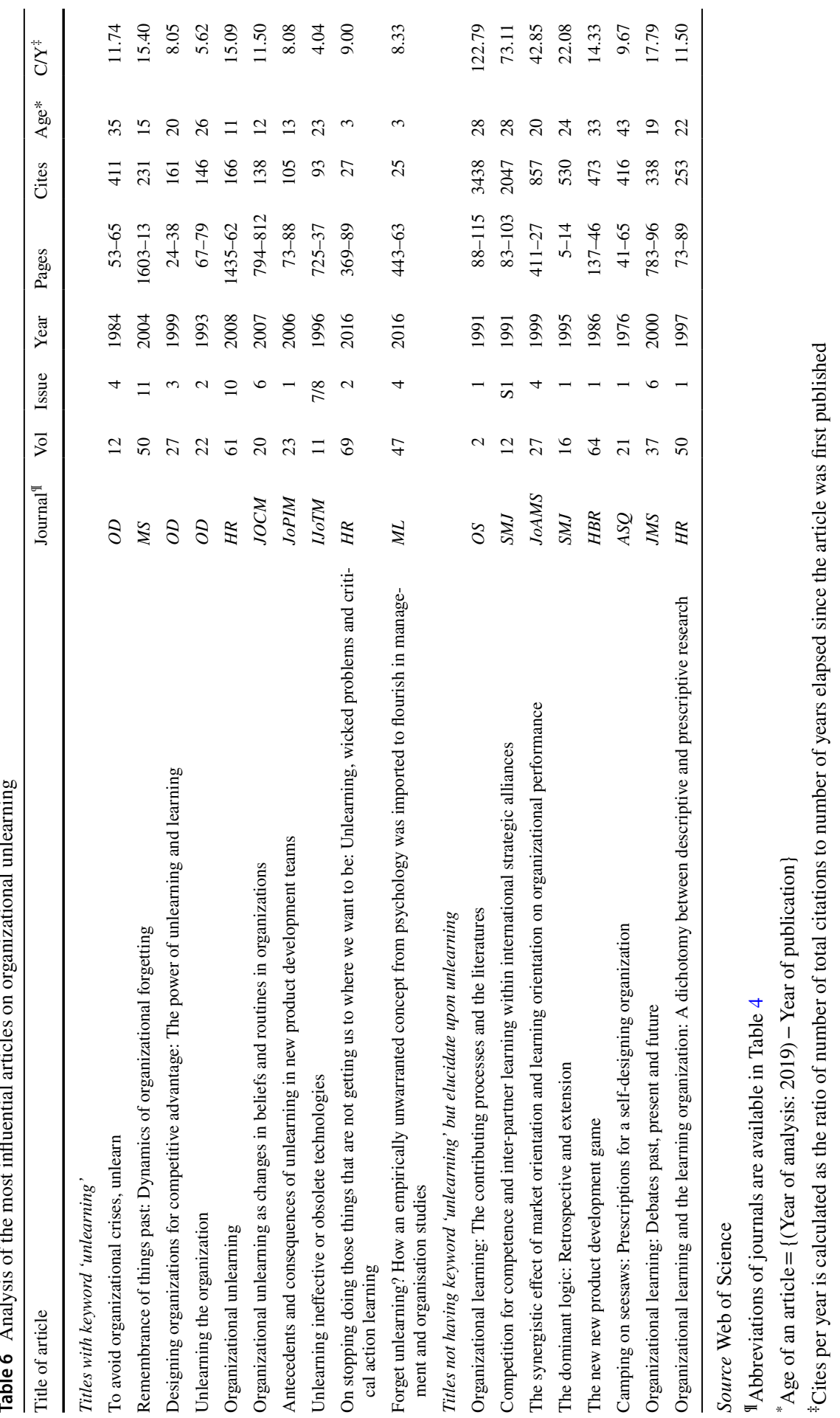


first category of articles will only attract citations from scholars interested in studying the nuances of unlearning. The three most cited and influential articles in the first category include Nystrom and Starbuck (1984), Martin de Holan and Phillips (2004a), and Lei et al. (1999). The most recent articles included in the first category are Howells and Scholderer (2016) and Brook et al. (2016).

As far as the second group is concerned, Huber (1991) is the most influential article with 122.79 citations per year. The seminal paper on unlearning by Hedberg et al. (1976) has received 416 Web of Science citations as of September 2020. Note that this list only includes articles published in academic journals and excludes one of the highly cited book chapters of Hedberg (1981), titled How Organizations Learn and Unlearn.

\subsubsection{Of nature of references in influential studies}

Table 7 presents a breakdown of the bibliographical sources used by the most influential articles on OU. As expected, scholarly journals constitute the most significant portion of references. This is followed by books and book chapters. However, this table does not describe which books and book chapters are most often cited by these influential studies. The following sub-section deals with this analysis.

\subsubsection{Of influential books and book chapters}

Tables 8 and 9 presents the most influential books and book chapters on OU, respectively. This analysis is essential because: first, readers of unlearning must be aware of these knowledge sources, and second, unlearning itself began with a book chapter by Hedberg (1981). Subsequently, this chapter is far more cited by scholars than the journal article of Hedberg et al. (1976) in ASQ. Unlearning is prominently discussed in books like Experience and Education by Dewey (1938), Strategy + Structure $=$ Performance..., edited by Thorelli (1977), Handbook of Organizational Design, edited by Nystrom and Starbuck (1981), Competing for the Future by Hamel and Prahalad (1994), and Unlearning or how not to be 'Governed' by Chokr (2009), among several others. The most influential book chapter is Hedberg (1981) with 4310 citations, followed by Imai et al.'s (1985) book chapter on how Japanese companies manage new product development using learning and unlearning.

\subsection{PageRank analysis}

In addition to citation analysis, Ding et al. (2009) emphasized that the 'prestige' of an article is also an important indicator of influence. Prestige is defined as the extent to which an article has been cited by other highly cited papers. It is based on the proposition that "not all citations are created equal." A highly cited paper may not necessarily be a prestigious paper (Mishra et al. 2016). PageRank is an alternative method to account for both the popularity and prestige of an article (Brin and Page 1998). It is calculated as follows: 


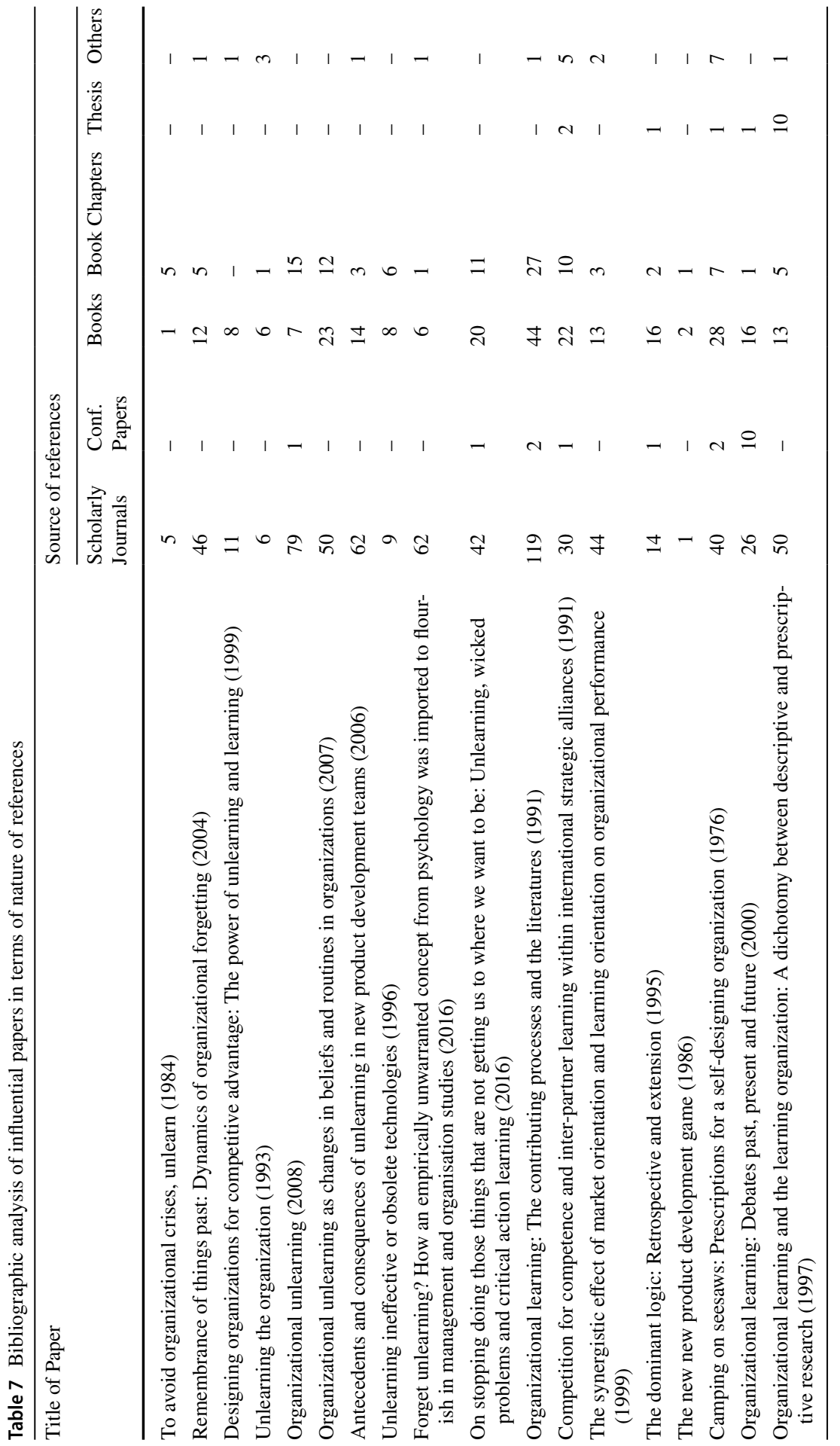




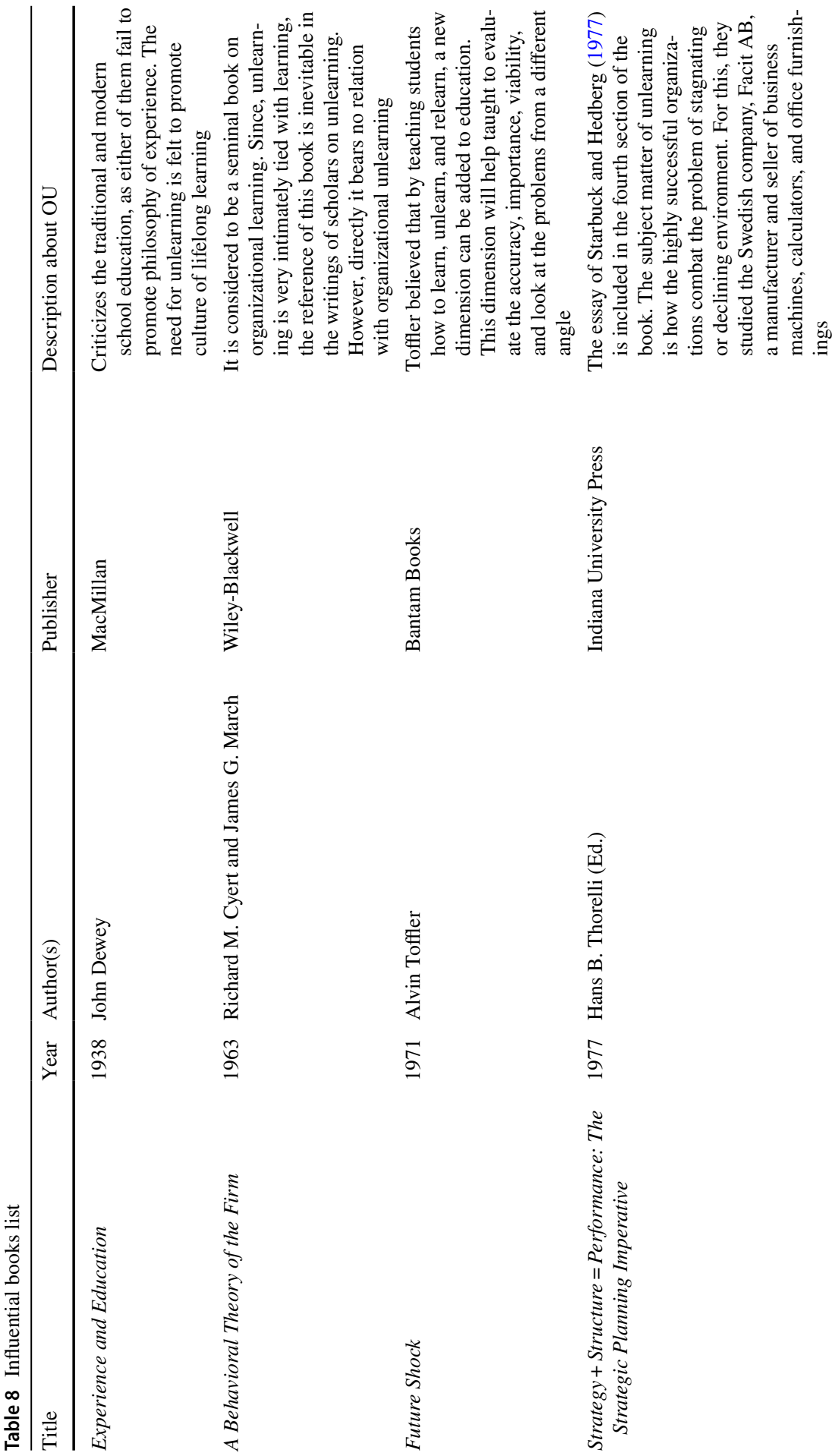




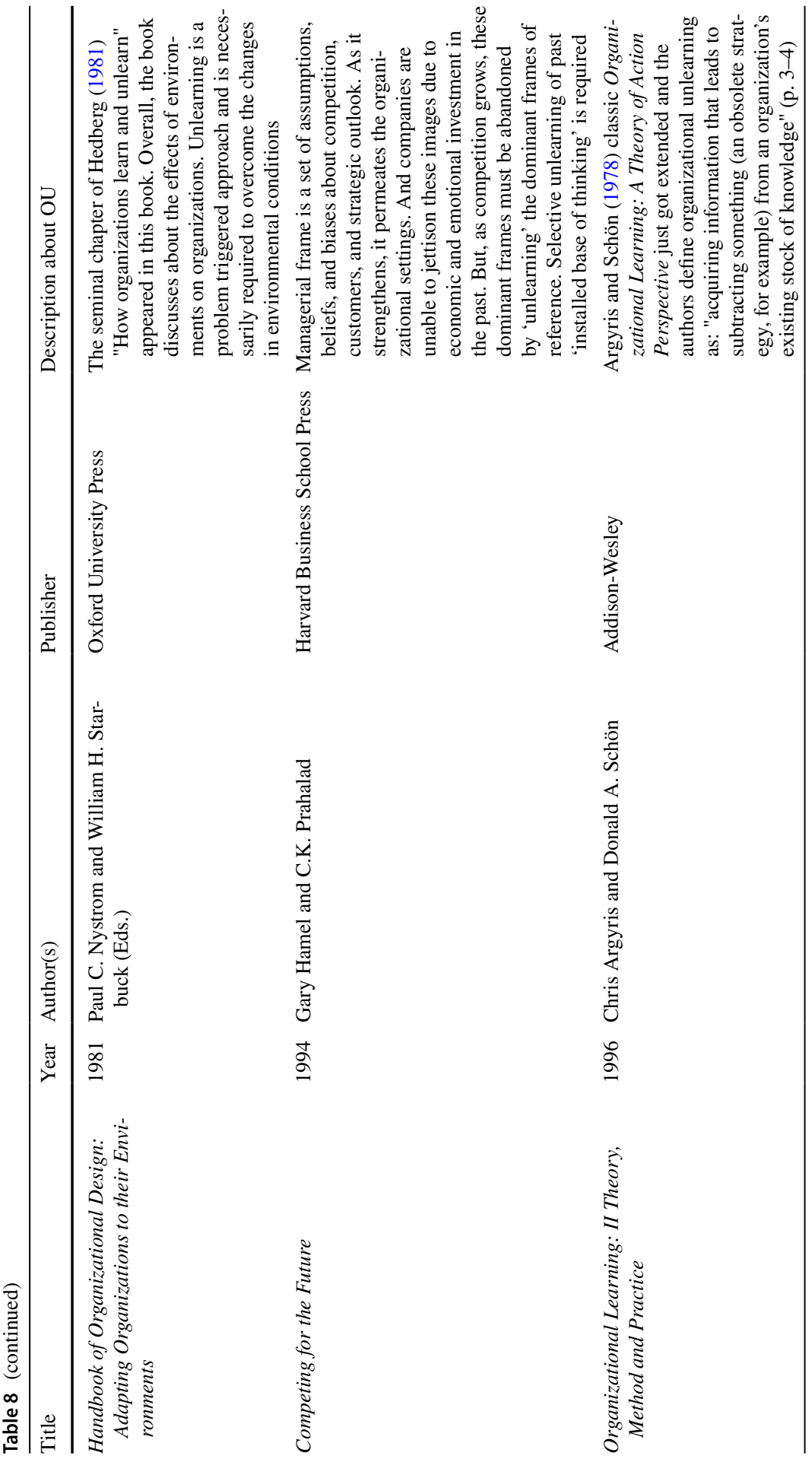




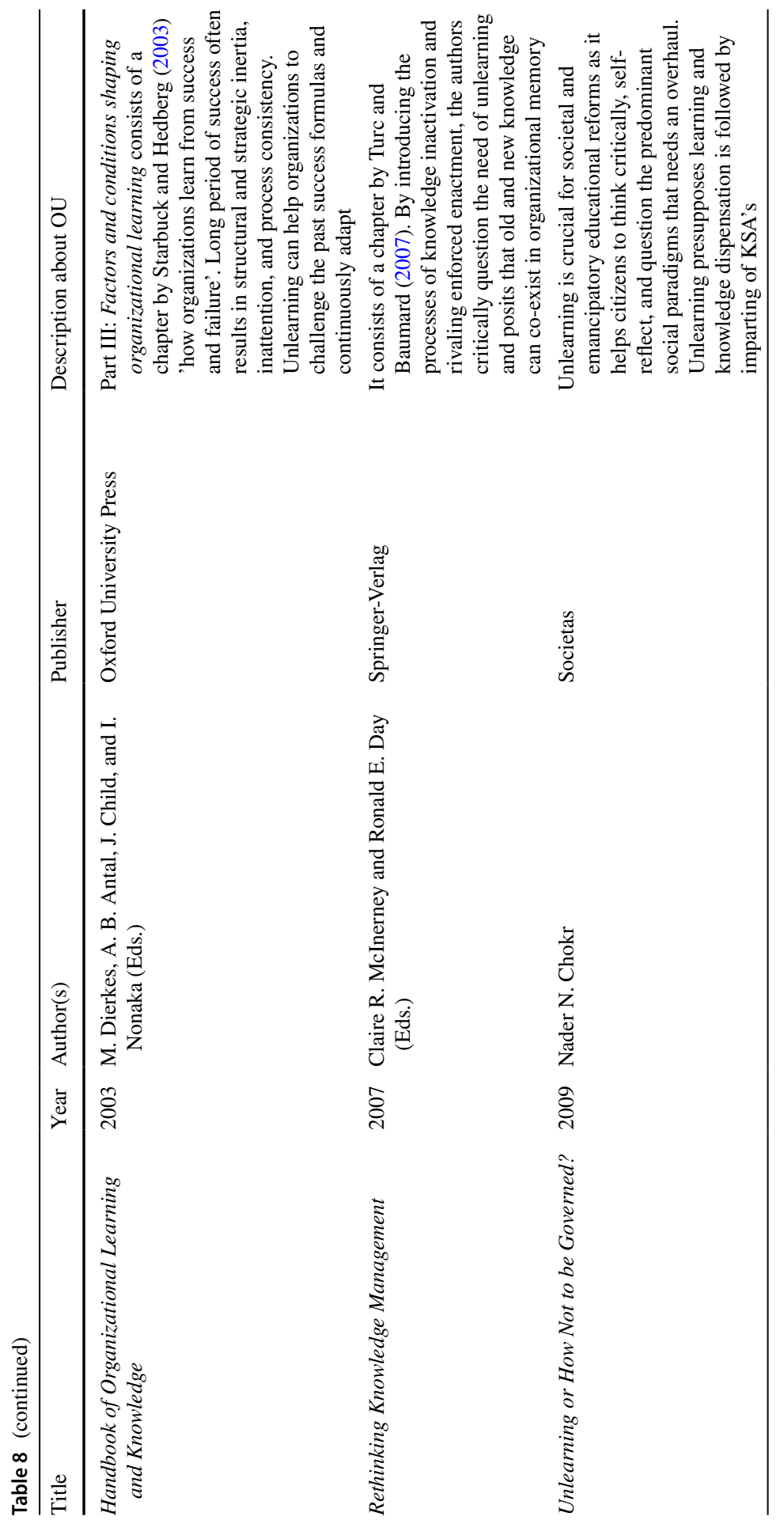




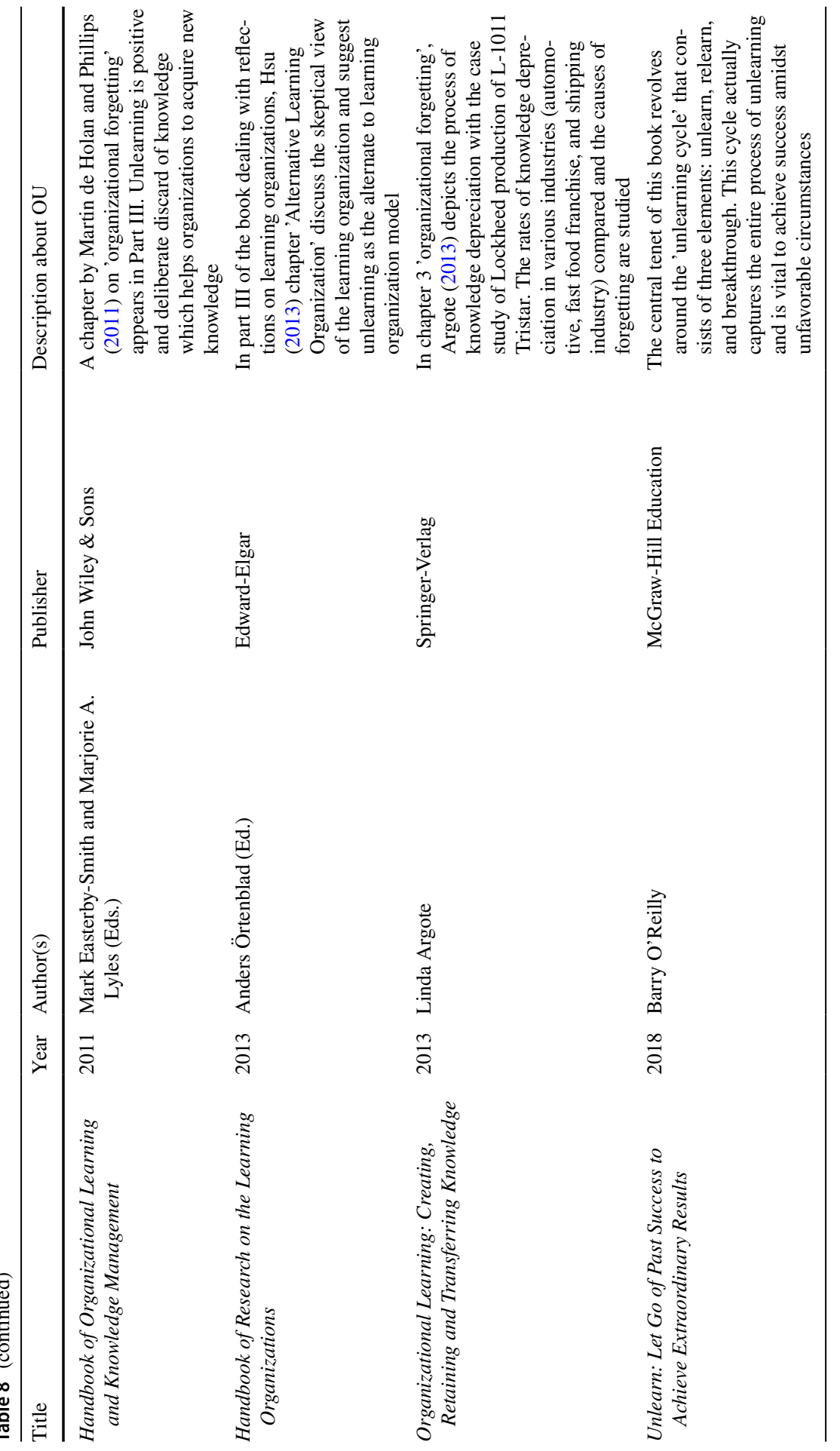




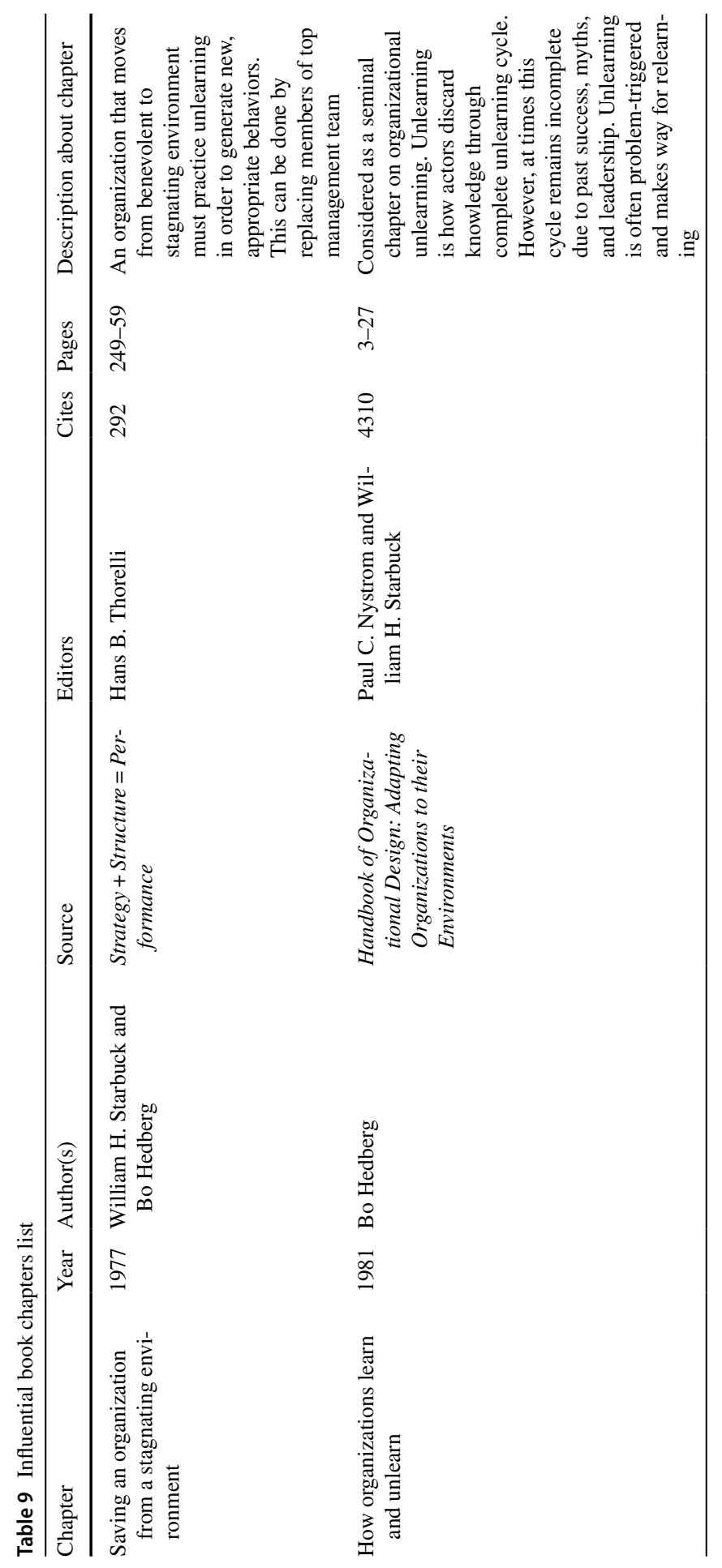




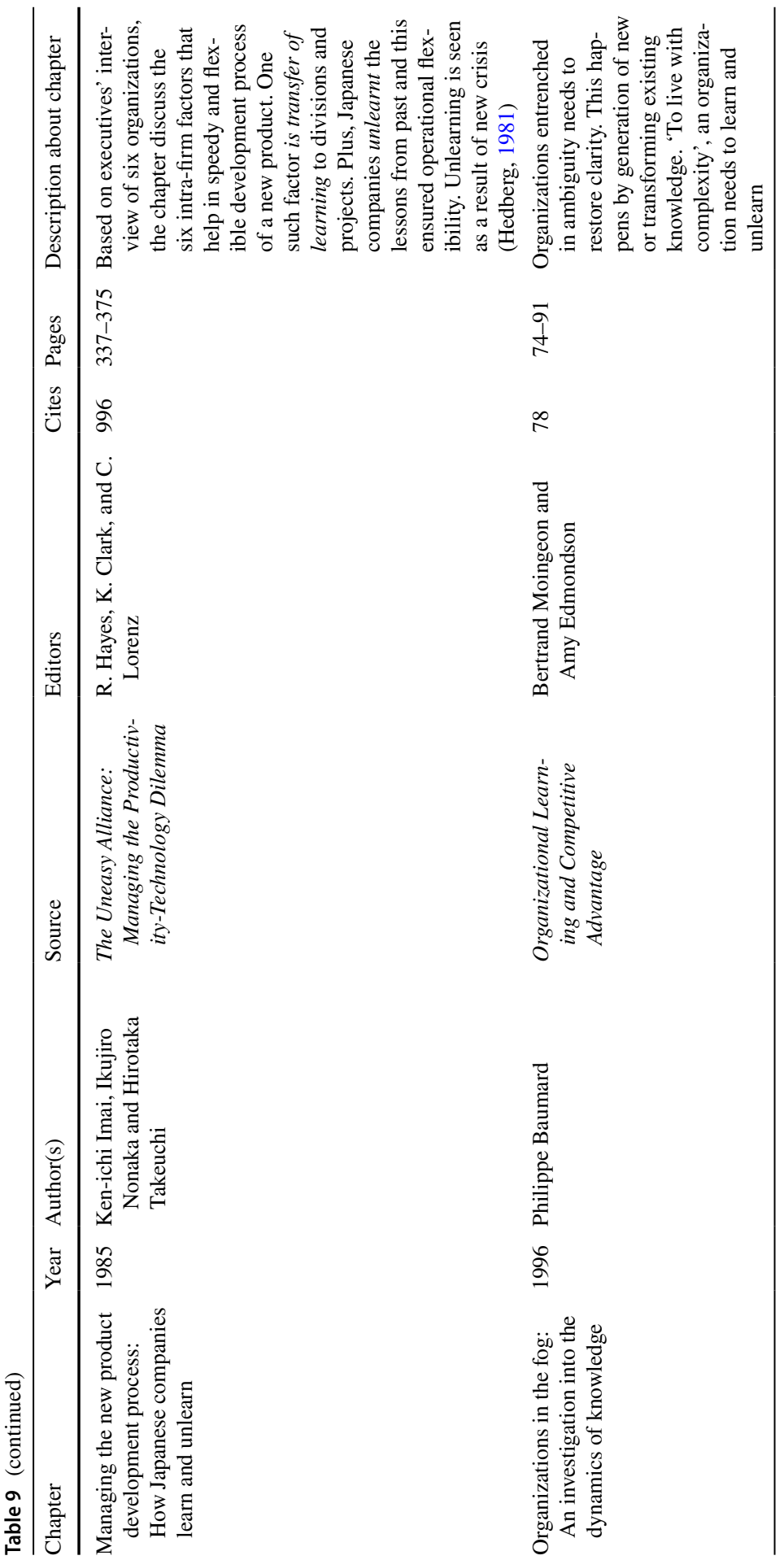




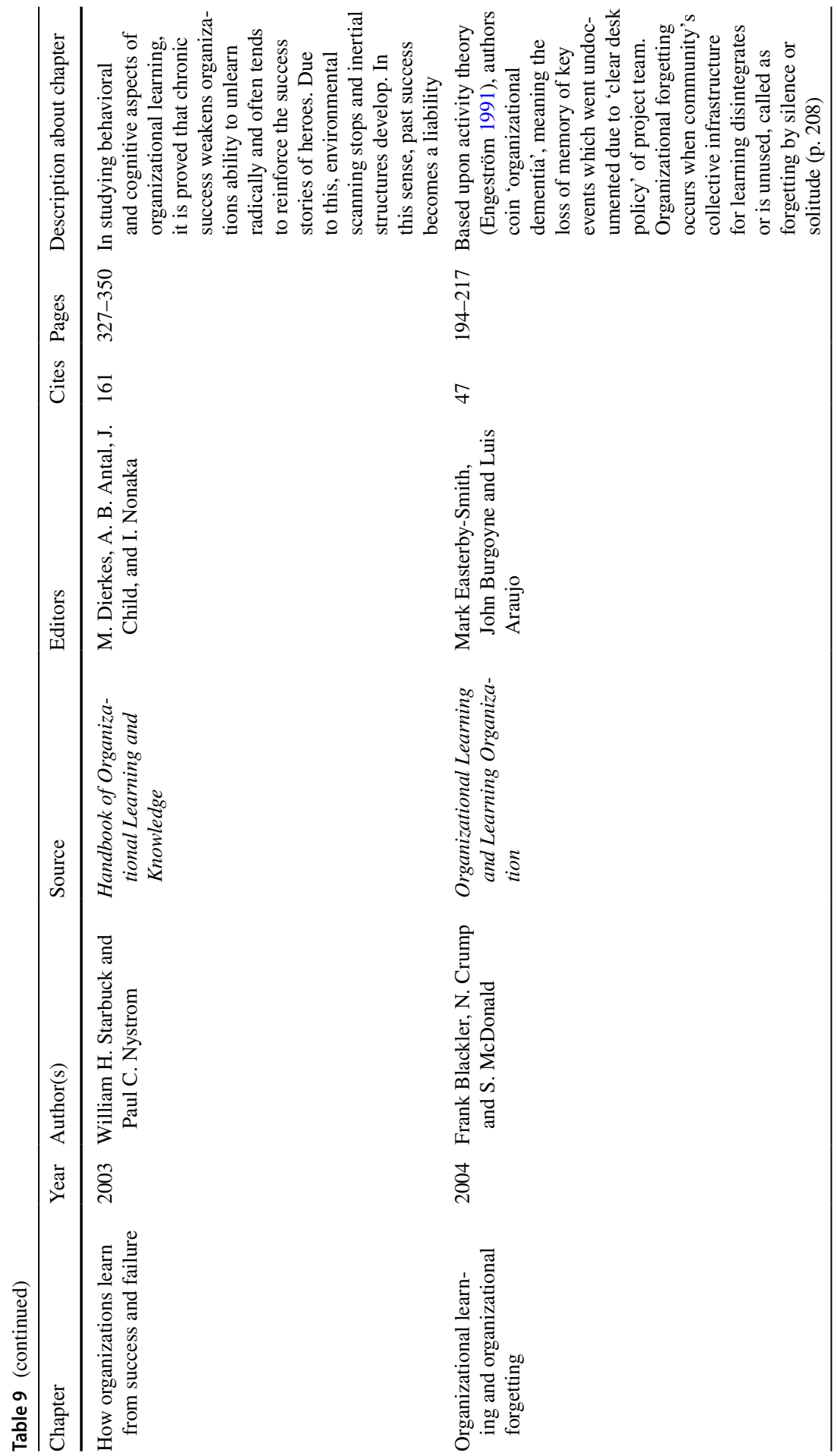




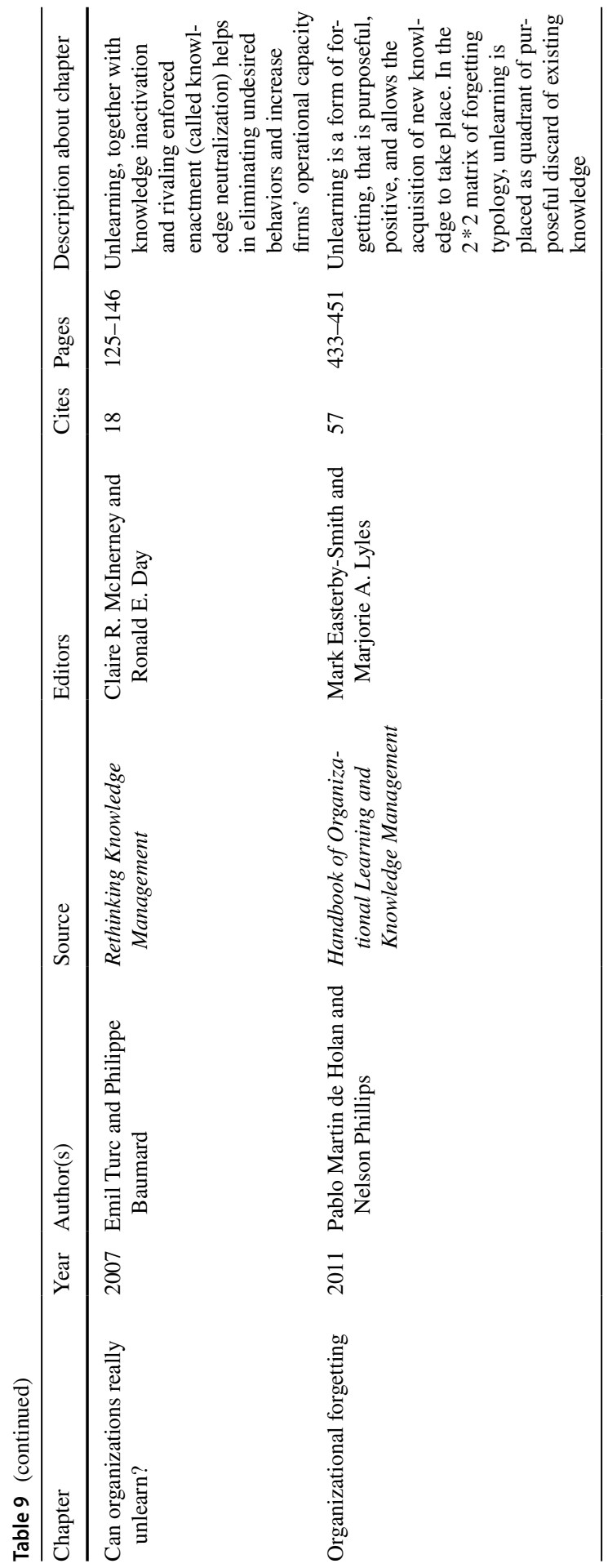


Suppose an article $\mathrm{X}$ is cited by papers $\mathrm{P} 1, \mathrm{P} 2, \ldots, \mathrm{Pn}$. Next, we define a damping factor $\mathrm{d}$, representing the fraction of random walks that continue to propagate along with the citations. Usually, the value of $d$ is fixed at 0.85 ; however, it can be set between 0 and 1 . Now, $\mathrm{C}(\mathrm{Pi})$ is the number of times paper Pi has cited other papers. The PageRank of article $\mathrm{X}$, denoted by $\mathrm{PR}(\mathrm{X})$ in a network of $\mathrm{N}$ papers, is as follows:

$$
\begin{gathered}
P R(X)=\frac{(1-d)}{N}+d\left(\frac{P R(P 1)}{C(P 1)}+\frac{P R(P 2)}{C(P 2)}+\cdots+\frac{P R(P n)}{C(P n)}\right) \\
\text { given, } 0\langle d\rangle 1
\end{gathered}
$$

Table 10 presents the top ten papers using the PageRank algorithm. Comparing Tables 6 and 10, we see that Tsang and Zahra's (2008) review paper on unlearning is in the first position. This list is different from Table 6, and hence, it proves that there is no significant correlation between highly cited articles and prestigious articles. The reasons for the difference between the results of Tables 6 and 10 can be explained as follows. PageRank analysis measures the impact of an article by counting the citations received and the influence of the citing article. In contrast, citation analysis only requires knowing the number of citations received, and it is immaterial to evaluate the influence of an article that cites the other document. Hence, citation analysis determines an article's popularity, whereas PageRank analysis deals with both the popularity and prestige of an article.

\subsection{Authorship pattern and collaboration indices}

Single-authored articles represent 29.27 percent, while multi-authored articles accumulate to 70.73 percent. The recent phase (2011-2019) has witnessed a sharp increase in articles by three or more authors (36.58 percent). This can be explained by the increased opportunities for collaboration and networking between researchers and practitioners. The number of papers written by authors belonging to one country overwhelms those written by authors belonging to two or more than two countries (65.85 percent vs. 34.15 percent). Moreover, multi-authored papers prefer to network with researchers of the same country of origin. Hence, during 2011-2019, although the number of multi-authored papers saw an increasing pattern, the single country representation was highest during this phase (60 percent). More than 63 percent of articles were written by authors from two or more institutions. Around one-third (36.59 percent) of articles were produced by authors representing the same institution. Therefore, even though cross-country participation is less preferred, authors collaborate with people from different institutions. The faculty participation rate has outnumbered research scholars and practitioners (96.34 percent vs. 14.63 percent). Moreover, authors publishing in the field of unlearning tend to be in the same discipline (67.07 percent). This trend has remained constant throughout the period of review (Table 11). 


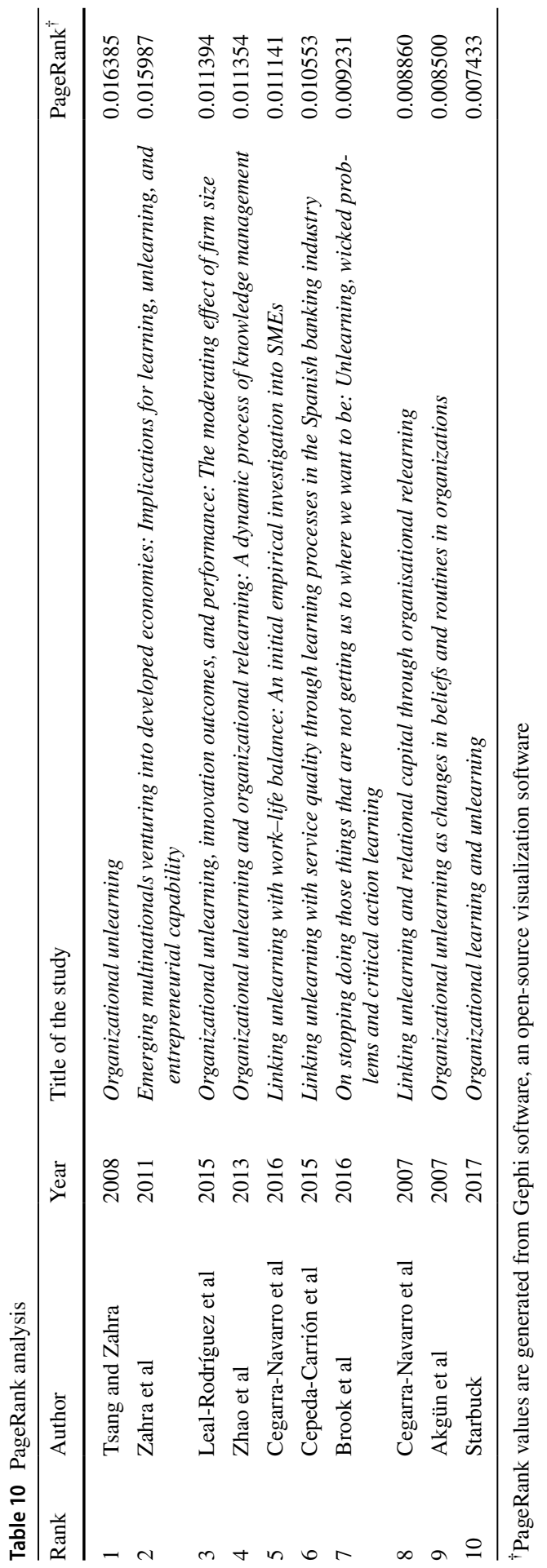


Table 11 Author characteristics and collaboration statistics

\begin{tabular}{|c|c|c|c|c|c|}
\hline \multirow[t]{2}{*}{ Author description } & \multirow[t]{2}{*}{ Total $(n=127)$} & \multicolumn{4}{|c|}{ Time period } \\
\hline & & $\begin{array}{l}1976- \\
1990 \\
(n=6)\end{array}$ & $\begin{array}{l}1991- \\
2000 \\
(n=20)\end{array}$ & $\begin{array}{l}2001- \\
2010 \\
(n=36)\end{array}$ & $\begin{array}{l}2011- \\
2019 \\
(n=65)\end{array}$ \\
\hline \multicolumn{6}{|c|}{ Number of authors involved in article $e^{\mathrm{g}}$} \\
\hline One & 25.20 & 16.67 & 45.00 & 33.33 & 15.38 \\
\hline Two & 38.58 & 66.66 & 40.00 & 41.67 & 33.85 \\
\hline Three and above & 36.22 & 16.67 & 15.00 & 25.00 & 50.77 \\
\hline \multicolumn{6}{|l|}{ Collaboration Indices } \\
\hline $\begin{array}{l}\text { (i) Degree of Collaboration } \\
\text { (DC) }\end{array}$ & - & 0.833 & 0.550 & 0.667 & 0.846 \\
\hline (ii) Collaborative Index (CI) & - & 2.400 & 1.700 & 1.667 & 2.508 \\
\hline $\begin{array}{l}\text { (iii) Collaborative Coefficient } \\
\text { (CC) }\end{array}$ & - & 0.445 & 0.300 & 0.378 & 0.525 \\
\hline \multicolumn{6}{|c|}{ Number of countries represented by authors ${ }^{\dagger}$} \\
\hline One & 66.93 & 50.00 & 90.00 & 69.44 & 60.00 \\
\hline Two & 29.92 & 50.00 & 10.00 & 27.78 & 35.38 \\
\hline Three and above & 3.15 & 0 & 0 & 2.78 & 4.62 \\
\hline \multicolumn{6}{|c|}{ Number of institutions/ universities collaborating $\$$} \\
\hline One & 33.08 & 33.33 & 45.00 & 44.44 & 23.08 \\
\hline Two & 42.51 & 66.67 & 45.00 & 27.78 & 47.69 \\
\hline Three and above & 24.41 & 0 & 10.00 & 27.78 & 29.23 \\
\hline \multicolumn{6}{|l|}{ Designation of authors ${ }^{\Omega}$} \\
\hline Faculty & 97.63 & 100.00 & 95.00 & 97.22 & 98.46 \\
\hline Research Scholar and others & 12.60 & 16.67 & 5.00 & 8.33 & 16.92 \\
\hline \multicolumn{6}{|c|}{ Number of disciplines represented by contributing authors } \\
\hline One & 71.65 & 33.33 & 80.00 & 72.22 & 72.30 \\
\hline Two & 22.83 & 50.00 & 20.00 & 27.78 & 18.46 \\
\hline Three and above & 5.52 & 16.67 & 0 & 0 & 9.24 \\
\hline
\end{tabular}

Note: All figures are in percentage

II In case article is an interview, only interviewer is counted

*Based on location of institution served at the time of publication of paper

§This, apart from authors' affiliation, represents institutes who have funded the project

${ }^{\Omega}$ This represents figure greater than number of articles because in articles: i. "Emerging Multinationals Venturing into Developed Economies Implication for Learning, Unlearning, and Entrepreneurial Capability"; ii. "How unlearning affects radical innovation: The dynamics of social capital and slack resources"; iii. "Linking organizational learning with technical innovation and organizational culture"; iv. "Organizational unlearning and organizational relearning: a dynamic process of knowledge management", both Ph.D. candidate and faculty have contributed. In "On stopping doing those things that are not getting us to where we want to be: Unlearning, wicked problems and critical action learning", a consultant and faculties have contributed 


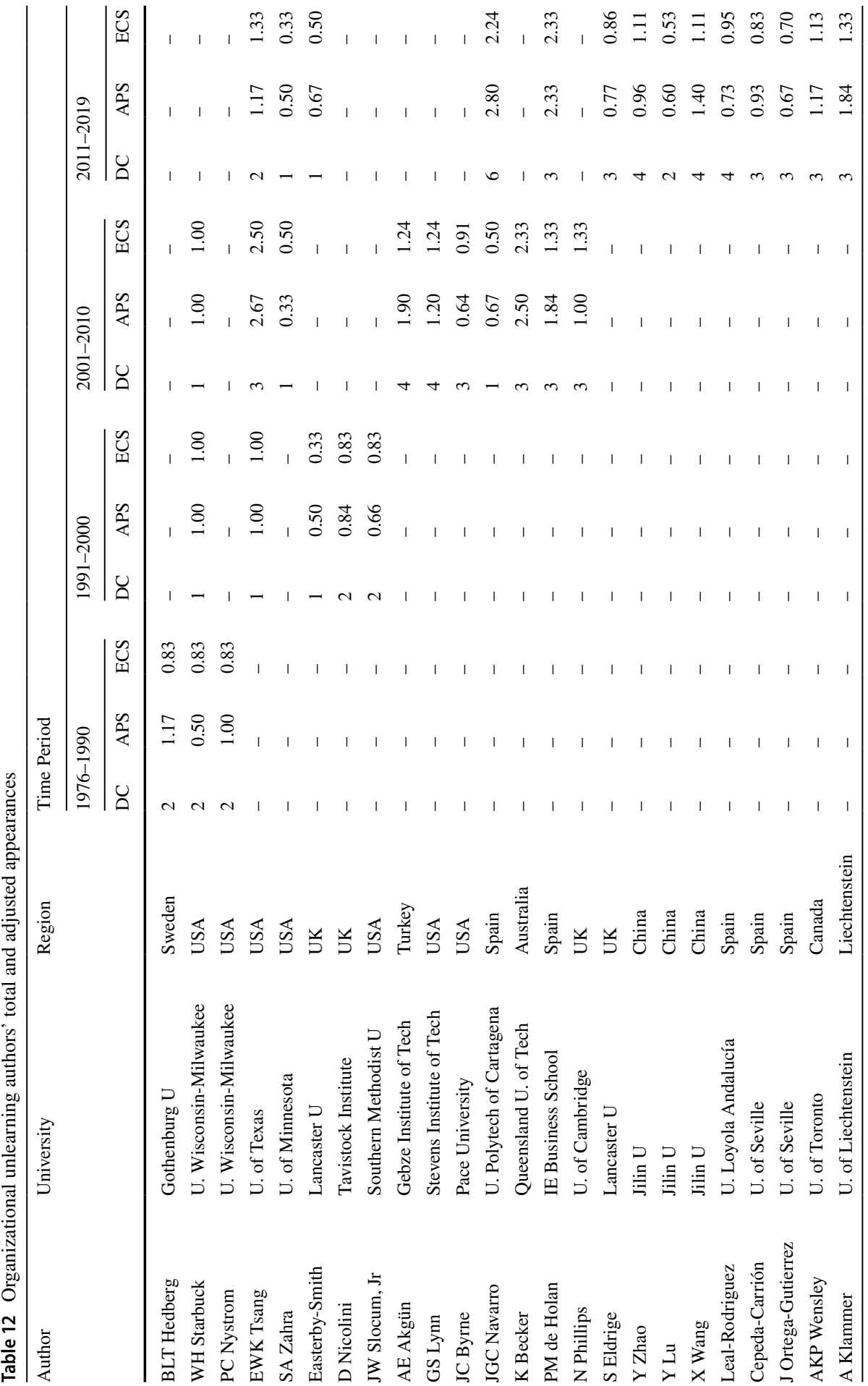




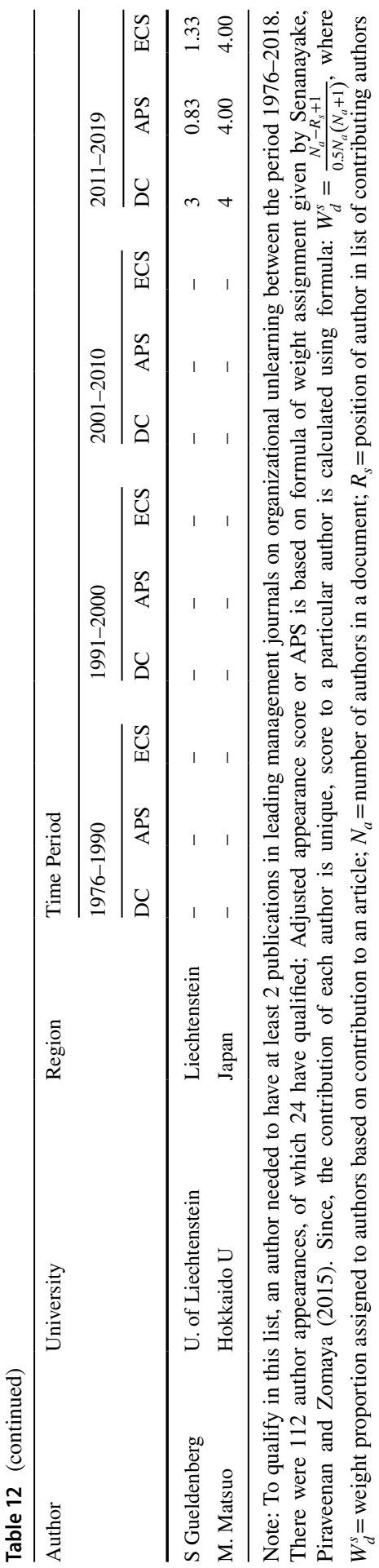


Earlier, we have seen that authors of unlearning are engaged in increasing collaborative links. Wu et al. (2019) attribute the reasons for rising collaboration as improvements in communication technology, the complexity of problems that require interdisciplinary solutions, and professional and career benefits. Quantitative assessment of research collaboration is made through (a.) degree of collaboration, DC; (b.) collaborative index, CI; and (c.) collaborative coefficient, CC (Subramanyam 1983; Andrés 2009). For understanding the mathematical calculations of these coefficients, refer to Appendix 2.

Table 11 shows that all three coefficients of collaboration (DC, CI, and CC) were highest during 2011-2019. Therefore, authors have exhibited a rising tendency to form large teams and work collaboratively to optimize knowledge discovery and dissemination (Wu et al. 2019).

\subsection{Author's productivity}

Table 12 presents the productivity score of leading authors publishing in highimpact journals on unlearning, using the three prominent credit allocation techniques: (a) normalized page size or NPS, (b) author position score or APS, (c) direct count or DC, and (d) equal credit score or ECS (Serenko et al. 2010). NPS is a ratio of the number of pages to the number of authors. NPS determines the relative contribution of each author. However, it is not considered a robust method as merely counting the page of an article cannot determine quality. Moreover, a majority of journals have restrictions regarding word count and pages of an article. This method is avoided in calculating the author's productivity.

Table 12 shows the temporal evolution of the most productive authors on OU. A few authors dominate each time period. However, Tsang and Starbuck are the authors who have consistently published on unlearning in leading management journals. The reported three coefficients are DC, APS, and ECS. DC is like an unadjusted appearance score and assigns a value of 1.00 for each author, regardless of the number and position of authors in a paper. Cegarra-Navarro is the most productive author according to this method, as he has published six articles during 2011-2019 in leading management journals.

APS considers the position of an author in a publication. It is akin to adjusted appearance and is calculated based on the recommendation of Senanayake et al. (2015). Since Tsang has published most of the articles alone, he has the highest APS during 2001-10.

ECS accords equal credit to all the authors irrespective of their position in a publication. It is calculated as $1 / \mathrm{N}$, where $\mathrm{N}$ is the number of authors in a paper. For example, if there are three authors, each author receives a $0.33(1 / 3)$ credit. Tsang has the highest ECS of 2.50 in 2001-10. Matsuo (4.00) is followed by Martin de Holan (2.33) in terms of the highest ECS in 2011-19. 


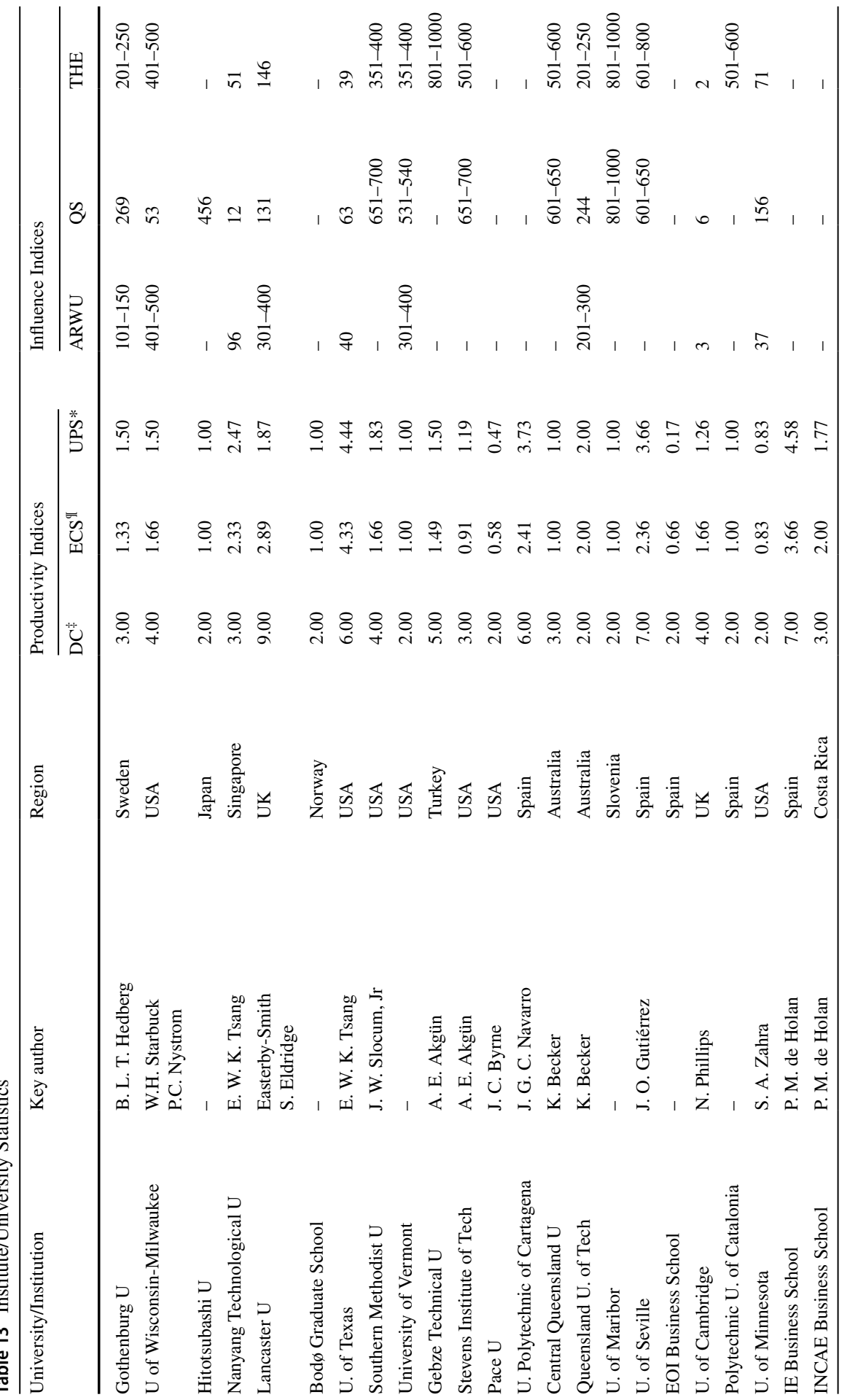




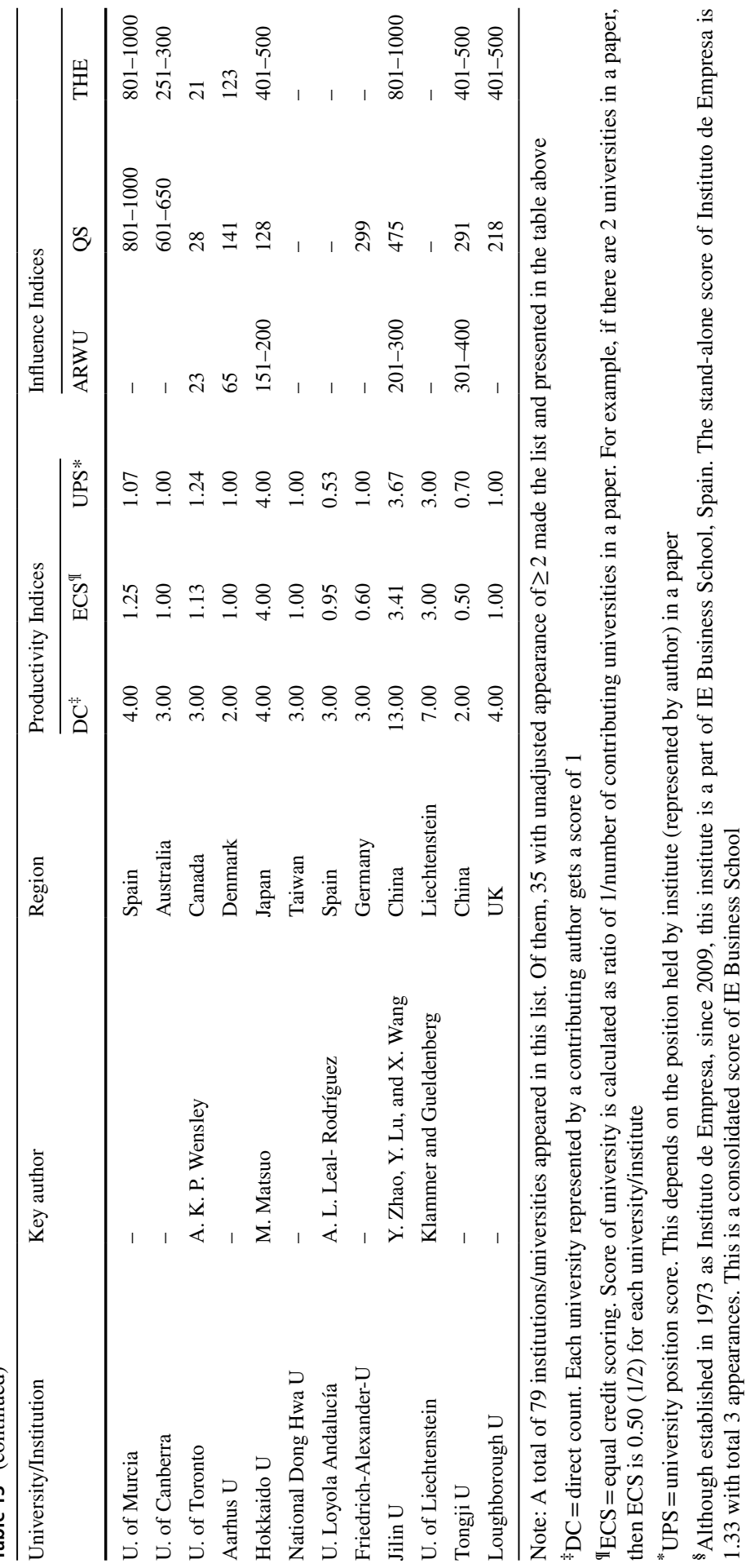




\subsection{Universities/institutions productivity}

Table 13 reports the productivity (direct count score, equal credit score, and university position score) and influence (Academic World University Rankings or ARWU, Quacquarelli-Symonds Rankings or QS, and Times Higher Education Ranking or THE) indices of universities/institutions that have published in leading management journals on unlearning (Serenko 2013). A majority of institutes from the US (7), Spain (7), and Australia (3) are included in Table 13. The DC score is equivalent to the unadjusted appearance score of universities. Here, irrespective of the institution's position in a publication, a score of 1.00 is awarded to all contributing universities. The top three institutions based on the DC technique include Jilin University (13.00), Lancaster University (9.00), and the University of Liechtenstein (7.00). ECS is equivalent to an adjusted appearance score. It is calculated as $1 /$ number of contributing universities in a paper. Like the DC technique, the EC score does not depend on the university's position in a publication. The top institutions based on ECS are the University of Texas (4.33) in the US, Hokkaido University (4.00) in Japan, IE Business School (3.66) in Spain, Jilin University (3.41) in China, and the University of Liechtenstein (3.00) in Liechtenstein. On the other hand, the university position score recognizes the contribution of the university in a publication. It depends on the position held by the representative author of a university in a paper. The university position score is calculated by using the formula proposed by Howard and Day (1995):

$$
\left(1.5^{n-i}\right) / \sum_{i=1}^{n} 1.5^{i-1}
$$

where $n$ represents the total number of universities and $i$ represents the ordinal position of a university in a publication.

For example, a paper with four universities generates a score of $0.415,0.277$, 0.185 , and 0.123 , respectively, depending on their position in the paper. The top three institutions, according to this credit allocation method, are the IE Business School (4.58), University of Texas (4.44), and the Hokkaido University (4.00),

The influence indices of universities are based on the ARWU, QS, and THE rankings. According to all the three ranking frameworks, the University of Cambridge is the most influential university publishing on OU. The University of Toronto is the second most influential university included in this review. The University of Texas is the third most influential university with a ranking of 40,63 , and 39 , according to ARWU, QS, and THE ranking, respectively. In this list, 21 universities did not have an ARWU rank, and 13 universities did not have either a QS or a THE rank.

\subsection{Research design in leading management journals}

The articles on OU in the first phase (1976-1990) did not involve empirical studies. This is because the concept was in its nascent stage. Empirical studies on unlearning were published after the 1990s. The preferred sample size was between 0 and 100 . Later on, the use of large samples increased during 2011-2019, and 12 studies reported 
Table 14 Research design of organizational unlearning in top management journals

\begin{tabular}{|c|c|c|c|c|c|}
\hline \multirow[t]{2}{*}{ Elements of research design } & \multirow[t]{2}{*}{ Total } & \multicolumn{4}{|l|}{ Time period } \\
\hline & & $1976-1990$ & $1991-2000$ & 2001-2010 & 2011-2019 \\
\hline \multicolumn{6}{|l|}{ Target Sample Size $e^{\dagger}$} \\
\hline $0-100$ & 17 & - & 3 & 7 & 10 \\
\hline $101-250$ & 13 & - & - & 2 & 11 \\
\hline $251-400$ & 5 & - & - & 2 & 3 \\
\hline $401-600$ & 9 & - & - & 1 & 8 \\
\hline 601 and above & 13 & - & 1 & 2 & 10 \\
\hline Not reported & 3 & - & - & 1 & 2 \\
\hline \multicolumn{6}{|l|}{ Response Rate Achieved } \\
\hline $0-10 \%$ & - & - & - & - & - \\
\hline $10-30 \%$ & 10 & - & 1 & 1 & 8 \\
\hline $30-50 \%$ & 4 & - & - & - & 4 \\
\hline $50 \%$ and above & 11 & - & - & 4 & 7 \\
\hline Not reported/not applicable & 38 & - & 3 & 10 & 25 \\
\hline \multicolumn{6}{|l|}{ Data Collection Method } \\
\hline $\begin{array}{l}\text { Structured, semi-structured and } \\
\text { unstructured interviews }\end{array}$ & 8 & - & - & 5 & 3 \\
\hline In-depth interviews & 10 & 1 & 3 & 1 & 5 \\
\hline Mail questionnaires & 29 & - & 1 & 6 & 22 \\
\hline Secondary sources & 13 & 2 & 2 & 4 & 5 \\
\hline Observations & 9 & - & 1 & 2 & 6 \\
\hline Others & 5 & - & - & - & 5 \\
\hline \multicolumn{6}{|l|}{ Respondent Profile } \\
\hline C-level officers (CEO's, CFO's etc.) & 10 & 1 & 2 & - & 7 \\
\hline Managers/Directors & 23 & 1 & 2 & 8 & 12 \\
\hline Employees & 14 & 1 & 1 & 3 & 9 \\
\hline Others/not reported & 23 & - & 2 & 4 & 17 \\
\hline \multicolumn{6}{|l|}{ Data Analysis Technique } \\
\hline Qualitative (case study, thematic) & 19 & 2 & 3 & 6 & 8 \\
\hline Quantitative & 48 & - & 1 & 9 & 38 \\
\hline Others & - & - & - & - & - \\
\hline \multicolumn{6}{|l|}{ Statistical Technique Employed } \\
\hline Descriptive Statistics & 6 & - & - & 1 & 5 \\
\hline Correlation Analysis & - & - & - & - & 6 \\
\hline Regression Analysis & 5 & - & - & 1 & 4 \\
\hline Exploratory Factor Analysis & 4 & - & - & 2 & 2 \\
\hline Confirmatory Factor Analysis & 7 & - & 1 & 3 & 3 \\
\hline Structural Equation Modelling & 8 & - & - & 1 & 7 \\
\hline Others & 16 & - & - & 3 & 13 \\
\hline \multicolumn{6}{|l|}{ Reliability and Validity } \\
\hline Reliability calculated & 20 & - & 1 & 5 & 14 \\
\hline Validity calculated & 20 & - & 1 & 5 & 14 \\
\hline
\end{tabular}


Table 14 (continued)

\begin{tabular}{|c|c|c|c|c|c|}
\hline \multirow[t]{2}{*}{ Elements of research design } & \multirow[t]{2}{*}{ Total } & \multicolumn{4}{|l|}{ Time period } \\
\hline & & 1976-1990 & $1991-2000$ & $2001-2010$ & 2011-2019 \\
\hline Not reported & 4 & - & - & - & 4 \\
\hline \multicolumn{6}{|l|}{ Unit of research analysis } \\
\hline Individual & 7 & - & - & 1 & 6 \\
\hline Teams and Firm/Business unit & 6 & - & - & 2 & 4 \\
\hline Organization & 38 & 2 & 3 & 11 & 22 \\
\hline Multinational Ventures & 10 & - & 1 & 2 & 7 \\
\hline
\end{tabular}

Note: Only empirical articles were considered for analysis in this table

IT The total number of studies can exceed the qualified empirical studies (as mentioned in Appendix 1 Table 19) because an article may have used multiple methodology for collection of data and/or analysis of results. For example, data about a case organization can be accumulated using secondary sources (annual reports, magazines, website) as well as interviews and/or observation by the researcher

${ }^{\dagger}$ This can denote the figure of respondents who initially agreed to provide data to researcher or initial target sample size, depending on the information available

a sample size above 400 (Table 14). The table also presents the response rate of studies on OU. Most of the studies (19) did not report the response rate. However, the response rate disclosure increased during 2011-2019 because journals have become stricter in adhering to transparency and disclosure guidelines of material facts. On average, the majority of studies (12) achieved a response rate between 10 and 49 percent.

Mail surveys have been considered the most convenient data collection method, followed by structured, semi-structured, and unstructured interviews. The respondent profile mainly included managers and employees. This is because employees are the primary actors during learning, unlearning, and relearning (Zhao et al. 2013). Most of the studies have used quantitative data analysis techniques. Use of case study, inductive and deductive logical reasoning, grounded theory, or thematic analysis are elusive. Moreover, statistical techniques like confirmatory factor analysis (CFA) and structural equation modeling (SEM) are the most prominently used techniques in quantitative data analysis methods. Prior to SEM's application, unlearning research was dominated by case-based analysis due to its highly abstract character. However, as the need to operationalize unlearning was felt, researchers applied CFA and SEM to develop novel measurement scales of OU. This application is quite appropriate because SEM is beneficial "when researchers deal with data obtained through questioning respondents via primary data collection such as surveys and experiments" (Davvetas et al. 2020: p. 253). Researchers operationalize unlearning as a reflective construct consisting of either two (Akgün et al. 2006; Matsuo 2018) or three dimensions (Cegarra-Navarro and Sánchez-Polo 2008; Martelo-Landroguez et al. 2018). Moreover, SEM is used to establish the relationship of unlearning with other variables. For instance, Leal-Rodríguez et al. (2015) used SEM to test the relationship of unlearning with organizational performance in the Spanish automotive components manufacturing sector. SEM is also helpful to study the influence of mediating and moderating variables that affect the relationship of unlearning with other variables. For example, Lyu et al. (2020) used firm size as a moderating variable to 


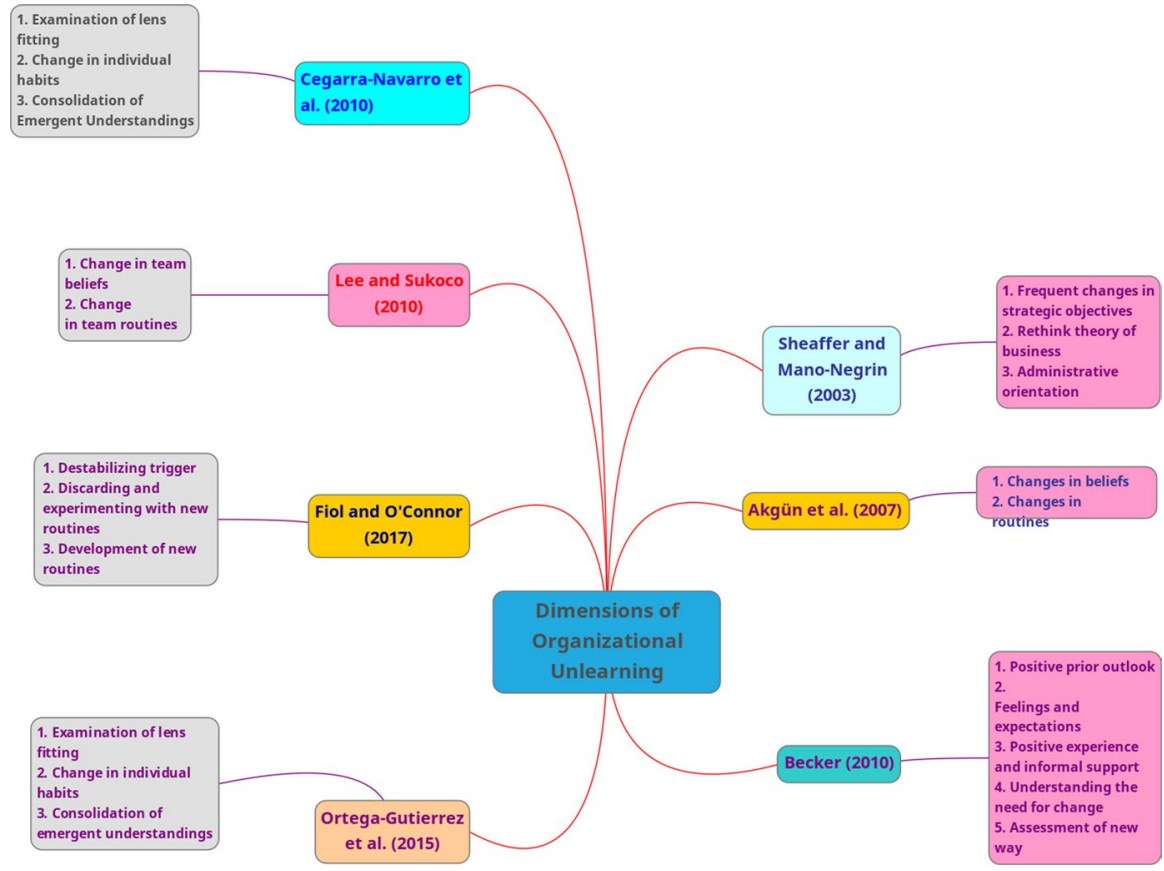

Fig. 3 Dimensions of organizational unlearning. Various authors have proposed different dimensions of organizational unlearning. The essence, however, remains the same. Unlearning usually begins with a destabilizing trigger (e. g. crisis, problems), followed by identifying and discarding obsolete knowledge, behavior, and routines. It ends with relearning or experimenting with new knowledge or behavior

investigate the linkage of unlearning with environmental turbulence and entrepreneurial orientation in Chinese manufacturing firms undergoing radical innovation. Lastly, CFA and SEM are applied to assess the psychometric properties (reliability and validity) of the measurement scales intended to measure OU. The techniques categorized as 'others' in Table 14 include agent-based modeling (Miller and Martignoni 2016) and hierarchical linear modeling (Matsuo 2018). Reliability and validity constitute the two important pillars that support the verifiability and generalizability of the research. Most of the studies (44) calculated these indices and reported them vividly. As expected, the unit of analysis of unlearning studies mainly pertains to the organizational level. However, research has proved that the other levels (individual, group, or team) of unlearning are equally important (Hislop et al. 2014; Zhao et al. 2013). The unlearning studies in multinational ventures relate to transferring routines and knowledge in overseas joint ventures (Tsang 2008). In addition, Tsang's (2008, 2017) case studies on Sino-foreign joint ventures are also included under this heading.

\subsection{Dimensions of organizational unlearning}

Since the publication of Hedberg's (1981) seminal chapter, researchers have measured the unlearning construct in numerous ways. For instance, Hedberg (1981) 


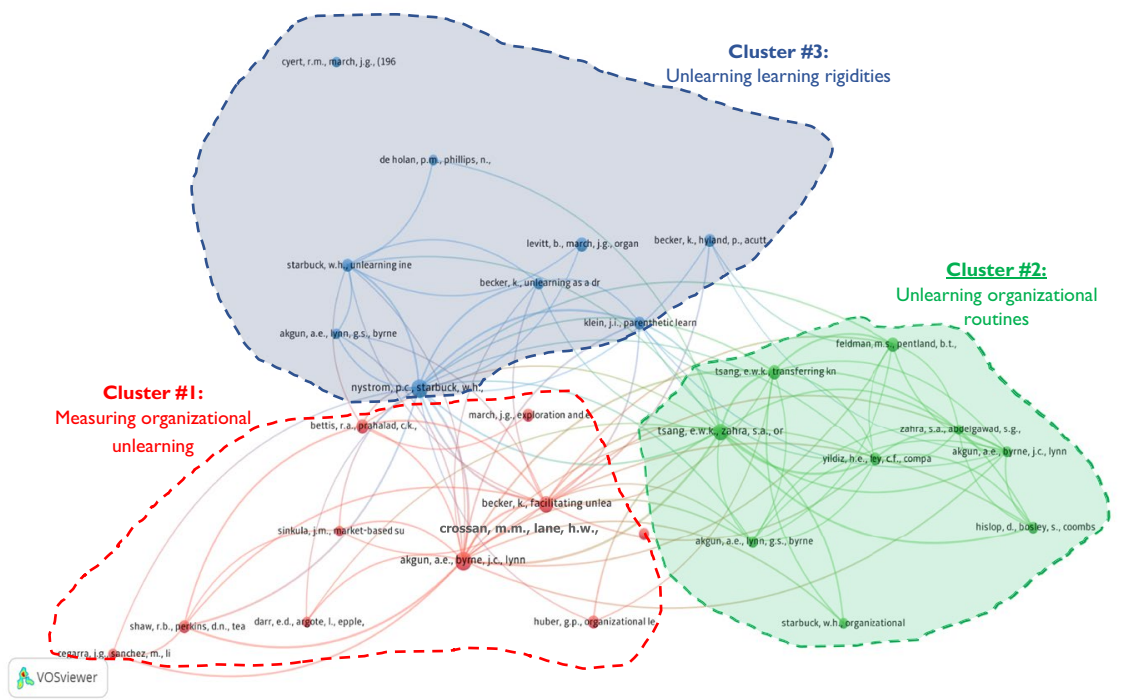

Fig. 4 Co-citation analysis of organizational unlearning references (1976-2019). This figure must be read vis-à-vis Table 15. The minimum occurrence of cited references was $>5.28$ references out of 7227 qualified for further analysis. As a result, three clusters are formed. The labels beside the cluster are only indicative and not software-generated

proposed three dimensions of unlearning: disconfirming mechanisms to identify and select stimuli, disconfirming the relationship between stimuli and response, and disconfirming connection between responses. Since Hedberg's (1981) work reviews psychology literature and incorporates interference theory, these dimensions naturally address the stimuli-response uncoupling mechanism. Figure 3 provides a summary of studies that have proposed various dimensions of unlearning. Of these, the dimensions developed by Akgün et al. (2007a) and Cegarra-Navarro and SánchezPolo (2008) are the most popular in the current scholarship. Akgün et al. (2007a) conceptualized unlearning as changes in beliefs and routines to become receptive to new markets and technologies. Cegarra-Navarro and Sánchez-Polo (2008) operationalized unlearning as a second-order construct with three dimensions: examining lens-fitting, changing individual habits, and consolidating emergent understandings. Several empirical studies have adapted these two classification schemes to measure unlearning in organizations (Cegarra-Navarro et al. 2011; Lee and Sukoco 2011; Martelo-Landroguez et al. 2018; Yang et al. 2014).

\subsection{Co-citation analysis of organizational unlearning}

Co-citation analysis ${ }^{4}$ is defined as the frequency with which two articles are cited together by another article (Small et al. 1973; Raghuram et al. 2019). It establishes

\footnotetext{
${ }^{4}$ We thank an anonymous reviewer for this insightful suggestion to conduct co-citation analysis of unlearning.
} 


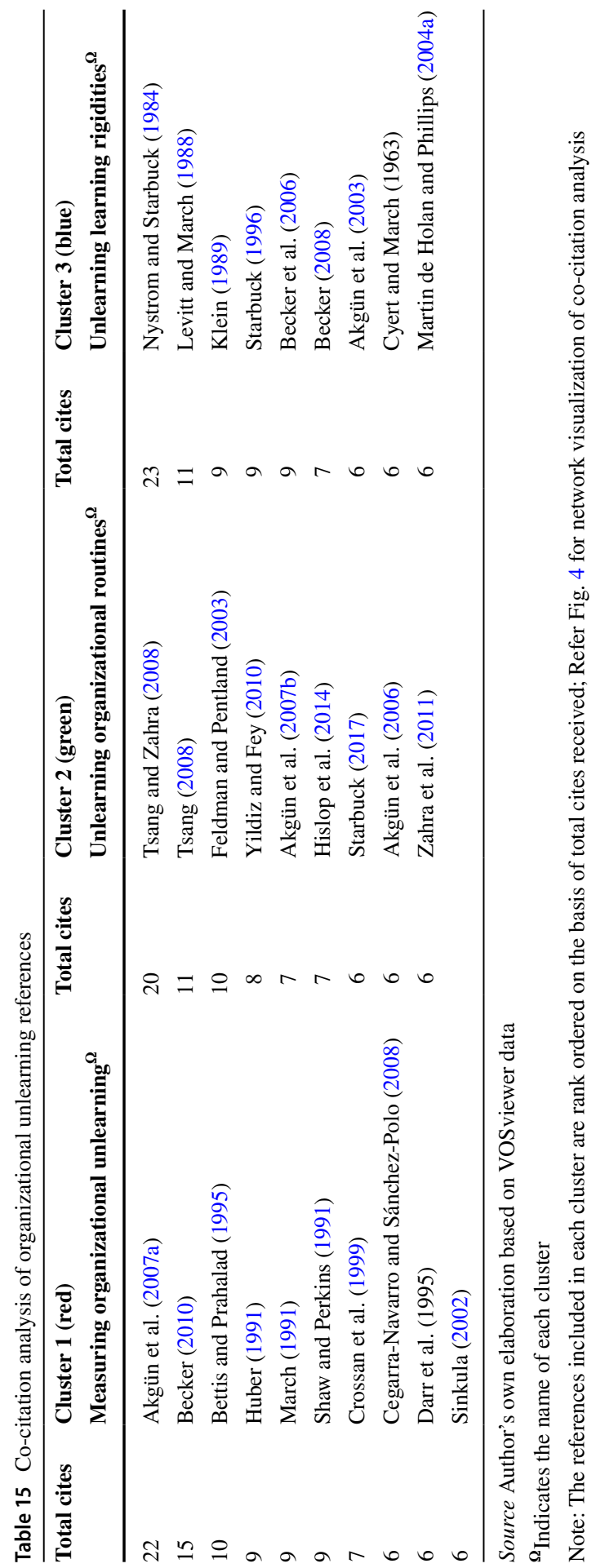


a relationship between two or more publications that have been previously published. Figure 4 presents a co-citation network of references appearing in unlearning articles. Each node (circle) is an article, and an edge (curved lines) connects these articles. To ensure that only influential articles were included in the analysis, we selected a threshold level so that each reference was cited at least five times in unlearning publications. This resulted in 28 references divided into three distinct clusters: Cluster 1 (red) measuring organizational unlearning (10 items), Cluster 2 (green) unlearning organizational routines (9 items), and Cluster 3 (blue) unlearning learning rigidities ( 9 items). Table 15 enlists the references included in each cluster and the number of times another publication cites them.

\subsubsection{Measuring organizational unlearning}

Cluster 1 is labeled as measuring organizational unlearning because most references in this group deal with operationalizing unlearning construct. Akgün et al. (2007a) is the most-cited paper in this cluster. It is a conceptual paper in which authors attempt to conceptualize and operationalize unlearning. Based on two dimensions - changes in beliefs and changes in routines - a typology of unlearning consisting of formative, operative, reinventive, and adjustive unlearning is developed. Other papers in this cluster manifest a balance of conceptual (Bettis and Prahalad 1995; Huber 1991; Sinkula 2002) and empirical (Becker 2010; Cegarra-Navarro and Sánchez-Polo 2008) articles. The analysis of cluster 1 is quite similar to the previous section, where we studied different dimensions of unlearning and synthesized the prior attempts of researchers to quantify the unlearning process (see Fig. 3). In this regard, Huber (1991) argues that unlearning directly affects information interpretation, i.e., attributing commonly understood interpretation to information, which, in turn, leads to OL. Later on, Bettis and Prahalad (1995) proposed an unlearning curve and devised a mathematical function which states that learning in a particular period (Lt) depends on the amount of unlearning in the past $(\mathrm{Ft}-1)$, or, $\mathrm{Lt}=\mathrm{f}[\mathrm{F}(\mathrm{t}-1)]$. Sinkula (2002) presented an unlearning ecology that draws heavily from Hedberg's (1981) stimuli-response uncoupling framework. Similarly, Becker (2010) identified seven factors (positive prior outlook, feelings and expectations, positive experiences and informal support, understanding the need for change, assessment of new way, history of organizational change, and organizational support and training) influencing unlearning during the implementation of enterprise information system in the Australian energy industry. However, Crossan et al. (1999), March (1991), and Shaw and Perkins (1991) do not deal with unlearning directly. But their arguments are quite relevant to the unlearning debate. For example, Shaw and Perkins (1991) advanced reflective and experimental organizations as two themes of learning-efficient organizations. These two themes are similar to unlearning, whereby organizations reflect their existing knowledge and routines to experiment with future actions (Cegarra-Navarro et al. 2012; Sinkula 2002). 


\subsubsection{Unlearning organizational routines}

Cluster 2 consists of articles that deal with unlearning organizational routines. The papers included in this cluster examine unlearning of routines at the individual level (Hislop et al. 2014), team level (Akgün et al. 2006, 2007b), and organizational level (Tsang and Zahra 2008), including multinational enterprises (Zahra et al. 2011), international joint ventures (Tsang 2008) and mergers and acquisitions (Yildiz and Fey 2010). Tsang and Zahra (2008) is the most cited paper in this cluster. They define OU as "discarding of old routines to make way for new ones, if any" (p. 1437). Prima facie, a routine is perceived as a source of inertia, inflexibility, and impossible to discard from organizational memory. However, Feldman and Pentland (2003) proposed two aspects of organizational routines—ostensive (an abstract idea of a routine) and performative (actual performance of a routine), which opens up the avenue for unlearning routines. Since the performative aspect involves a human element, therefore, "participants engage in reflective self-monitoring in order to see what they are doing" (Feldman and Pentland 2003: p. 102). Conclusively, routines can be improvised, and it is quite possible to unlearn and relearn organizational routines via self-reflective learning by organizational members.

The behavioral dimension of unlearning deals explicitly with setting aside old routines, beliefs, standard operating procedures, and daily practices (Yildiz and Fey 2010). Baker and Sinkula (1999) assert that "when organizations proactively question long-held routines, assumptions, and beliefs, they are engaging in the practice of unlearning" (p. 413). Behavioral unlearning helps in the institutionalization of newly acquired knowledge. Empirical evidence suggests that organizational members resist implementing new routines due to not-invented-here syndrome, status quo bias (Kim and Kankanhalli 2009), and incompatibility of new routines with the existing organizational values and beliefs (Tsang 2008; Wang et al. 2017; Yildiz and Fey 2010). Therefore, unlearning this legacy of the past may help organizations acquire, implement, and institutionalize new routines effectively.

In addition to facilitating knowledge institutionalization, behavioral unlearning is also instrumental in efficient knowledge transfer by international joint ventures (Tsang 2008) and mergers and acquisitions (Wang et al. 2017; Yildiz and Fey 2010). Research has shown that acquired mergers and acquisitions and joint ventures usually operate with their own set of routines and values. These routines and values create a stumbling block in the path of acquiring new routines. Unlike greenfield ventures, acquisition ventures are not 'clean slates,' and before transferring new routines to local enterprises, a foreign partner needs to ensure that local employees are willing and able to unlearn the prior routines. For this to happen, educate local employees about the necessity and benefits of setting aside old ways and experiment with new routines, foster a culture of unlearning, and augment the compatibility of new routines with existing routines (Tsang 2008; Yildiz and Fey 2010).

\subsubsection{Unlearning learning rigidities}

Cluster 3 mainly deals with unlearning learning rigidities. The articles in this cluster include Nystrom and Starbuck (1984), Levitt and March (1988), Klein (1989), 
Starbuck (1996), Akgün et al. (2003), Becker et al. (2006), and Becker (2008). Undoubtedly, OL is critical to sustaining competitive advantage (Argyris and Schön 1996). However, management scholars express their concerns when OL becomes a source of rigidity rather than flexibility (Contu et al. 2003; Starbuck 2017). When organizations learn, they encode incoming knowledge into programs, routines, and standard operating procedures that guide future behavior (Levitt and March 1988). This conviction of organizational efficiency augments during a stable environment and continued success, resulting in reinforcement of past routines without questioning their usefulness. However, organizations fail to recognize that "knowledge grows, and simultaneously it becomes obsolete as reality changes" (Hedberg 1981: p. 3). As a result, the same learning that produced intended outcomes in the past becomes a source of inertia and manifests in an internal crisis. The culmination of learning rigidity is when top managers fail to sense alternative opportunities. This is because their dominant logics and cognitive structures were never really challenged in a stable environment (Bettis and Prahalad 1995). Therefore, the central theme of this cluster is that in order to break the shackles of past learning that causes inertia, organizations also need to create a culture of unlearning by promoting experimentation, awareness, tolerance for failure (Klammer et al. 2019), coaching and performance feedback (Becker et al. 2006), and critical reflexive thinking (Matsuo 2018).

\subsection{Thematic areas of organizational unlearning}

The co-occurrence of keywords (Callon et al. 1991) examines the inter-relationship between the concepts represented by carefully chosen keywords. Unlearning literature was categorized into four major headings related to (a) learning, (b) unlearning, (c) knowledge management, and (d) organizational strategy (Table 16). Surprisingly, not even a single paper published in leading management journals from 1976 to 2000 used 'unlearning' related keywords. This can be attributed to the fact that unlearning was considered subsumable under organizational learning and other psychological concepts like extinction and inhibition. Apart from this, Table 16 shows that five papers (83.33 percent) during 1976-1990 and 12 papers (60.00 percent) during 1991-2000 did not report any keyword. Another interesting analysis is that during 2001-2010, the highest number of papers $(n=13,36.11$ percent $)$ used 'unlearning' in the title but did not include 'unlearn*' as a keyword. With the growing recognition of the need for unlearning, this figure has come down to 13.85 percent during 2011-2019.

However, Table 16 is not enough to study the inter-relationship between four broad categories of keywords and unlearning in organizations. To bridge this gap, Fig. 5 depicts the network visualization of the most prominent keywords used in OU articles from 1976 to 2019 using VOSviewer. Figure 5 complements the results of Table 16.

Figure 5 shows eight research clusters similar to the broad categorization of thematic areas of OU in Table 16. Cluster 1, the largest cluster in terms of keywords, expands upon the relationship between unlearning and organizational change. The articles included in this cluster were published mostly after the year 2000. Cluster 2 


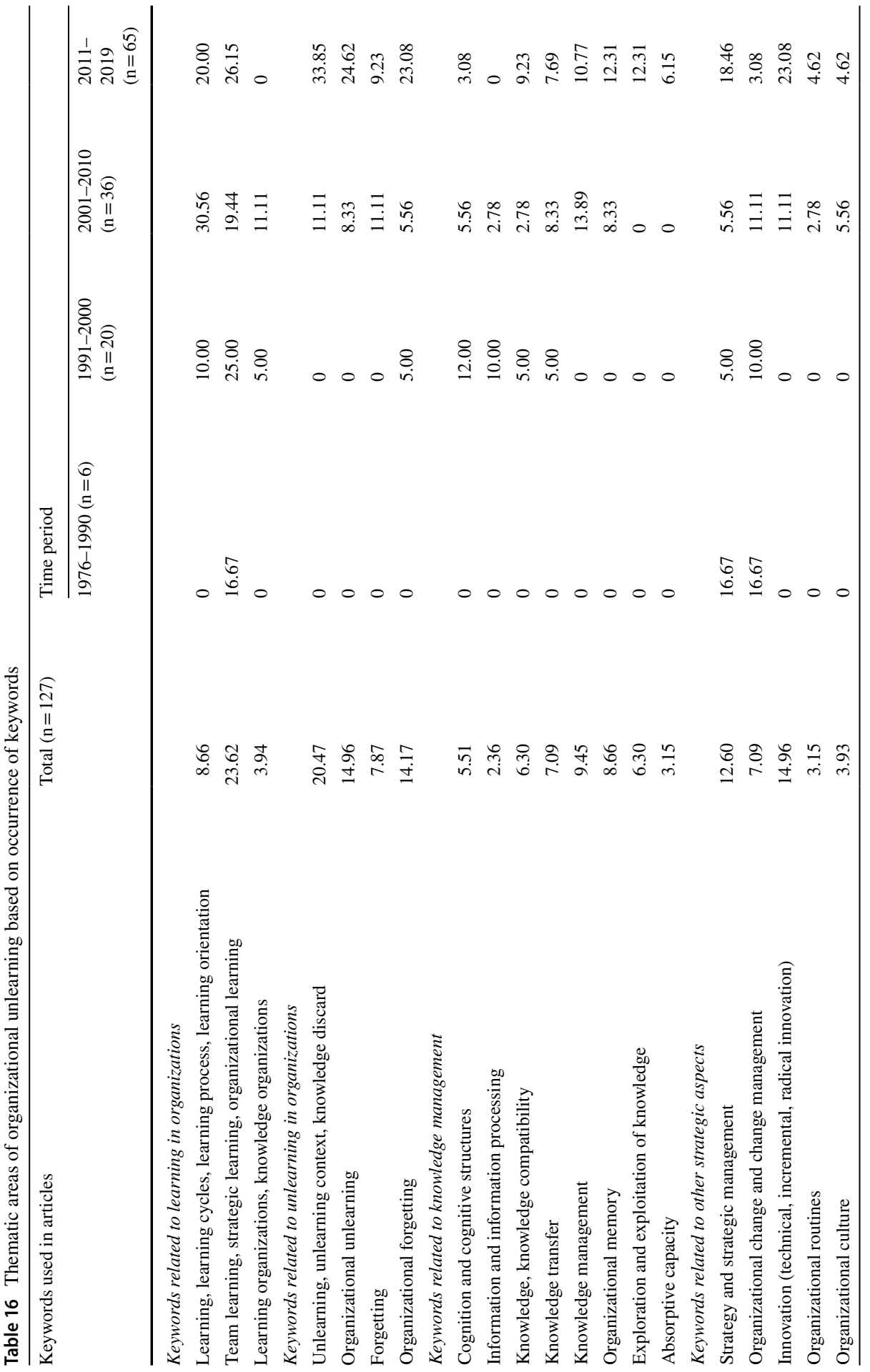




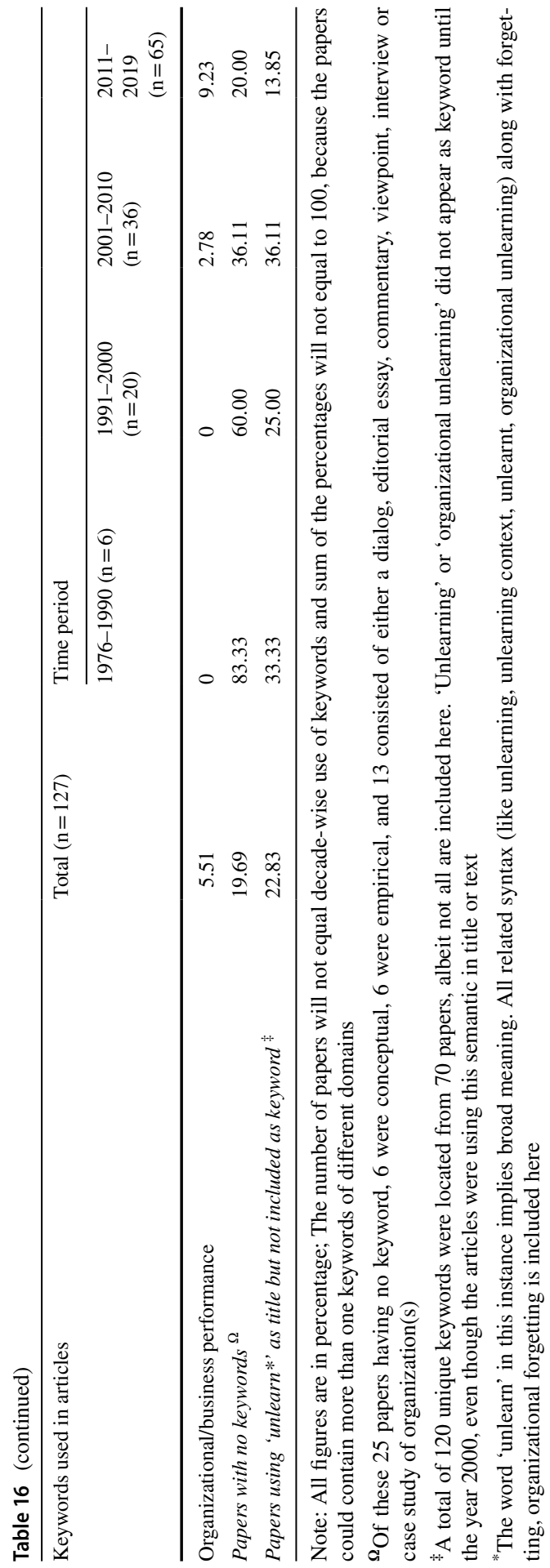




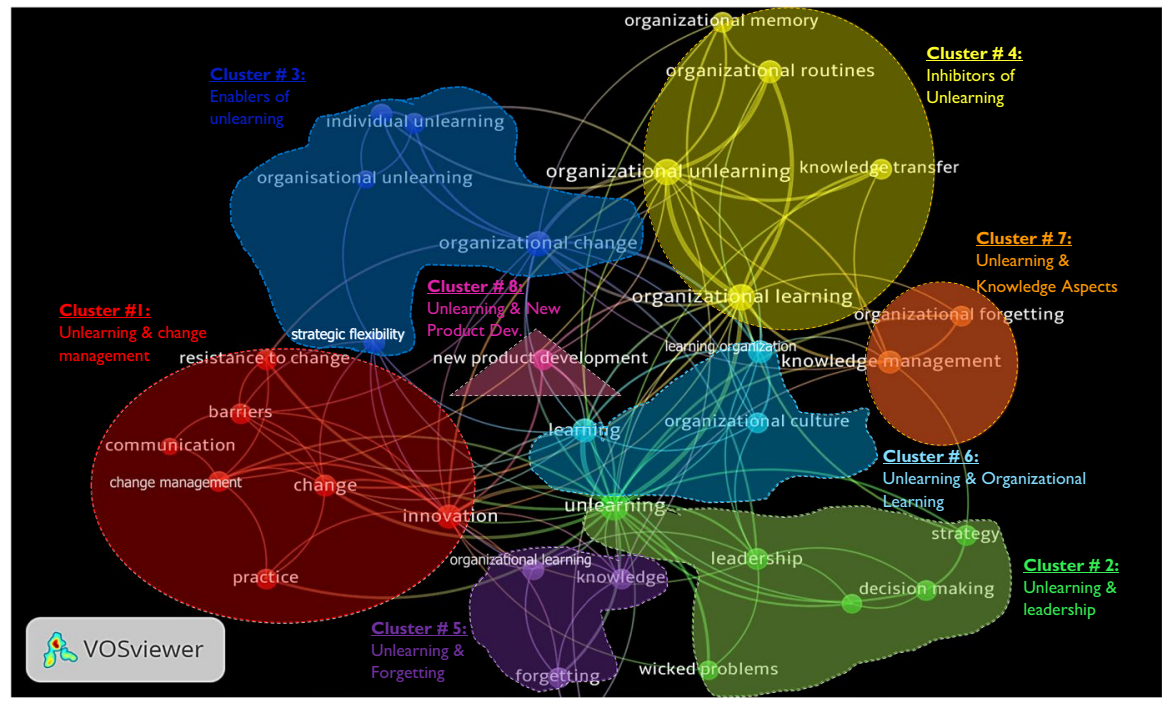

Fig. 5 Co-occurrence of keyword analysis of organizational unlearning (1976-2019). This figure must be read vis-à-vis Tables 16 and 17. The minimum occurrence of keywords was $>5.36$ keywords out of 427 qualified for further analysis. As a result, eight clusters are formed. The labels beside the cluster are only indicative and not software-generated

includes papers relating to the role of leadership in fostering a culture of unlearning in organizations. The debate about the importance of the leadership team in unlearning is recognized since the seminal article of Hedberg et al. (1976). Cluster 3 and cluster 4 form the gamut of unlearning and include papers explaining the enablers and inhibitors of unlearning. However, the understanding of factors that enable and inhibit the unlearning process still lacks in literature. Nevertheless, these two clusters give an overview of factors that affect unlearning at the workplace. Cluster 5 draws the attention towards clarifying the difference between two commonly used terms, yet erroneously used interchangeably in literature-unlearning and forgetting. Cluster 6, like cluster 2, includes papers published during the initial phase of unlearning (1976-1990). This cluster is represented by the linkage of OL and unlearning. Cluster 7 is primarily based on studies that highlight the role of unlearning in the knowledge management process. The early definitions have conceptualized unlearning as discarding obsolete knowledge (Hedberg 1981; Newstrom 1983). Subsequently, this cluster represents papers that have carried this relationship further, owing to the dawn of knowledge-based organizations (Drucker 1999). Lastly, cluster 8 deals with the role of unlearning during radical innovation, including technological innovation and new product development. A detailed analysis of each cluster is presented further.

\subsubsection{Cluster \# 1 (Red) "Unlearning and Aspects of Change Management"}

This cluster consists of seven keywords that broadly discuss the role of OU during organizational change. The cluster consists of ten articles. Most of these articles deal 
with unlearning at the organizational level. However, some studies analyze unlearning at the individual level because individual unlearning enables OU (Becker 2008, 2010; Scheiner et al. 2016). Individual unlearning is defined as a process by which individuals deliberately discard knowledge, values, and behaviors to acquire new ones (Matsuo 2018). Indeed, Zhao et al. (2013) affirm that "the process of organisational unlearning is the continuous evolution of individual unlearning-group unlearning-organisational unlearning" (p. 905). Mainly, the studies in this cluster have employed an exploratory research design by using qualitative methods like case studies (Becker 2008; Pratt and Barnett 1997) and semi-structured interviews (Conway and Monks 2011; Scheiner et al. 2016), and quantitative techniques like exploratory factor analysis (Becker 2010).

Unlearning is a vital constituent for changing organizations (Conway and Monks 2011; Pratt and Barnett 1997). Change is usually accompanied by individual resistance due to implicit norms or conventions held by organizational members, emotional attachment in the past, and the fear of moving to an unknown territory (Griffiths et al. 2005; Inkpen 2008; Wilkins and Bristow 1987). Status quo bias theory is often used to explain people's preference to maintain their current status or position (Kim and Kankanhalli 2009). According to status quo bias theory, people resist change if costs of change are higher than benefits (rational decision making), to avoid losses (cognitive misperception), and to retain control of their situation (psychological commitment). Unlearning can facilitate change by stimulating disconfirmation and dissonance with current practices, routines, and policies (Hedberg, 1981). This initial disconfirmation (awareness or questioning) sets a cycle of unlearning in motion followed by relinquishing the current way of doing things and relearning new practices (Becker 2005; Cegarra-Navarro and Wensley 2019). This entire process is captured using Lewin's change model (1951). It describes change using three stages: (a) unfreezing or disconfirming the status quo, (b) transition or developing new mental structure, and (c) refreezing or reinforcing the new equilibrium. Pratt and Barnett (1997) believe that unlearning is similar to the unfreezing stage, and Akgün et al. (2007a) consider unlearning to indicate the transition stage of the change model. However, we argue that unlearning captures all the three steps of Lewin's change model because it ensures that organizational members do not regress to old practices after transitioning to new practices (Tsang 2008). The outcome-oriented definitions (as discussed in Sect. 2) of OU substantiate this proposition. According to these definitions, unlearning processes do not terminate only after discarding obsolete practices but continue until organizations have relearned new ones.

Particularly, literature has associated unlearning and change management with the implementation of new technology. For instance, Becker (2010) identified several individual factors (understanding need for change, assessment of new way, positive experience, and informal support) and a couple of organizational factors (history of organizational change and organizational support and training) that propels the unlearning process during implementation of enterprise information system in public sector corporations operating in the Australian energy industry. Thus, unlearning acts as a catalyst to the change process (Akgün et al. 2007a). 


\subsubsection{Cluster \# 2 (Light Green) "Unlearning and Leadership Aspects"}

This cluster consists of six keywords mainly related to the role of leadership during the unlearning process. The contributors to this cluster include Hedberg et al. (1976), Nystrom and Starbuck (1984), Bettis and Prahalad (1995), Tripsas and Gavetti (2000), Hamori and Koyuncu (2015), and Matsuo (2019). The papers included in this cluster narrate incidents when organizations transition from a stable to a dynamic business environment. Most of the articles have used a case-based approach to show that the cognitive inertia of top managers or founders' biases is one of the barriers to unlearning obsolete practices. For instance, Nystrom and Starbuck (1984) have narrated the case of Facit AB, a Swedish manufacturer of mechanical calculators, whose leaders failed to sense the advent of the electronic revolution and continued investment in mechanical calculators. Similarly, Tripsas and Gavetti (2000) narrate the example of Polaroid Corporation, an American consumer electronics company that declined to accept the shift from analog to digital photography. This proposition can be explained using the threat-rigidity effects theory (Staw et al. 1981) and imprinting theory (Marquis and Tilcsik 2013). According to the threat-rigidity thesis, organizations respond to environmental change by restricting information processing and constriction in control. By restricting information inflow from limited sources, organizations rely heavily on past knowledge that does not challenge the status quo or solicit advice that confirms their preferences and decisions. Similarly, by centralizing authority and increasing formalization (constriction of control), decision-makers are reluctant to drift from the organization's core values and reinforce the proven formulas, irrespective of its relevance in changed circumstances (Staw et al. 1981). Imprinting theory suggests that organizations inherit the characteristics of a founder's personality, and their future decision-making is guided by these impressions (Marquis and Tilcsik 2013). A diverse body of evidence suggests that the founders' initial dominant strategy has a persistent effect on the subsequent leadership team (Dimov et al. 2012; Sinha et al. 2020). Moreover, past experience in a leadership position can adversely affect individual performance in a new setting because prior knowledge and skills must be unlearned before learning can happen in the changed context (Hamori and Koyuncu 2015). Therefore, in the above-mentioned studies, the imprinting lens highlights that leaders' failure to sense alternative opportunities can arise due to leaders' prior experience and founders' imprints.

Consequently, Nystrom and Starbuck (1984) proposed replacing the top management team, appointing new leaders, and hiring outside consultants to accelerate unlearning and adaptation. In addition, the top management team must listen to dissenters, seek new learning opportunities, experiment, and create an error-forgiving culture to create an environment for unlearning (Klammer et al. 2019). Nooyi and Govindarajan (2020) provide an overview of how PepsiCo unlearned the decadelong dominant logic (in production and marketing of soft drinks) by introducing Performance with Purpose program under the leadership of its former Chief Executive Officer, Indra Nooyi. The theoretical underpinning behind the linkage between unlearning and top management is explained using the upper echelons' perspective. It states that top managers' cognitive values and experience influence organizations' 
capability to withstand future opportunities and threats (Hambrick and Mason 1984; Matsuo 2019).

\subsubsection{Cluster \# 3 (Dark Blue) "Enablers of Organizational Unlearning" \& Cluster \# 4 (Yellow) "Inhibitors of Organizational Unlearning"}

Cluster three "Enablers of Organizational Unlearning" and cluster four "Inhibitors of Organizational Unlearning" consist of five keywords each and forms the thirdlargest network structure of OU. These two clusters include 35 papers, and the main contributors include Becker (2005), Brook et al. (2016), Cegarra-Navarro and Wensley (2019), Hislop et al. (2014), Howells and Scholderer (2016), Klammer et al. (2019), Nystrom and Starbuck (1984), Tripsas and Gavetti (2000), and Tsang and Zahra (2008). Most of the studies have reported the enablers and barriers of unlearning at the organizational level. In this cluster, 15 studies are empirical (e.g., Matsuo 2019), six studies are conceptual (e.g., Cegarra-Navarro and Wensley 2019), ten studies are classified into the 'others' category (e.g., Klammer et al. 2019), and four review articles (e.g., Hislop et al. 2014).

Research on unlearning is more inclined towards the 'what' aspect, thereby ignoring the understanding of 'how.' This realization of how to instigate and sustain unlearning, i.e., what are the various factors that either positively or negatively affect $\mathrm{OU}$, forms the subject matter of clusters three and four. It is essential because unlearning is not easy and involves substantial resistance from members during execution (Hedberg et al. 1976; Rushmer and Davies 2004). During initial phases of unlearning research, purging top leadership (as discussed in cluster two), organizational crisis, listening to dissents (like complaints, warnings, and disagreements), inputs from stakeholders, exploiting learning opportunities, and experimentation were considered to enable OU (Nystrom and Starbuck 1984; Starbuck 1996). However, context-specific enablers and barriers were required to understand OU's process during innovation, transformation, and technology implementation. In this line, Becker (2010) proposed some individual and organizational factors like positive prior outlook, positive experience, informal support, history of organizational change, and organizational support to catalyze the unlearning process during a technological change in the Australian energy sector. During the new product development process, Akgün et al. (2006) suggested certain factors like creating a sense of urgency, team crisis, team anxiety, and avoiding groupthink to enhance OU. The enablers of unlearning during radical innovation include environmental turbulence, entrepreneurial orientation (Lyu et al. 2020), creating awareness, temporal and spatial freedom, and error-forgiving culture (Klammer et al. 2019), and team reflexivity and team stress (Lee and Sukoco 2011).

\subsubsection{Cluster \# 5 (Purple) "Organizational Unlearning and Organizational Forgetting"}

This cluster consists of four keywords (forgetting, knowledge, organizational learning, and management development). It includes contributions like Martin de Holan and Phillips (2004a, 2004b), Martin de Holan et al. (2004), Fernandez and Sune 


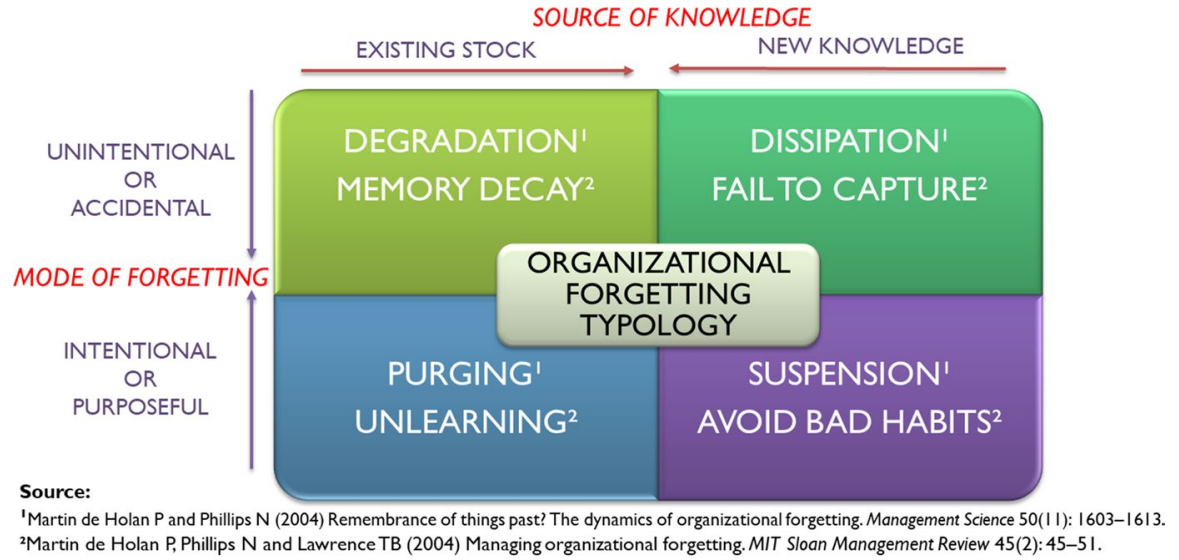

Fig. 6 Typology of organizational forgetting. This typology was developed by Martin de Holan and Phillips (2004a) and Martin de Holan et al. (2004) based on their research on Cuban hotels. The four quadrants are based on two dimensions: mode of forgetting (intentional or unintentional) and source of knowledge (existing knowledge or new knowledge that has not yet been codified). When an organization accidentally loses the existing stock of knowledge, it is called forgetting, degradation, or memory decay (upper left quadrant). The deliberate loss of existing knowledge is called unlearning or purging (lower left quadrant). When the new knowledge is accidentally lost, it is termed as dissipation or fail to capture (upper right quadrant). The deliberate loss of new knowledge is termed as suspension or avoid bad habits (lower right quadrant)

(2009), Martin de Holan (2011), Easterby-Smith and Lyles (2011), Miller and Martignoni (2016), and Cegarra-Navarro and Wensley (2019). There are 22 papers in this cluster. Three papers are conceptual (e.g., Martin de Holan et al. 2004), 11 are empirical (e.g., Miller and Martignoni 2016), and eight papers are classified into 'others' category because they analyze organizational forgetting using case-based analysis (e.g., Martin de Holan and Phillips 2004a).

The classic learning curve model asserts that knowledge accumulated from prior learning does not depreciate. Lately, researchers have empirically examined the element of organizational forgetting (OF) in the learning process, thereby developing a new approach incorporating both aspects, i.e., learning and forgetting (Agrawal and Muthulingam 2015; Argote 2013; Carmona and Grönlund 1998; Causholli 2016; Kim and Seo 2009; Thompson 2007). Forgetting is defined as an inadvertent loss of knowledge, routines, or practices from organizational memory due to personnel turnover, disuse of knowledge, and failure to capture/ codify new knowledge (Agrawal and Muthulingam 2015; Argote 2013; EasterbySmith and Lyles 2011; Fernandez and Sune 2009; López and Sune 2013; Martin de Holan and Phillips 2004a; Meschi and Métais 2013). Easterby-Smith and Lyles (2011) analyze OF from cognitive, behavioral, and social perspectives. The cognitive view of forgetting is the decay of records as a function of time, turnover of people, and failure to codify tacit knowledge into explicit knowledge (Argote 2013). The behavioral perspective is a loss of rationale to establish routines and habits. It can also be due to the turnover of key personnel who championed 
these routines and practices. Lastly, the social perspective is the loss of social networks in organizations due to retirement, turnover, and breakdown in shared perspectives (Martin de Holan et al. 2004). The theories used to describe forgetting includes disuse theory and interference (or inhibition) theory. Both theories are adapted from the psychology discipline. The disuse theory states that as the connection between a stimulus and a response becomes suspended for a considerable length of time, the strength of the relationship between stimuli and response attenuates and is ultimately forgotten. Inhibition or interference theory states that the existence of past knowledge inhibits the acquisition of new knowledge (proactive interference) or vice versa (retroactive interference), thereby leading to forgetting of knowledge that cannot be recalled (Hedberg 1981).

Regardless of conceptualization, forgetting is often confused with unlearning. Several authors undermine the need to distinguish these two concepts by using them interchangeably (Huang et al. 2018; Meschi and Métais 2013; Zeng et al. 2019). Furthermore, the use of terms like intentional forgetting (CegarraNavarro and Wensley 2019) and routine unlearning (Rushmer and Davies 2004) hinders the attempt to distinguish between the two terms. As a result, several typologies were developed by Martin de Holan and associates (2004a, b), Azmi (2008), and Fernandez and Sune (2009) to differentiate these two terms. Figure 6 presents one such typology that distinguishes OF and OU. The $2 * 2$ matrix employs two dimensions: intentionality and stock of knowledge. Forgetting/ degradation/memory decay is an intersection of accidental loss of existing stock of knowledge. Unlearning/purging is a deliberate discard of existing knowledge (Martin de Holan and Phillips 2004a; Martin de Holan et al. 2004). Moreover, OF takes place at an individual level because organizations are incapable of forgetting themselves. On the other hand, OU is an organizational-level phenomenon where an old knowledge structure is replaced by a new knowledge structure (Cegarra-Navarro et al. 2014a, b). Another important line of distinction between unlearning and forgetting in terms of outcomes associated with these two processes is proposed by Carmona and Grönlund (1998). They state that unlearning is deliberately pursued by organizations to reach higher levels of learning. In contrast, forgetting does not involve replacing existing practices with better ones since it is accidental in nature. Consequently, unlearning is a functional process leading to higher learning levels, whereas forgetting is a dysfunctional process leading to an adverse impact on organizational performance (Agrawal and Muthulingam 2015; Azmi 2008; Causholli 2016; López and Sune 2013; Meschi and Métais 2013).

\subsubsection{Cluster \# 6 (Sky Blue) "Organizational Unlearning and Organizational Learning"5}

This cluster consists of three keywords. There are 31 papers in this cluster, and the contributors include Klein (1989), Huber (1991), Bettis and Prahalad (1995), Baker

\footnotetext{
5 We thank an anonymous reviewer for this insightful suggestion to rename cluster 6 in its present form.
} 
and Sinkula (1999), Tsang (2001), Tsang (2001, 2008), Tsang and Zahra (2008), Antonacopoulou (2009), Zahra et al. (2011), and Matsuo (2018, 2019). The papers in this cluster mostly deal with the organizational level of analysis $(n=21)$, and most of them are conceptual $(n=12)$.

Any debate on OU is incomplete without deliberating on its relationship to OL. Numerous reviews (Easterby-Smith et al. 2000) and conceptual frameworks (Huber 1991; Baker and Sinkula 1999) of OL have realized the importance of unlearning at the workplace. For instance, Easterby-Smith et al. (2000) posited the notion of unlearning as one of the seven significant contributions that have been influential since Organizational Learning: A Theory of Action Perspective. ${ }^{6}$ OL is a process of encoding past success stories, routines, and behaviors into organizational memory (Levitt and March 1988). Through invigorating case-based analysis of crisis-stricken companies, the proponents of unlearning identified that past learning created a roadblock for organizational adaptation and change (Hedberg et al. 1976; Nystrom and Starbuck 1984). The inertia engendered by prior learning hampered organizations' ability to introspect current strategies, let alone formulate new strategies (Starbuck 2017). Thus, OU emerged as a solution to dismantle such rigidities by intentionally discarding the existing routines, knowledge, and behaviors that lost their sheen and no longer contributed to organizational effectiveness. Gradually, unlearning assumed a pivotal position in academic debates about OL, albeit misconstrued as being subsumed in the latter (Huber 1991). This (mis)apprehension continued to dominate the early part of the 2000s and consequently precluded the opportunity for unlearning to thrive as a separate phenomenon independent of OL. Subsequently, Tsang's (2008) case study of Sino-foreign joint ventures (both greenfield and acquisition) established unlearning and learning as two mutually exclusive and distinct processes. Moreover, every instance of new learning may not necessarily require prior unlearning (Bettis and Prahalad 1995; Newstrom 1983; Sharma and Lenka 2019; Tsang and Zahra 2008), which forms the central premise of parenthetic learning theory (Klein 1989).

\subsubsection{Cluster \# 7 (Orange) "Unlearning and Aspects of Knowledge Management"}

Cluster 7 consists of two keywords-knowledge management and organizational forgetting. This cluster manifests a certain degree of overlap with cluster 5 (unlearning and forgetting) due to the presence of somewhat identical keywords. ${ }^{7}$ However, the subject matter of these two clusters is entirely different. In cluster 7, 'knowledge management' appears as a keyword along with 'organizational forgetting.' As we have already dealt with forgetting and its relationship with OU in cluster 5, this cluster will provide an overview of the linkages between unlearning and knowledge management.

\footnotetext{
${ }^{6}$ Although Argyris and Schön (1978) did not use the concept of unlearning in this book. It was only in Organizational Learning II: Theory, Methods, and Practices that unlearning appeared in writing of Argyris and Schön (1996).

7 We thank an anonymous reviewer for this insightful suggestion to clarify the overlap between cluster \#5 and \#7.
} 
There are 15 articles in this cluster, and the main contributors include Tsang (2008, 2016), Yildiz and Fey (2010), Cegarra-Navarro et al. (2011), Zhao et al. (2013), Cegarra-Navarro et al. (2014a, b), Wang et al. (2017), and Delshab and Boroujerdi (2018). These articles mainly investigate the impact of unlearning dimensions on knowledge management at the organizational level $(n=11)$ using quantitative data analysis techniques $(n=10)$. Studies in the context of international mergers and acquisitions and joint ventures have articulated the difficulty faced by foreign partners in transferring knowledge and routines to local enterprises (Inkpen 2008; Tsang 2008, 2016; Wang et al. 2017; Yildiz and Fey 2010). Two theoretical perspectives explicate this finding. First, internal stickiness theory states that the transfer of knowledge, routines, and best practices - either within an organization or beyond organizational boundaries-is replete with several barriers that have been categorized into four major headings (Szulanski 1996). These barriers emanate from knowledge transfer characteristics, knowledge source characteristics, knowledge recipient characteristics, and context characteristics (Inkpen 2008; Zeng et al. 2019). Second, congruence theory states that the degree to which the knowledge structures, attitudes, and routines of the sender and recipient unit are similar (or compatible), higher will be the knowledge absorption, and lower will be the probability of transfer stickiness (Wang et al. 2017; Zeng et al. 2019). Subsequently, unlearning is suggested as an alternative to correct knowledge transfer problems by discarding existing routines in such enterprises.

Knowledge has remained a vital element in unlearning definitions (Becker 2018; Hedberg 1981; Huber 1991). The relevance of OU in knowledge management (particularly during the creation and acquisition of new knowledge) has been especially emphasized (Becker 2018; Zhao et al. 2013). Indeed, successful unlearning creates a fertile ground for acquiring new knowledge (Inkpen 2008; Starbuck 1996; Wang et al. 2019; Yildiz and Fey 2010). Researchers substantiate this claim by adopting a knowledge-based view of the firm, which states that knowledge is an intangible and valuable resource that helps an organization sustain competitive advantage (Conner and Prahalad 1996). However, organizations must also discount the rate of knowledge obsolescence. The obsolete knowledge has to be unlearned and renewed with new knowledge appropriate for the ever-changing business environment. How unlearning creates a way to acquire new knowledge can be justified by three reasons: (a) the volume and velocity of technological advancement and radical innovation make the existing knowledge old and invalid for today's realities. Therefore, unlearning can help organizations discard obsolete knowledge and adapt to new knowledge; (b) if the new knowledge is perceived as inconsistent with the existing values and past experiences of the organization, then the old knowledge often impedes the acquisition of new knowledge. For this, unlearning those pieces of knowledge that are incompatible with the new knowledge can facilitate the institutionalization of the new knowledge (Mariano and Casey 2015; Wang et al. 2017; Yildiz and Fey 2010); and (c) the transition to modern knowledge sharing tools, popularly known as "Knowledge Management 2.0" or "Conversational Knowledge Management," can lead to the creation of counter-knowledge (Cegarra-Navarro et al. 2014a, b). Counter-knowledge is defined as "flaws in individuals' mental models which arise from rumors, inappropriate knowledge structures, and outdated routines or procedures" 
and leads to degradation of existing knowledge and hinders the learning capability of organizations (Cegarra-Navarro et al. 2014a, b: p. 165). Therefore, unlearning corrects this problem by replacing counter-knowledge with new knowledge structures.

\subsubsection{Cluster \# 8 (Pink) "Organizational Unlearning and New Product Development"}

This cluster consists of 10 articles and talks about the role of unlearning during innovation, particularly in terms of new product development (NPD) and radical innovation. The main contributors to this cluster are Takeuchi and Nonaka (1986), Akgün et al. (2006), Akgün et al. (2007b), Lee and Sukoco (2011), Wang et al. (2013), Yang et al. (2014), and Lyu et al. (2020). Perhaps, this is the only cluster that analyzes team-level unlearning. Most articles $(n=7)$ study unlearning at the organizational level, and empirical articles $(n=7)$ are primarily published in this cluster.

The traditional linear model of NPD is now moving towards a more flexible, open, and improvised NPD process (Takeuchi and Nonaka 1986). This is due to changing customer preferences, increased competition, and the limited shelf life of products. It is imprudent to institutionalize the past success of product innovation into standard practices (García-Muiña et al. 2009). Institutionalization creates rigidity in employees' mindsets, and they cannot meet the changing demands of the market and technology. This theme leverages two theoretical perspectives: path-dependence theory (Sydow et al. 2009) and imprinting theory (Marquis and Tilcsik 2013). Path dependence theory states that the unintended consequences of past decisions and positive feedback processes develop into a rigid and potentially inefficient action pattern, thereby organizations losing the capability to adapt to changing environments and explore better alternatives (Sydow et al. 2009). Imprinting theory is similar to path dependence theory because organizations cannot relinquish the cognitive schemes and competencies (imprints) developed during founding or other sensitive periods of organizational life cycle, thereby leading to a replicated decision-making pattern (Marquis and Tilcsik 2013; Sinha et al. 2020). However, it is different from path dependence because "the replicated pattern in the imprinting approach is readymade at the beginning... and continues to influence future processes" (Sydow et al. 2009: p. 696).

Given these repercussions, Akgün et al. (2006) highlight the need for unlearning (change in beliefs and routines) in NPD teams. Unlearning helps NPD teams to operate in a state of "zero-information" - a condition where prior information does not matter (Takeuchi and Nonaka 1986). They must be prepared to incorporate stakeholders' cues into organizational offerings, which often challenges the established product development procedures and organizational beliefs. In this regard, Hamel and Zanini (2018) exemplify the case of Haier, a Chinese consumer electronics company, inviting responses from potential users about their needs and preferences for a new home air-conditioner. This allowed Haier to unlearn the past knowledge of product development procedures and address the problem of minimizing risk by radically rethinking the design of the air-conditioner. 


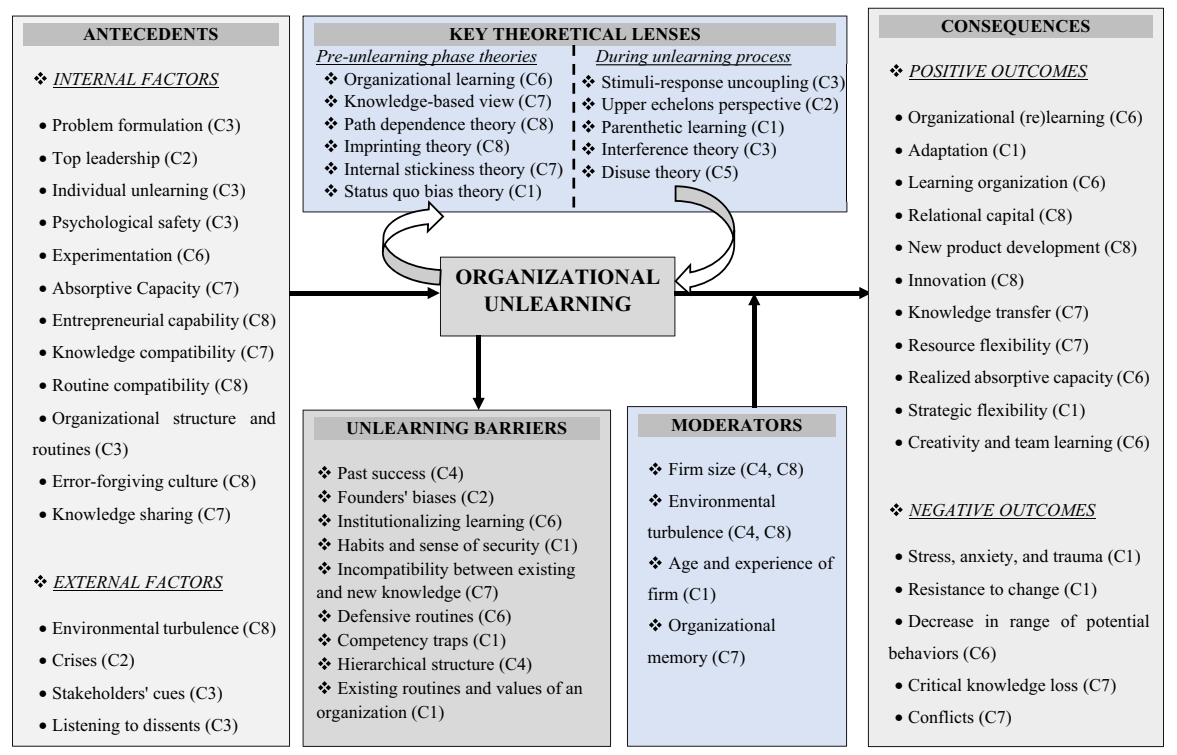

Fig. 7 An integrative framework of organizational unlearning. This framework is based on the co-occurrence of keyword analysis and eight themes derived therefrom (see Fig. 5 and Table 17). Against each antecedent, barrier, moderator, theoretical lens, and consequence, we have mentioned the respective cluster $(\mathrm{C} 1, \mathrm{C} 2, \mathrm{C} 3 \ldots, \mathrm{C} 8)$ to which that variable belongs. $C 1$-change management; $C 2-$ leadership; $C 3-$ enablers; $C 4$-inhibitors; $C 5$-forgetting; $C 6$-organizational learning; $C 7$-knowledge management; C8-new product development

Unlearning the conventional practices, routines, and competencies can also stimulate the process of radical innovation as it is based on entirely new technology (Escrig et al. 2019; Lyu et al. 2020; Yang et al. 2014). Sandberg and Aarikka-Stenroos (2014) enlist radical innovation barriers like restrictive mindsets, lack of competencies, and unsupportive organizational culture. These barriers can be mitigated by creating an unlearning context that promotes entrepreneurial spirit by being open to new ideas and searching for innovation opportunities (Klammer et al. 2019).

\subsection{Integrative overview of organizational unlearning clusters ${ }^{8}$}

To articulate the relationship between eight clusters of OU, we organized the major topics in each cluster into an integrative framework, as shown in Fig. 7. This framework describes the antecedents, moderators, barriers, key theoretical aspects, and consequences of unlearning. We have also included the cluster number $(\mathrm{C} 1, \mathrm{C} 2 \ldots$, C8) against each component. The antecedents are classified into two broad categories-internal and external (Lyu et al. 2020). As the name suggests, internal antecedents (e.g., top leadership, individual unlearning, psychological safety, and

\footnotetext{
${ }^{8}$ We thank an anonymous reviewer for this insightful suggestion to inform a conceptual model of unlearning.
} 
knowledge sharing) constitute factors that operate within the organizations and initiate the unlearning process as a proactive measure to combat environmental uncertainty. External antecedents (e.g., environmental turbulence, stakeholders' cues, and crises) consist of factors that lie beyond organizations' control and instigate unlearning as a reactive measure to changing circumstances. The majority of these antecedents are derived from clusters 3, 7, and 8. However, unlearning is negatively affected by barriers like founders' biases (Hedberg 1981), knowledge institutionalization (Yildiz and Fey 2010), incompatible knowledge (Wang et al. 2017), defensive routines (Argyris and Schön 1996; Akgün et al. 2006), and hierarchical organization structure (Imai et al. 1984). Few moderating variables are also studied in unlearning research. For example, firm size (Leal-Rodríguez et al. 2015; Lyu et al. 2020), environmental turbulence (Huang et al. 2018), nature, and type of organization (Tsang 2008), and organizational memory. The consequences of OU are divided into positive and negative outcomes. Positive outcomes (e.g., relearning, adaptation, learning organizations, new product development, innovation, and change) are favorable results of unlearning, and negative outcomes (resistance to change, critical knowledge loss, and conflicts) are unfavorable by-products of unlearning.

Unlearning research is grounded on multiple theoretical lenses mainly adopted from disciplines like strategic management and cognitive psychology. We have already discussed the fundamental theories that operate within each thematic cluster of OU. However, these theories can be divided into two categories as well, depending on whether they operate in the pre-unlearning phase (e.g., path dependence theory, imprinting theory, knowledge-based view, internal stickiness theory, and status quo bias theory) or during the unlearning process (stimuli-response decoupling, parenthetic learning, interference theory, upper echelons perspective, and disuse theory). The pre-unlearning theories emphasize the need for OU. As discussed in cluster 3 of co-citation analysis (Sect. 4.9.3) and cluster 8 of co-word analysis (Sect. 4.10.7), organizations get "locked-in" in specific historical imprints or patterns that they are unable to reverse (Akgün et al. 2007b; Sydow et al. 2009). Once the need for unlearning is recognized, it is essential to contemplate the unlearning mechanism to break these persistent patterns. This function is carried out by the second set of theories - theoretical perspectives during the unlearning process - so that organizations can frame appropriate strategies during each phase of OU.

\section{Discussion and conclusions}

\subsection{Discussion}

This study has provided an in-depth examination of the unlearning literature published in leading management journals by incorporating a combination of systematic literature review and bibliometric analysis. The rationale for selecting leading management journals is based on the quality and rigor employed by these outlets in publishing articles (Gomes et al. 2016; Sergeeva and Andreeva 2016). Hence, Aguinis et al. (2020) consider publications in top-rated journals as the new bottom line for valuing academic research. An umpteen number of journal ranking lists are 
available that classify journals based on merit and impact (e.g., JCR, ABDC, CABS, etc.). However, due to competing methodologies adopted by these quality lists, a particular journal is ranked very high in one list and moderately ranked in another quality list. To do away with this limitation, we have used an extensive criterion for selecting leading journals. This has ensured coverage of more unlearning articles and maintained the rigor in selecting these outlets.

Certainly, unlearning is no longer playing second fiddle in OL research. Instead, learning discourses embrace the importance of unlearning to the extent that it is described as one of the seven significant contributions that have been influential since 1978 in the field of OL (Easterby-Smith et al. 2004). However, critics of unlearning envisage that it should be dropped from scholarly discourse because it is "allegedly imported from psychology literature" and lacks conceptual rigor (Howells and Scholderer 2016: p. 443). Since "organizational unlearning helps researchers describe certain phenomena," it then stands to reason that "how far the concept of organizational unlearning has a firm root in the psychology literature should not significantly affect its usefulness in advancing organizational research" (Tsang 2017: p. 40). Moreover, we believe that the relevance of unlearning will intensify during the ongoing crisis of SARS-CoV-2 (Covid-19). For instance, most companies have either shifted or contemplating a shift towards a substantially remote workforce. This ensues adopting new digital technologies for office collaboration (like group videoconferencing) as well as unlearning the past methods of doing work (e.g., inperson office interactions and informal conversations). ${ }^{9}$ The employees will have to unlearn the prior working norms and understand that previous work experience will hold minimal value in the new work setting. Similarly, as the manufacturing facilities are relocated and regulatory regimes are overhauled (e.g., changes in stock market listing requirements), organizations have to unlearn much of the pre-crisis knowledge that will no longer hold valid once the catastrophic effect of the pandemic has subdued. Unlearning will also play a dominant role because the leaders of major behemoths do not expect that organizations will revert to pre-Covid-19 levels. ${ }^{10}$ Hence, employees' learning and development needs must shift the focus from skills development to capabilities development to help people adapt and cope well with a similar crisis in the future (Lundberg and Westerman 2020).

This review has also uncovered the intellectual territory of unlearning, which comprises eight research clusters that have addressed various aspects of organizational studies like change management, leadership, OL, new product development, radical innovation, and knowledge management. These clusters practically summarize the entire gamut of unlearning research and mutually constitutive because one theme of OU affects another theme in one sense or another. For instance, cluster 8 (unlearning and new product development) is related to cluster 7 (unlearning and aspects of knowledge management) and cluster 1 (unlearning and change

\footnotetext{
9 https://www.wsj.com/articles/facebook-to-shift-permanently-toward-more-remote-work-after-coronavirus-11590081300.

10 https://www.mckinsey.com/industries/pharmaceuticals-and-medical-products/our-insights/gsks-brianmcnamara-on-the-business-impact-of-covid-19.
} 
Table 17 Directions for future research based on research clusters of unlearning

\begin{tabular}{|c|c|c|c|c|c|}
\hline $\begin{array}{l}\text { S. } \\
\text { No. }\end{array}$ & Cluster theme & Coding & Key theory & Key topics in cluster & Directions for future research \\
\hline 1 & $\begin{array}{l}\text { Unlearning and } \\
\text { change } \\
\text { management }\end{array}$ & & $\begin{array}{l}\text { Lewin's model of } \\
\text { change, Path } \\
\text { dependance, } \\
\text { Imprinting theory }\end{array}$ & $\begin{array}{l}\text { Organizational change, change, } \\
\text { resistance to change, culture } \\
\text { change, strategic resilience, } \\
\text { metamorphosis, continuous } \\
\text { change, planned change }\end{array}$ & $\begin{array}{l}\text { Difference in enablers, outcomes, barriers, type, intensity, and } \\
\text { degree of unlearning during radical (transformational) and } \\
\text { incremental (continuous) change, role of unlearning to reduce } \\
\text { employees' resistance to change }\end{array}$ \\
\hline 2 & $\begin{array}{l}\text { Unlearning and } \\
\text { leadership }\end{array}$ & & $\begin{array}{l}\text { Upper echelon } \\
\text { theory, Imprinting } \\
\text { theory, Threat } \\
\text { Rigidity Effects } \\
\text { theory }\end{array}$ & $\begin{array}{l}\text { Leadership, decision making, } \\
\text { strategy }\end{array}$ & $\begin{array}{l}\text { Role, type, and leadership style in motivating various echelons } \\
\text { of management to identify, report, and question obsolete and } \\
\text { misleading knowledge; how does the leadership experience in } \\
\text { one organization affect organizational performance in the } \\
\text { presence and absence of unlearning prior experience }\end{array}$ \\
\hline 3 & $\begin{array}{l}\text { Enablers of } \\
\text { unlearning }\end{array}$ & & & $\begin{array}{l}\text { Individual unlearning, } \\
\text { organizational change }\end{array}$ & \multirow{2}{*}{$\begin{array}{l}\text { Enablers and barriers of unlearning, difference in unlearning } \\
\text { process in business and non-business organizations, methods } \\
\text { that can spur unlearning process, develop a scale for measuring } \\
\text { unlearning in organizations, cases of organizations that } \\
\text { succeeded due to unlearning, practitioners' oriented viewpoints } \\
\text { on unlearning process, moderating and mediating variables } \\
\text { affecting unlearning, role of HR practices in unlearning, } \\
\text { linkages between unlearning and financial performance, 'hard' } \\
\text { methods to detect the need for unlearning (like financial } \\
\text { statement analysis, value added reporting etc.) }\end{array}$} \\
\hline 4 & $\begin{array}{l}\text { Inhibitors of } \\
\text { unlearning }\end{array}$ & & $\begin{array}{l}\text { Stimuli-response } \\
\text { decoupling, } \\
\text { Parenthetic } \\
\text { learning theory, } \\
\text { Interference } \\
\text { theory }\end{array}$ & $\begin{array}{l}\text { Routines, organizational learning, } \\
\text { organizational memory }\end{array}$ & \\
\hline 5 & $\begin{array}{l}\text { Unlearning and } \\
\text { forgetting }\end{array}$ & & $\begin{array}{l}\text { Theory of disuse, } \\
\text { Interference or } \\
\text { inhibition theory, } \\
\text { Overlearning }\end{array}$ & $\begin{array}{l}\text { Unlearning, organizational } \\
\text { unlearning, individual unlearning, } \\
\text { unlearning context, forgetting, } \\
\text { organizational forgetting, } \\
\text { intentional forgetting, accidental } \\
\text { forgetting, knowledge loss, } \\
\text { intentional unlearning, accidental } \\
\text { unlearning }\end{array}$ & $\begin{array}{l}\text { Differentiate between organizational unlearning and } \\
\text { organizational forgetting, is unlearning a part of broader } \\
\text { framework of organizational forgetting or both processes } \\
\text { entirely different, functional and dysfunctional outcomes of } \\
\text { unlearning and forgetting, contextual factors governing the } \\
\text { adequacy of unlearning and forgetting in organizations }\end{array}$ \\
\hline 6 & $\begin{array}{l}\text { Unlearning and } \\
\text { organizational } \\
\text { learning }\end{array}$ & & $\begin{array}{l}\text { Organizational } \\
\text { learning theory, } \\
\text { Situated learning, } \\
\text { Experiential } \\
\text { learning, Action } \\
\text { learning }\end{array}$ & $\begin{array}{l}\text { Learning, organizational learning, } \\
\text { double-loop learning, learning } \\
\text { organizations, team learning, } \\
\text { continuous learning, organizational } \\
\text { relearning, individual relearning, } \\
\text { action learning, } \\
\text { deinstitutionalization, learning } \\
\text { climate, deutero-learning, systems } \\
\text { thinking, organizational learning } \\
\text { capability }\end{array}$ & $\begin{array}{l}\text { Establish the linkage between unlearning and higher order } \\
\text { learning (deuterolearning, double loop learning, and triple loop } \\
\text { learning), investigate the outcome of unlearning: is unlearning } \\
\text { always followed by acquisition of new learning, modifications } \\
\text { needed in learning climate and organizational learning } \\
\text { mechanisms to spur the process of unlearning, enabling factors } \\
\text { to help transfer of individual and team unlearning to } \\
\text { organizational level, role of unlearning in developing a learning } \\
\text { organization }\end{array}$ \\
\hline 7 & $\begin{array}{l}\text { Unlearning and } \\
\text { knowledge } \\
\text { aspects }\end{array}$ & & $\begin{array}{l}\text { Knowledge-based } \\
\text { view, Internal } \\
\text { stickiness theory, } \\
\text { Congruence } \\
\text { theory }\end{array}$ & $\begin{array}{l}\text { Knowledge, knowledge } \\
\text { management, knowledge transfer, } \\
\text { organizational memory, tacit } \\
\text { knowledge, knowledge } \\
\text { compatibility, counter knowledge, } \\
\text { knowledge creation, knowledge } \\
\text { discard, knowledge sharing, } \\
\text { knowledge stickiness, knowledge } \\
\text { processes, obsolete knowledge, } \\
\text { exploration and exploitation of } \\
\text { knowledge, actionable knowledge }\end{array}$ & $\begin{array}{l}\text { Incorporating unlearning aspect in knowledge management } \\
\text { systems, role of unlearning in institutionalizing transfer of } \\
\text { knowledge from one unit/department to another } \\
\text { unit/department, developing knowledge structures that help } \\
\text { organizations to challenge obsolete knowledge, role of } \\
\text { unlearning in ambidextrous organizations (exploration and } \\
\text { exploitation of knowledge), difficulties faced by organizations } \\
\text { to unlearn incompatible pieces of knowledge, unlearning and } \\
\text { its linkage to organizational memory, differences between } \\
\text { unlearning, knowledge leakage, and deinstitutionalization }\end{array}$ \\
\hline 8 & $\begin{array}{l}\text { Unlearning and } \\
\text { new product } \\
\text { development }\end{array}$ & & $\begin{array}{l}\text { Path dependence } \\
\text { theory, Imprinting } \\
\text { theory, Adaptation } \\
\text { theory }\end{array}$ & $\begin{array}{l}\text { Innovation, radical innovation, } \\
\text { open innovation, path-dependence, } \\
\text { soft innovation, incremental } \\
\text { innovation, innovation capability, } \\
\text { technology evaluation, technology } \\
\text { identification, innovation outcomes }\end{array}$ & $\begin{array}{l}\text { Role of unlearning in learning from failures during innovation } \\
\text { process, role of unlearning in open innovation, drivers and } \\
\text { barriers of unlearning during business model innovation, } \\
\text { industry-specific (e.g. manufacturing, services, small and } \\
\text { medium size enterprises) understanding of unlearning during } \\
\text { innovation }\end{array}$ \\
\hline
\end{tabular}

management). This is because organizations cannot rely on their existing knowledge structure during radical innovation and need to change the mental models and outdated paradigms of getting things done (Lyu et al. 2020). Moreover, the role of the top management team in radical innovation is exemplified in PepsiCo's Performance with Purpose program (Nooyi and Govindarajan 2020). Accordingly, an integrative framework of unlearning is proposed in Fig. 7, which will help the researchers to connect these research clusters. This analysis will also help researchers converge the knowledge from disparate knowledge sources and engender a new perspective of OU. Moreover, the credulity of this argument remains intact because "knowledge in management studies often times develop along disciplinary lines resulting in different theoretical perspectives not sufficiently informing and drawing from each other" (Post et al. 2020: p. 352).

Another theoretical implication of this study is that unlearning lies at the intersection of organizational persistence and organizational adaptation theories. Persistence theories like organizational path dependence and imprinting theory explain 
how organizations' previous history affects their future decision-making and limits organizations' vision to exploitative learning at the expense of explorative learning (March 1991; Sydow et al. 2009). Once these rigid paths develop, organizations find it challenging to change and improvise. In this way, persistence theories answer the 'why' of unlearning, i.e., reasons that trigger an organization's unlearning process. In contrast, adaptation theory lies at the other end of the unlearning continuum. Organizations unlearn to adapt to a changing environment by discarding obsolete knowledge and routines that are no longer suited for the current competitive landscape. Moreover, theories like stimuli-response uncoupling (Hedberg 1981), parenthetic learning (Klein 1989), and upper echelons perspective (Hambrick and Mason 1984) explain the 'how' of unlearning, i.e., enablers which contribute to this transition from organizational persistence to organizational adaptation.

\subsection{Directions for future research}

The bibliometric review helped uncover several research directions that can serve as a possible avenue for future investigations. Table 17 presents the future research directions based on the broad clusters discovered using a thematic analysis of unlearning research. Conclusively, these research avenues are based on the construct of unlearning per se, linkages of unlearning with change management, innovation, knowledge management, OL, and other strategic aspects that share a close association with OU.

\subsection{Limitations}

There are certain limitations to be addressed. First, this study was limited to 42 leading business and management journals, and it might lead to neglecting articles published in several other management journals. Moreover, the exclusion of non-English articles and conference papers can also lead to the loss of valuable information. Second, other bibliometric indicators like bibliographic coupling and certain performance indicators like $h$-index and altmetrics were not used in this study. Third, although our findings are indispensable for scholars interested in undertaking future research on unlearning, it is less likely to benefit practitioners directly. Lastly, in identifying the research clusters of OU, we used the author-supplied keywords as a representative to uncover the intellectual structure of the field. While the earlier bibliometric studies in other areas have acknowledged the merit of this method (Ferreira et al. 2014; Xi et al. 2015). However, an in-depth content analysis of papers can provide additional insights.

\section{Appendix 1}

See Tables 18 and 19. 


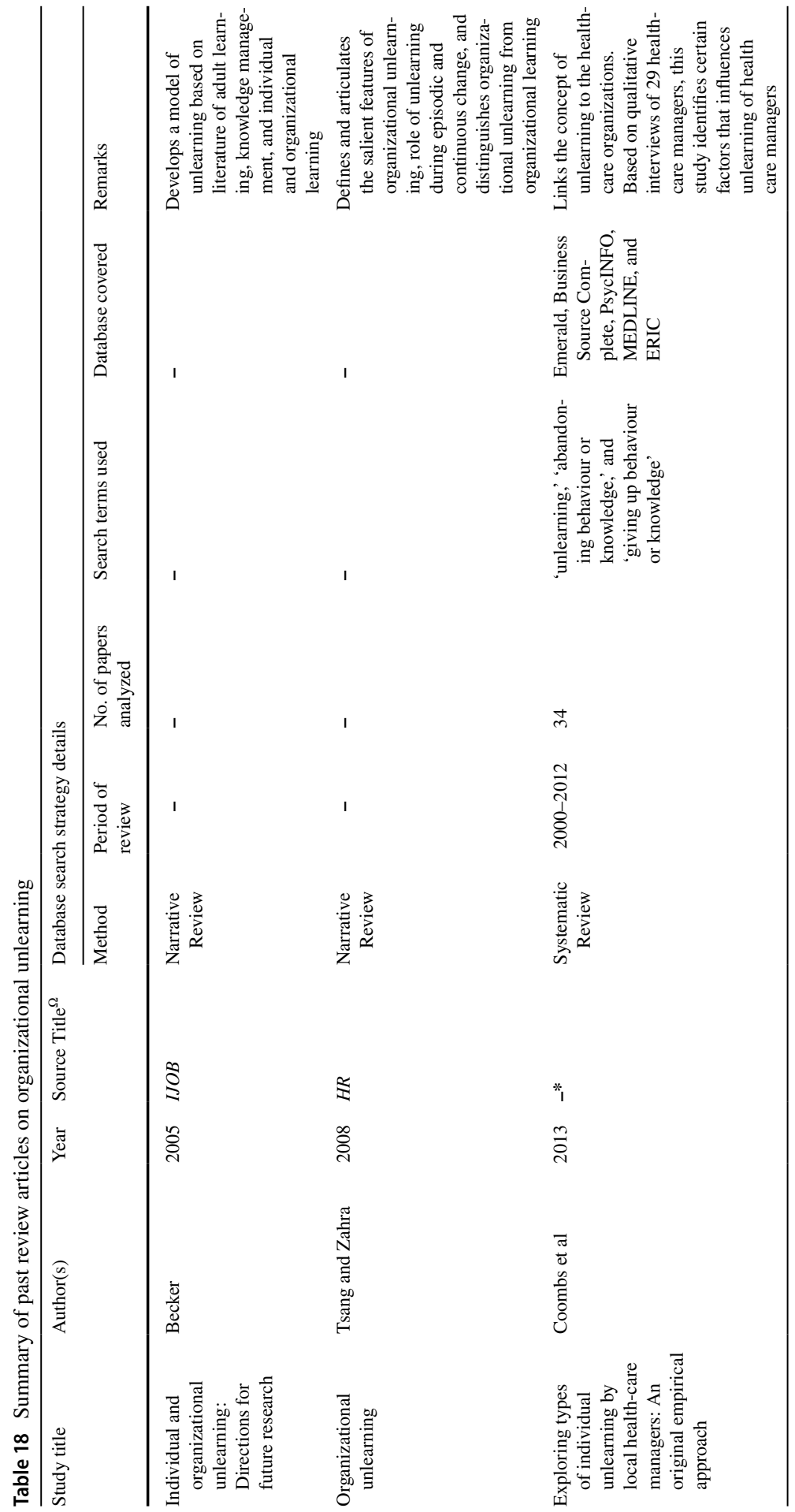




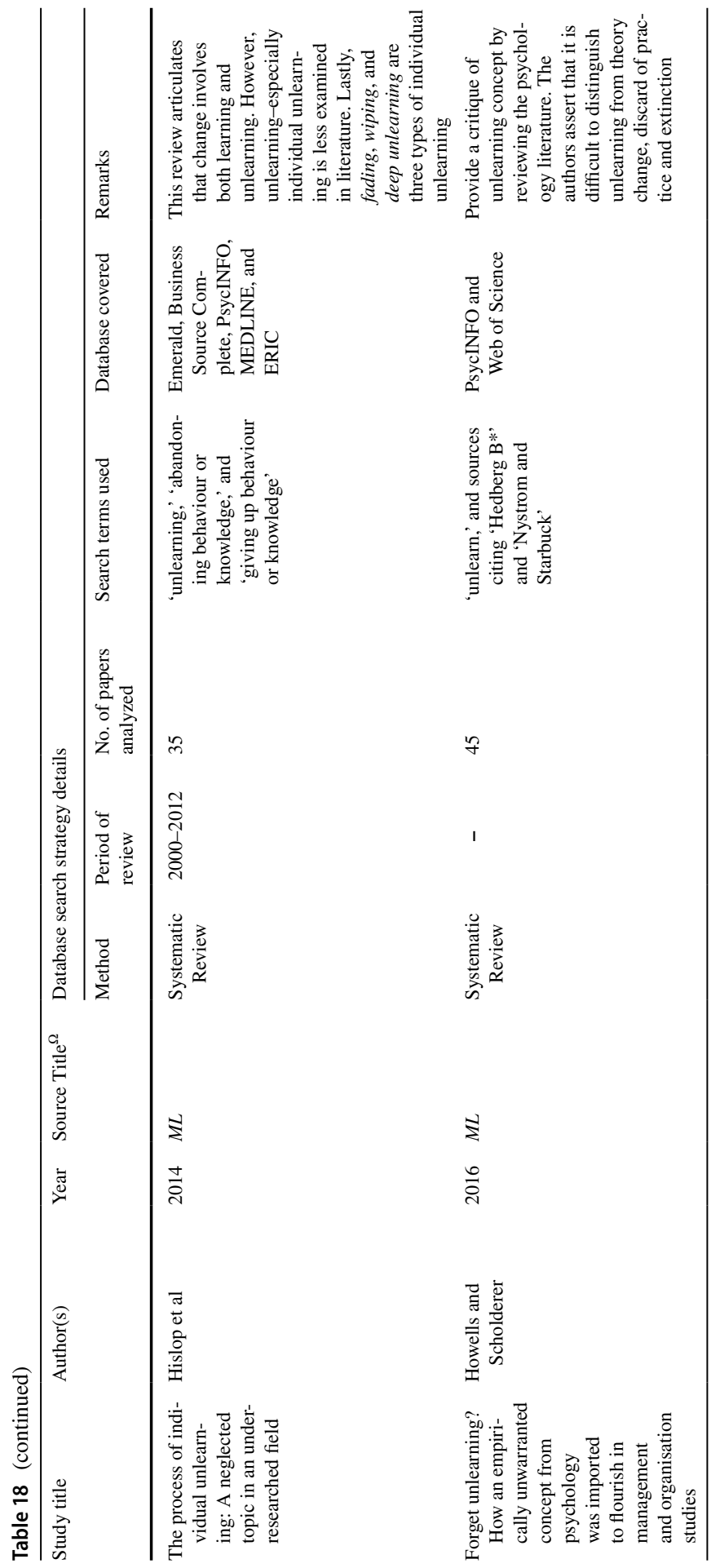




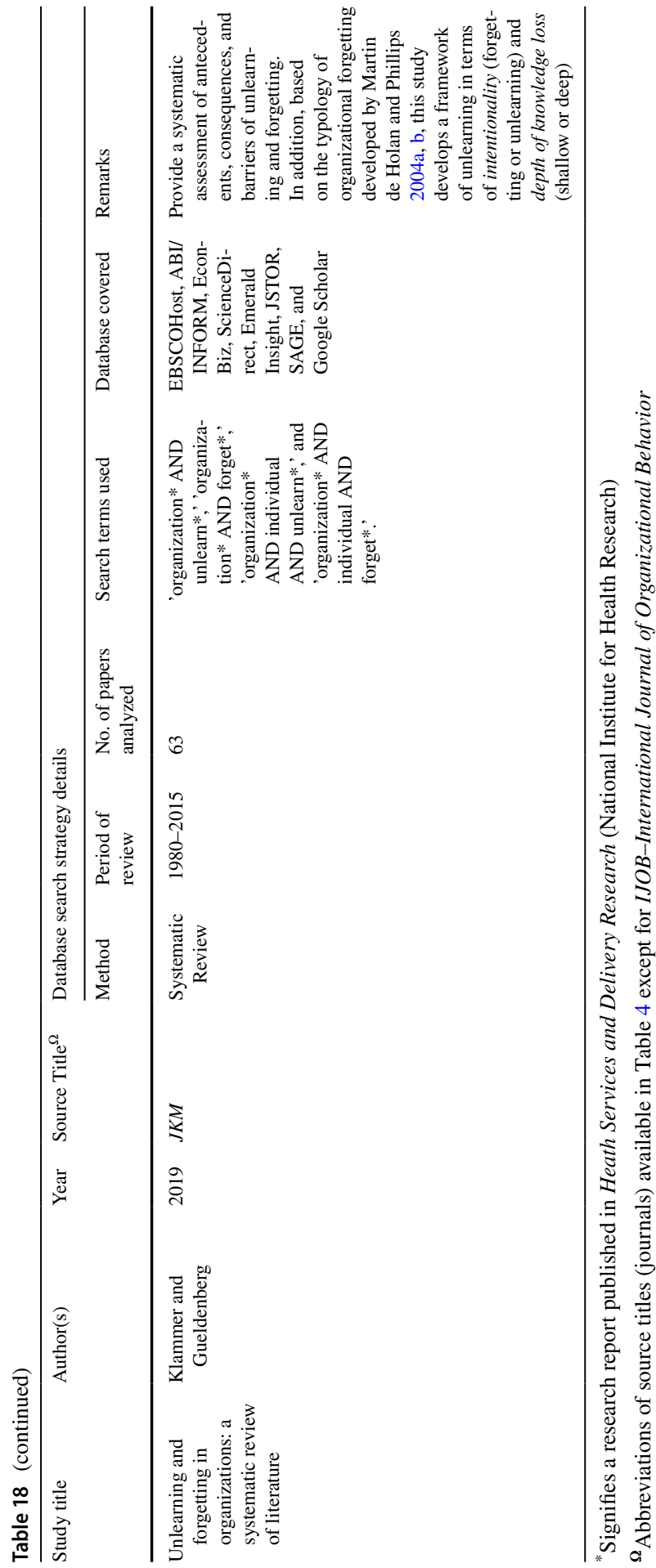




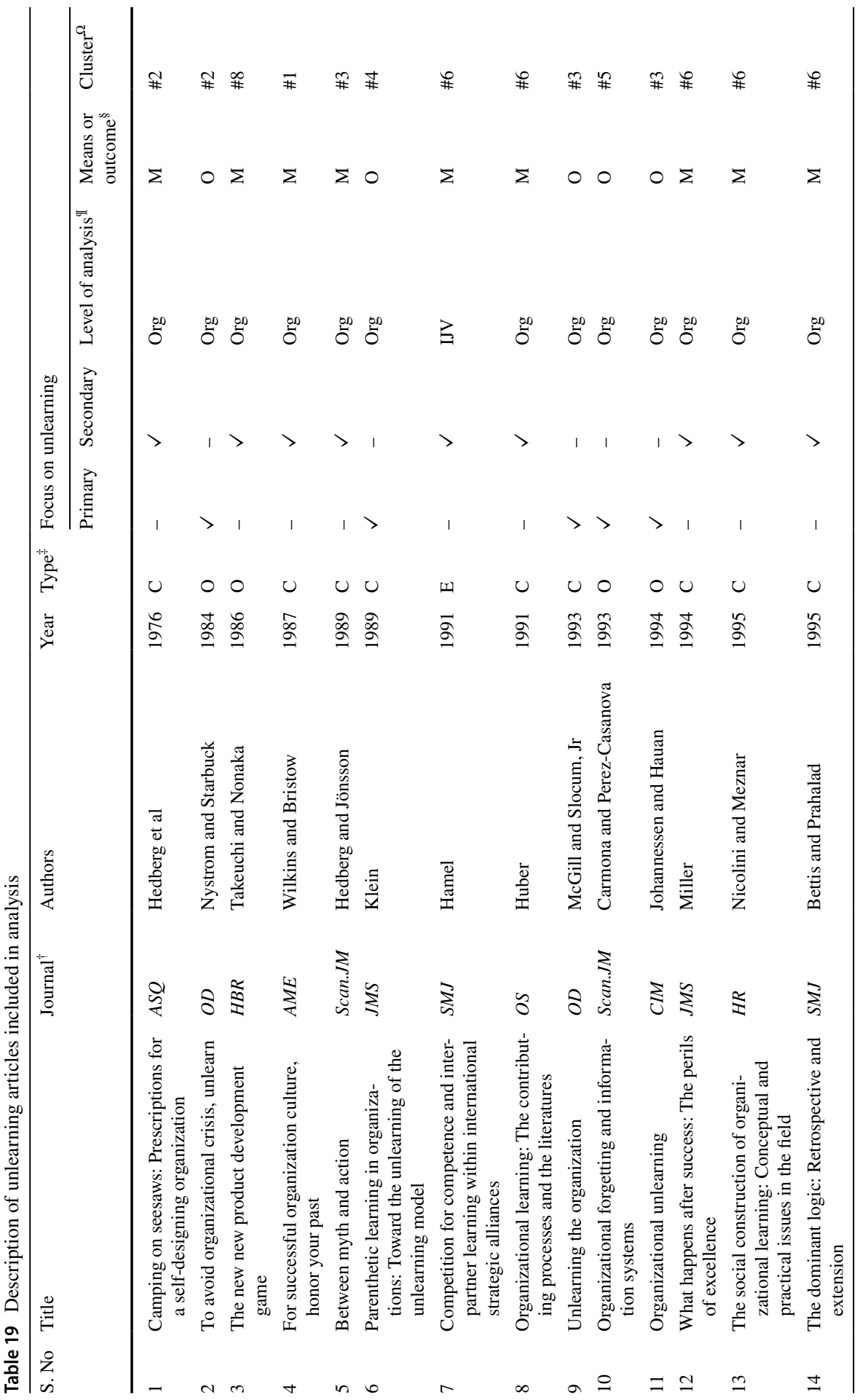




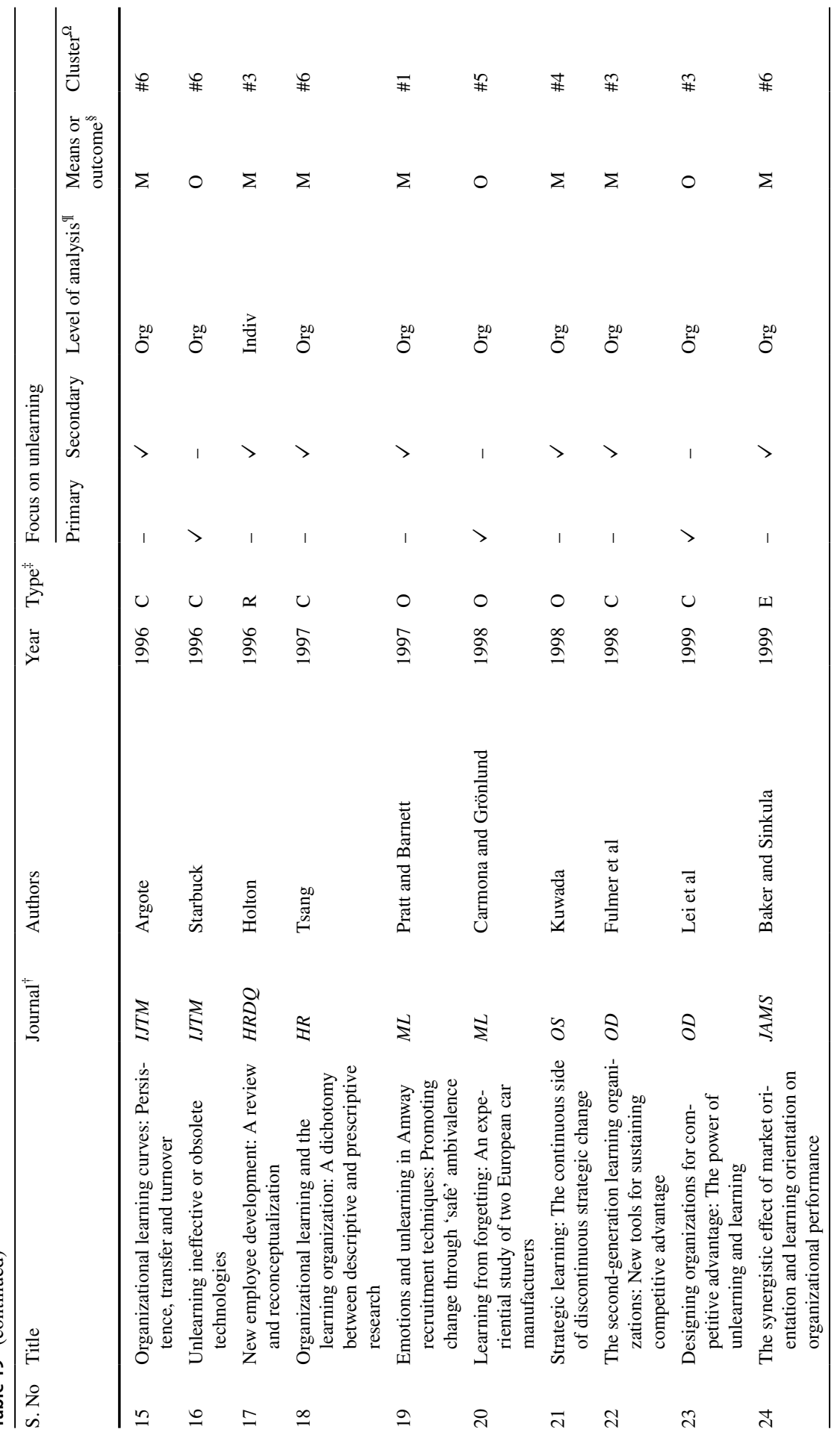




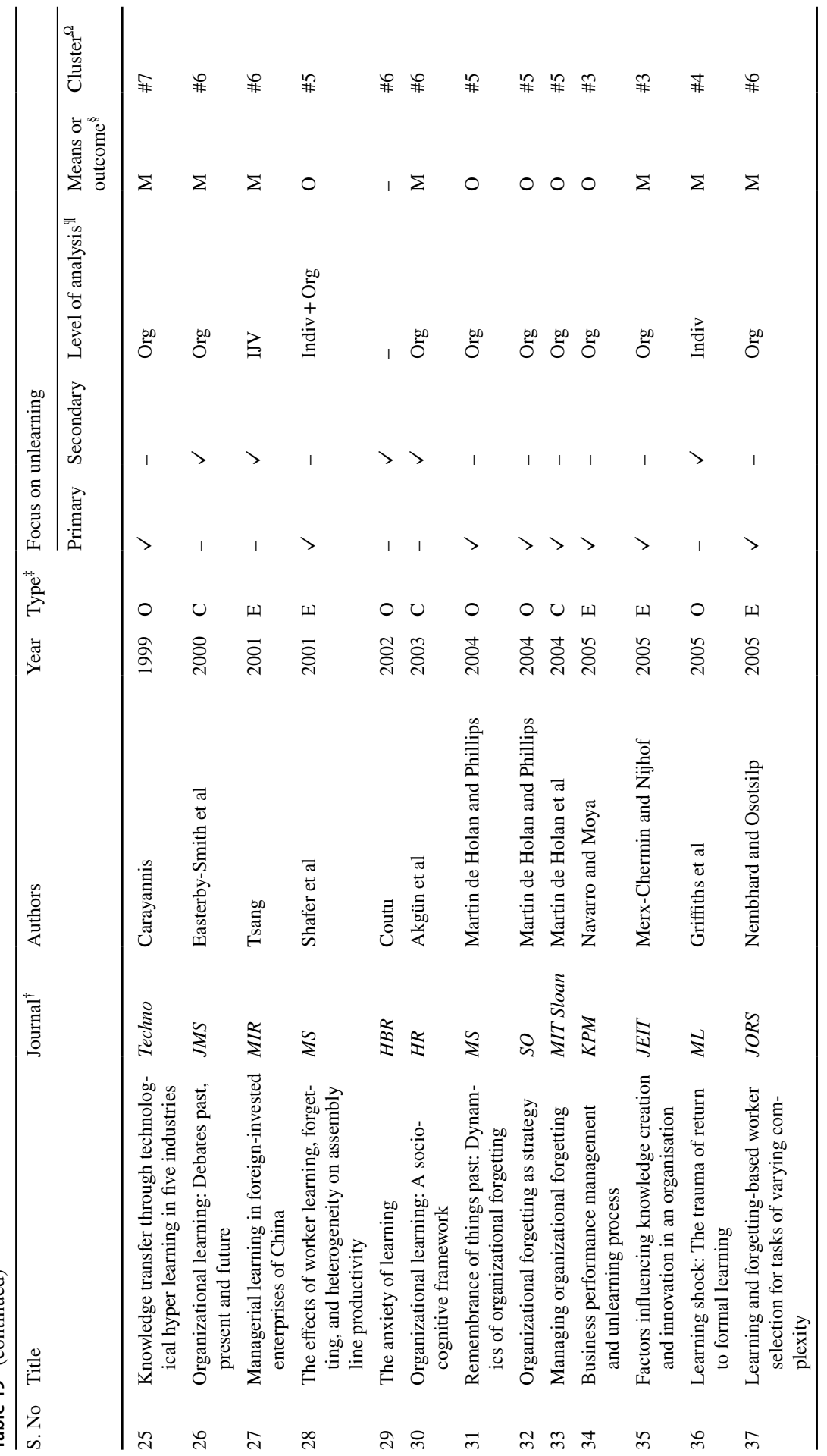




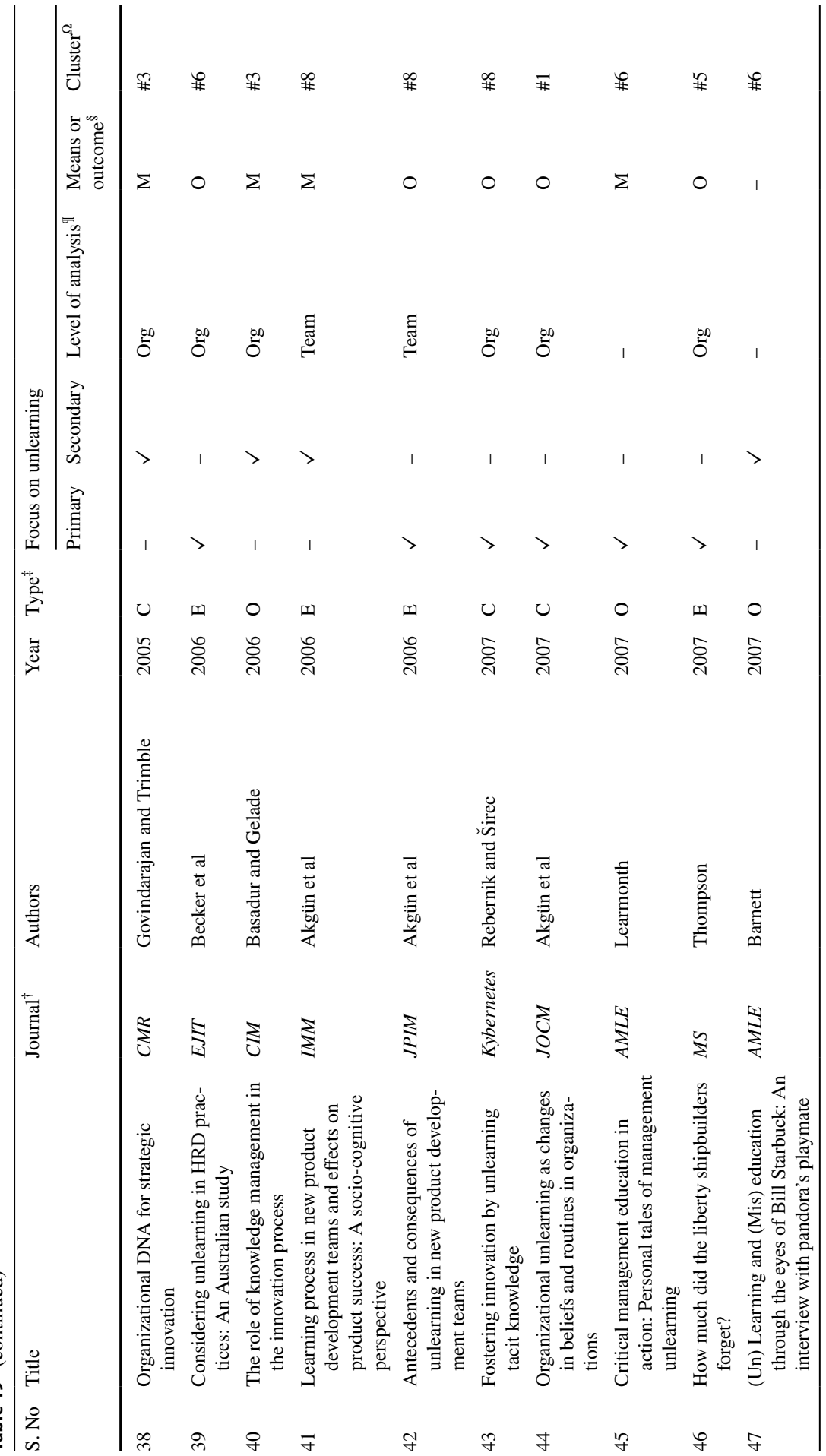




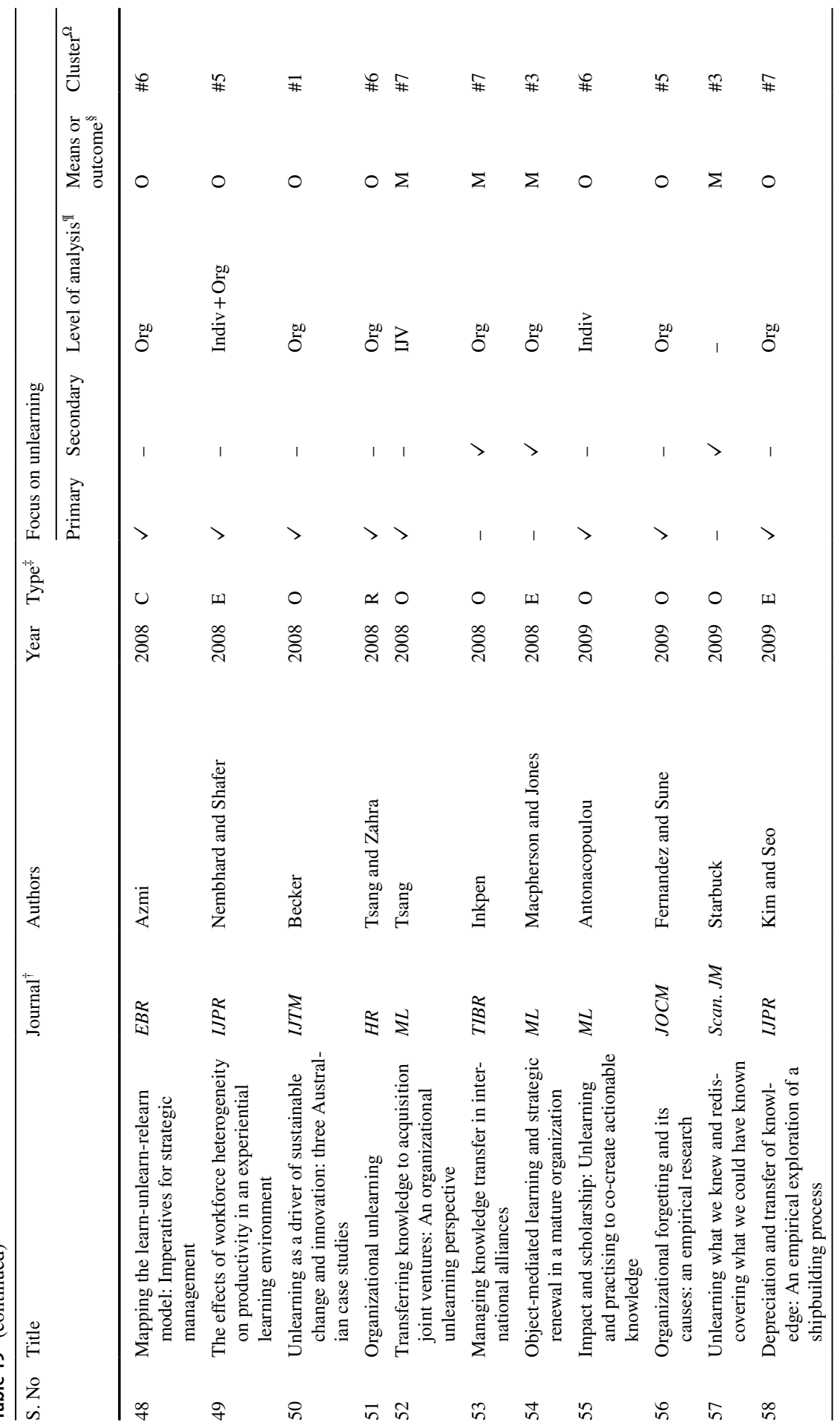




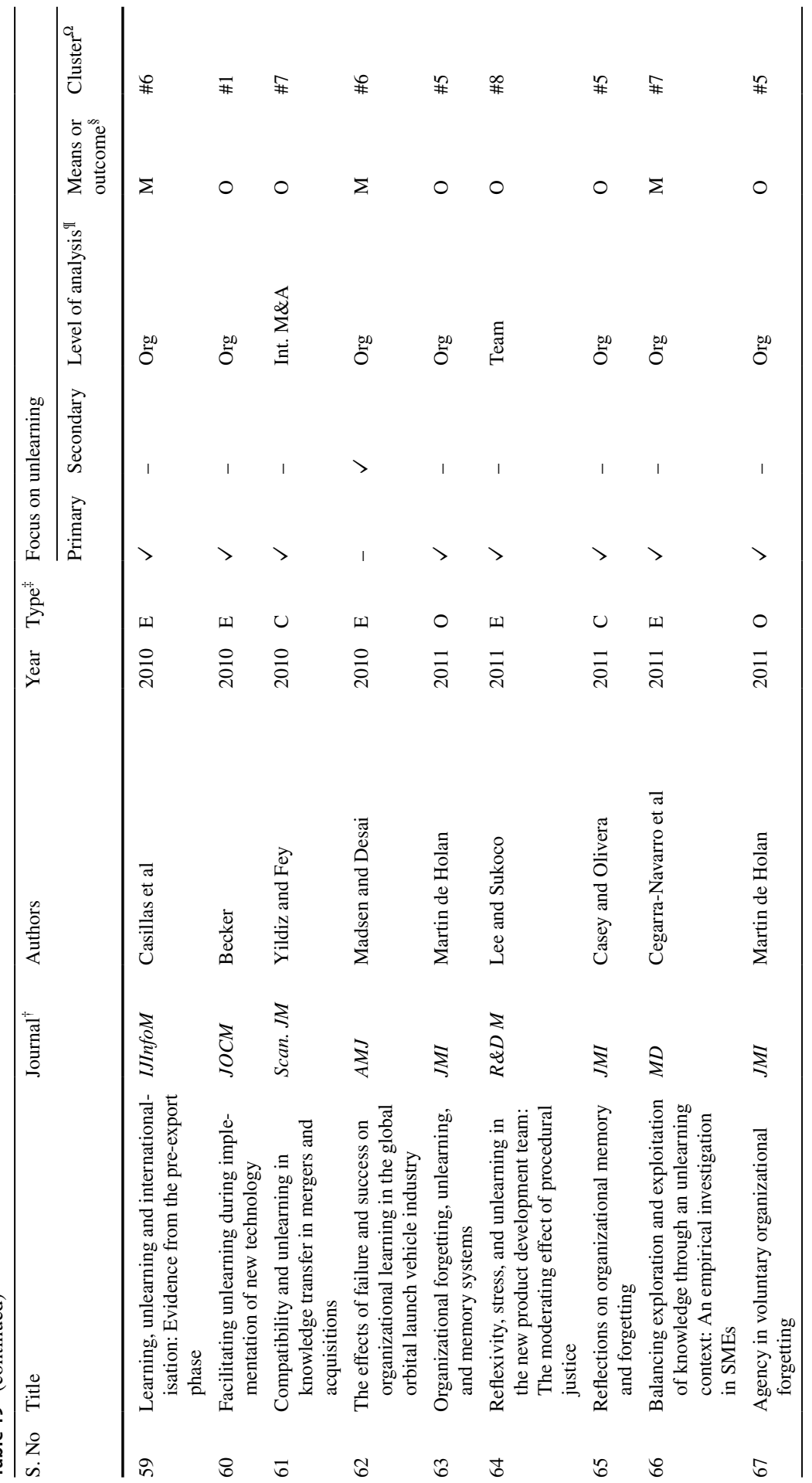




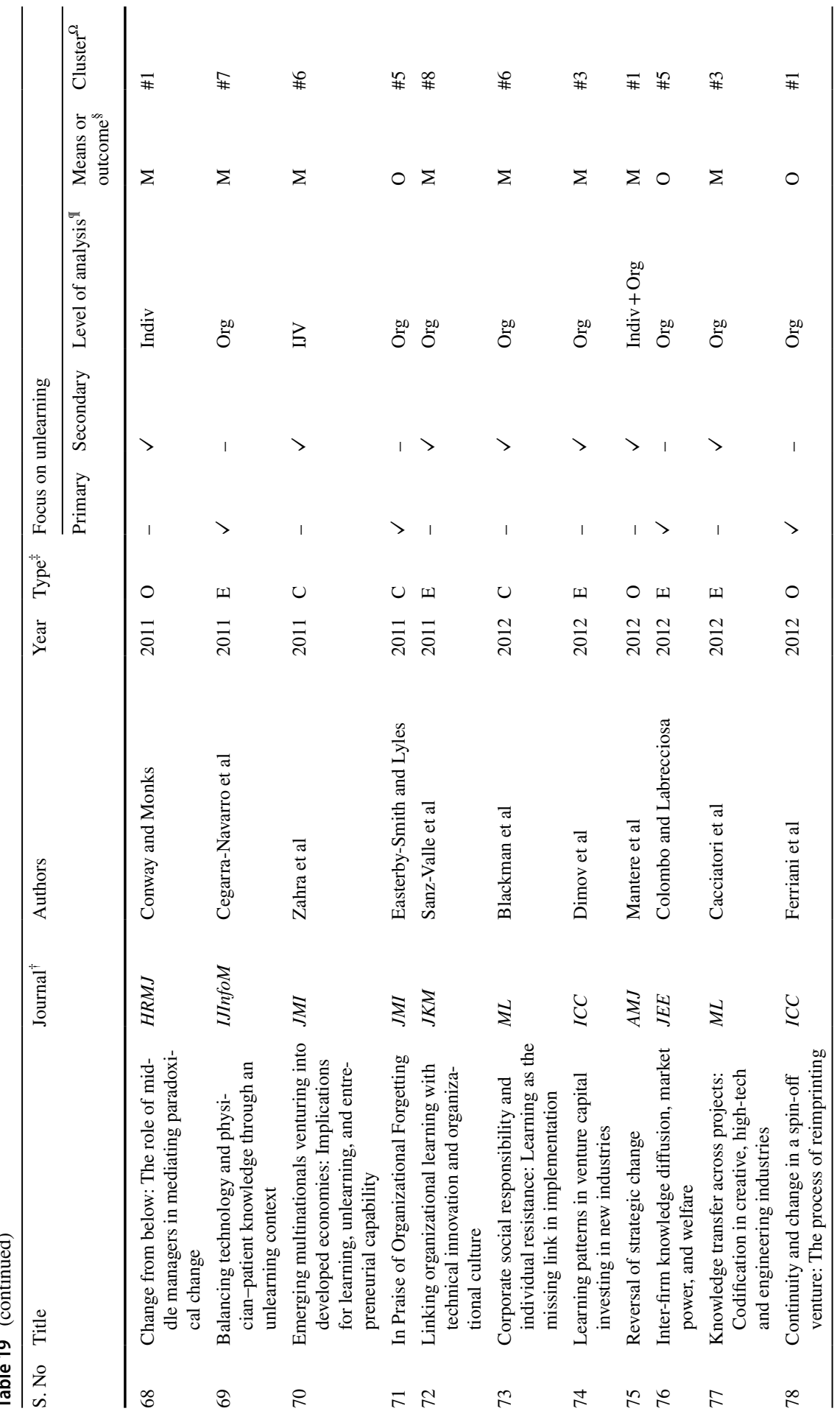




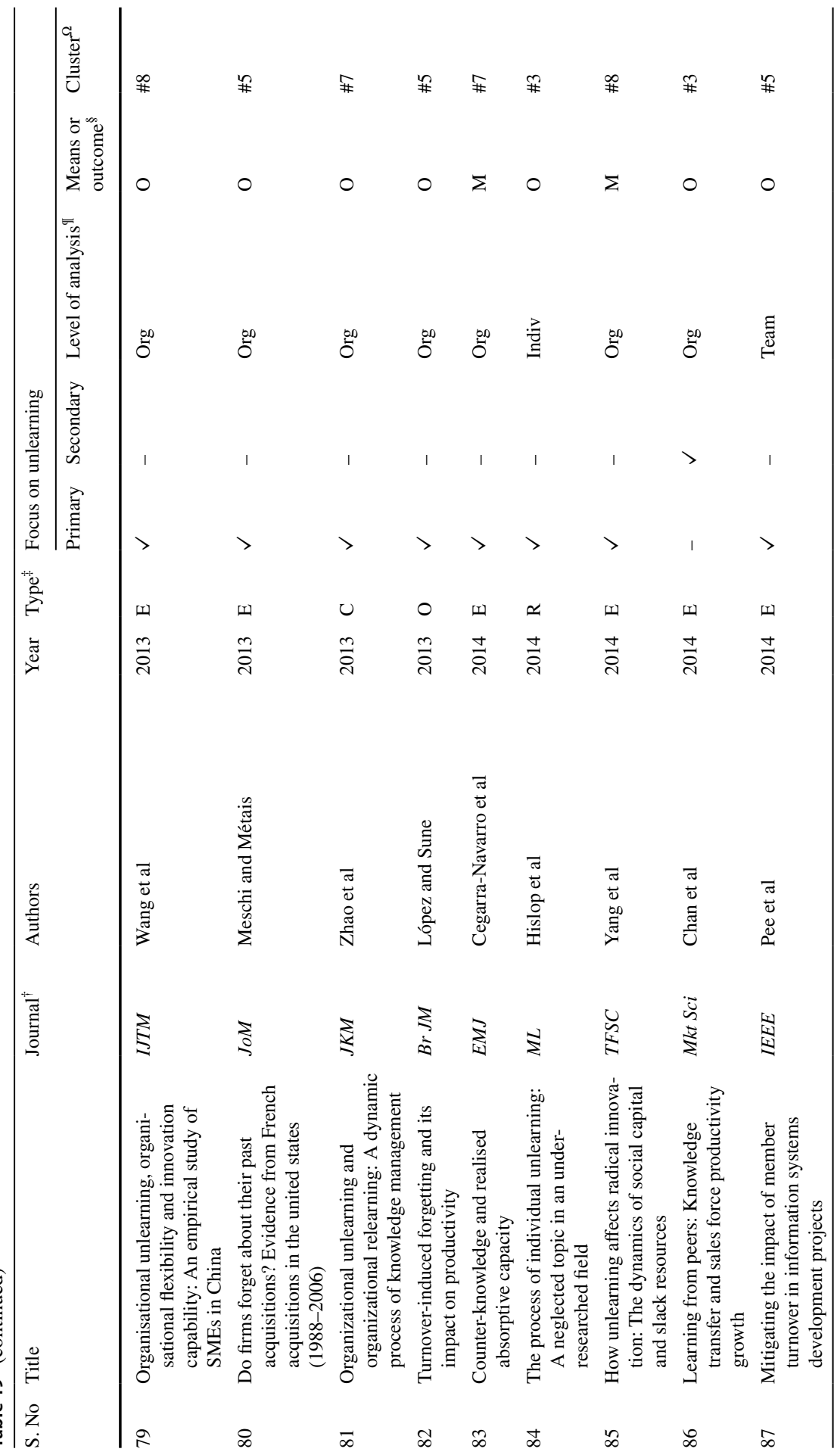




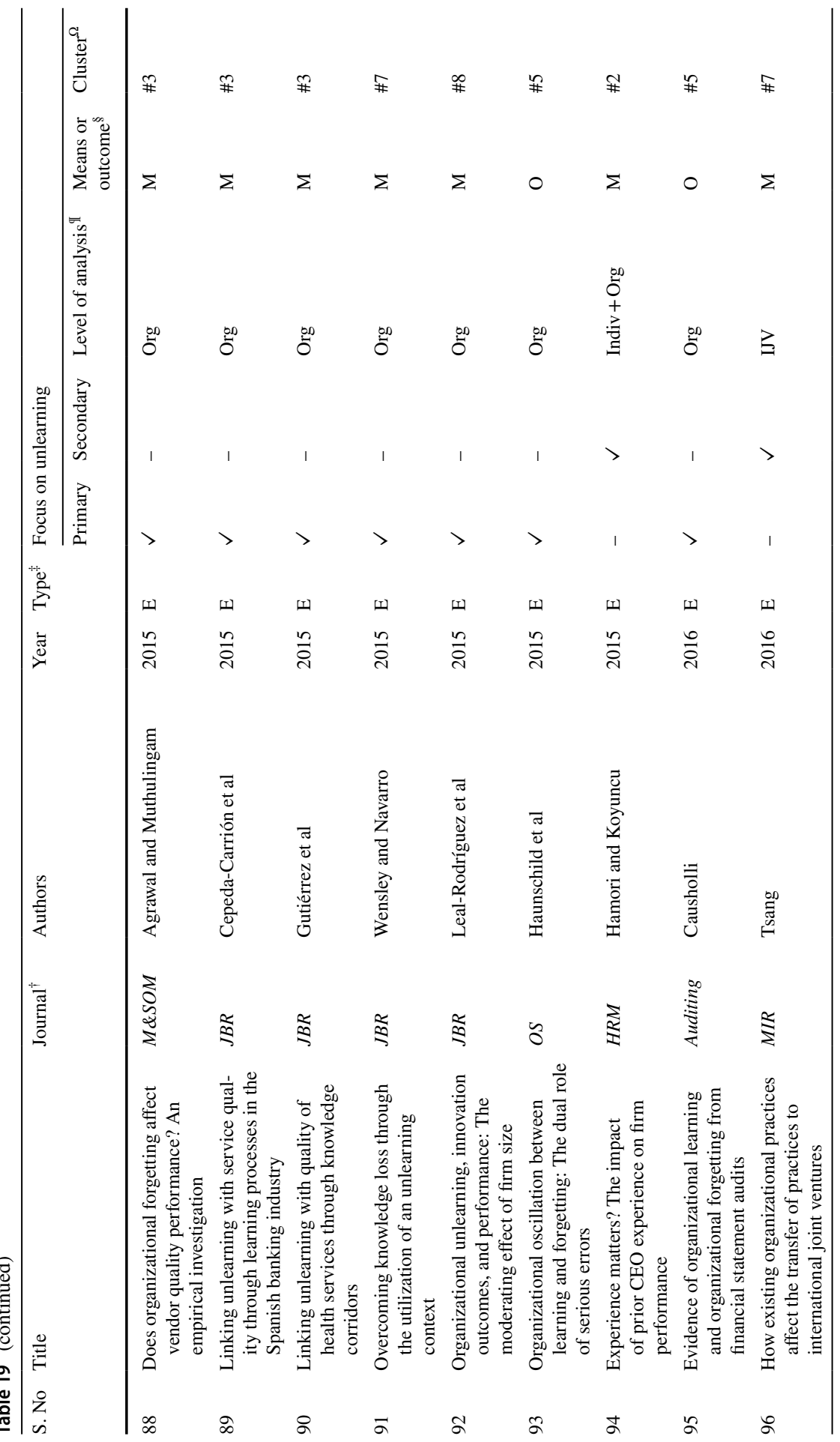




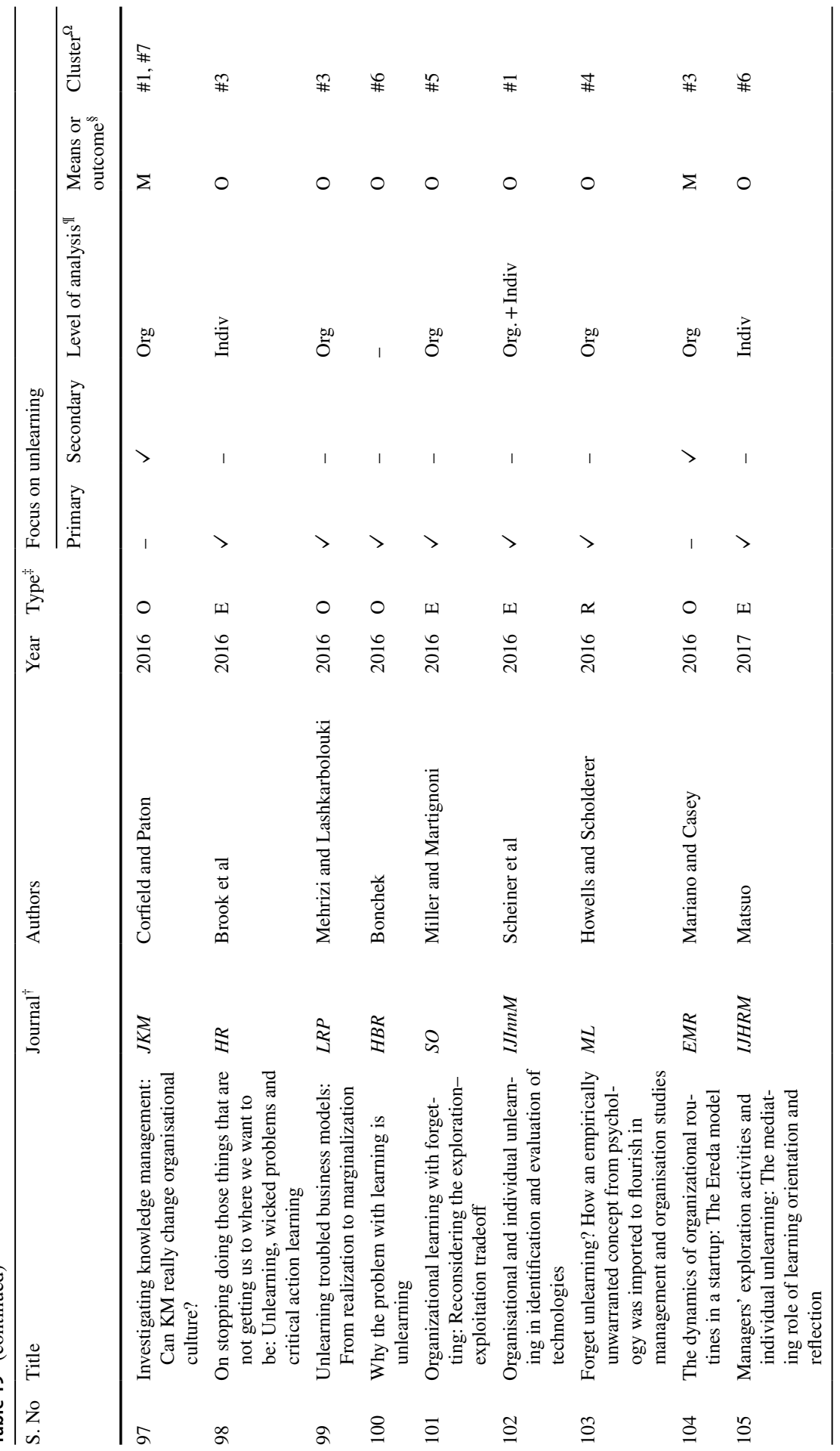




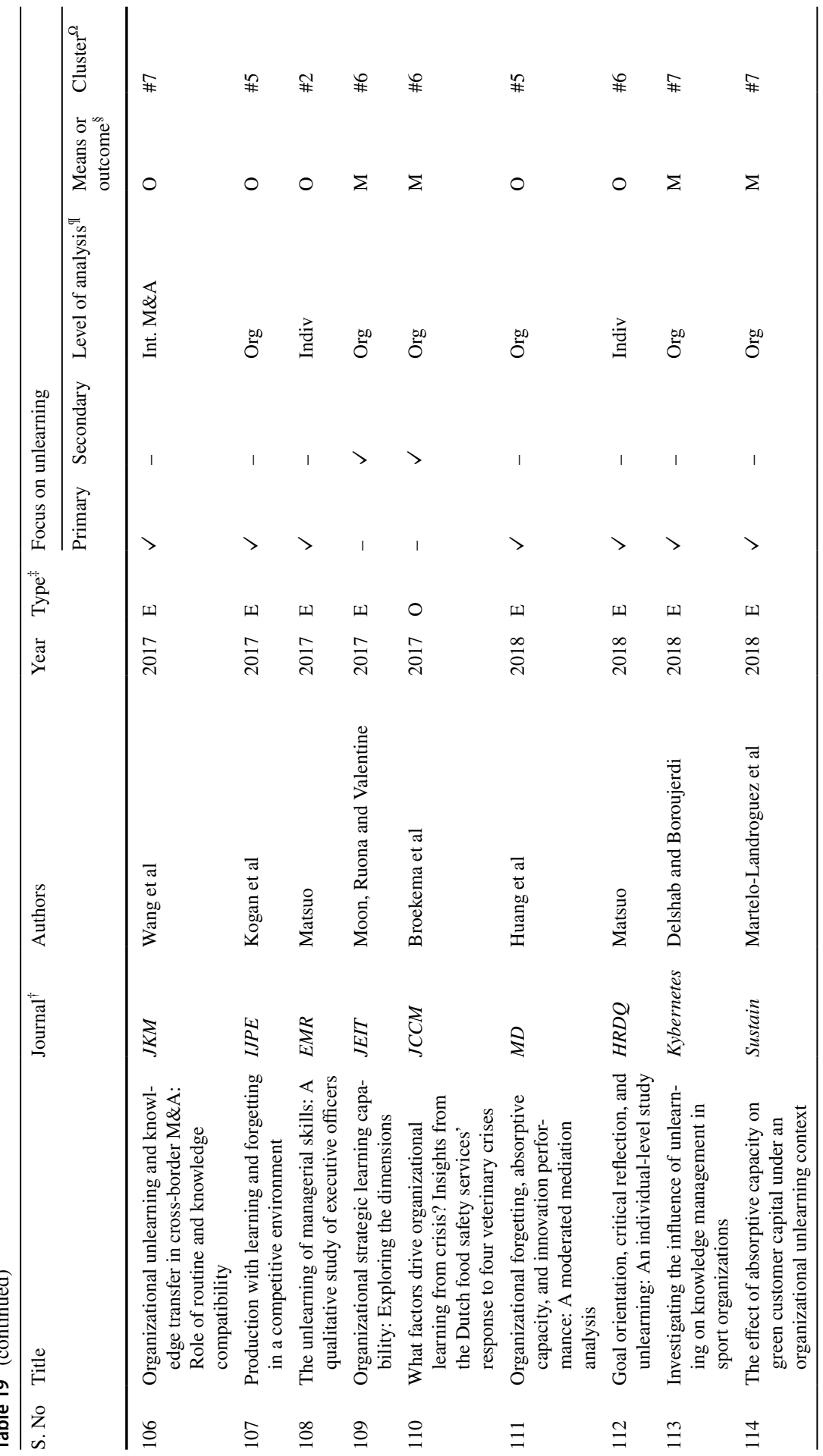




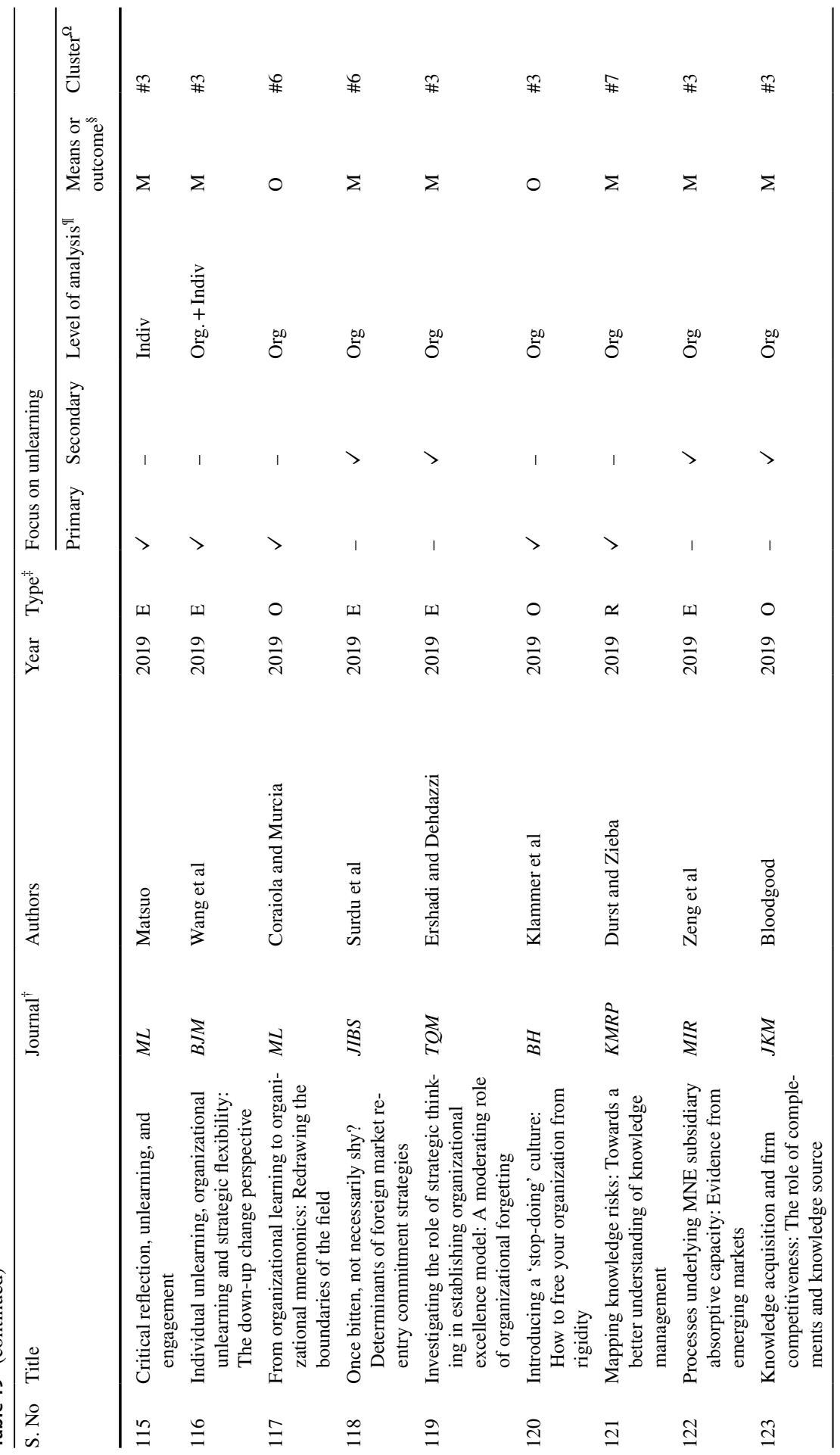




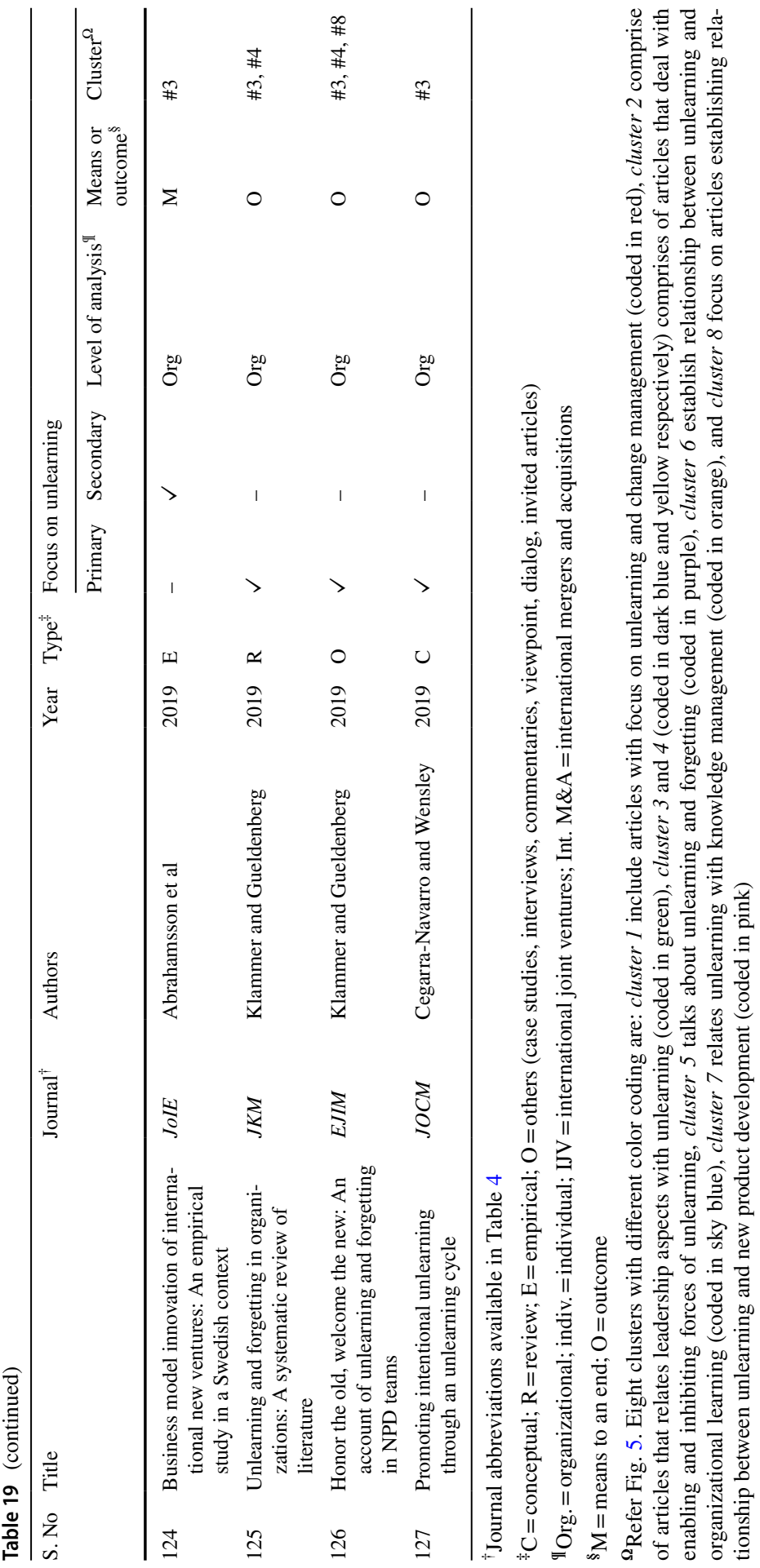




\section{Appendix 2}

\section{Mathematical calculation of collaboration coefficients}

This appendix describes the mathematical calculations behind three collaboration indices-degree of collaboration (DC), collaborative index (CI), collaborative coefficient (CC). The representative calculations are shown for the first phase (1976-1990) only.

\section{Degree of collaboration}

DC is defined as a ratio of the number of multi-authored papers in the field during a year to the total number of papers (either single- or multi-authored) published during the same year (Subramanyam, 1983). It is expressed mathematically as,

$$
D C_{\text {year }}=\frac{\text { Number of multi }- \text { authored papers in a field }}{\text { Number of single authored }+ \text { multi }- \text { authored papers }}
$$

During 1976-1990, there was only one single authored paper (Klein 1989) and five multi-authored papers on unlearning. Therefore,

$$
\begin{aligned}
& D C_{(1976-1990, O U)}=\frac{5}{1+5} \\
& D C_{(1976-1990, O U)}=0.833
\end{aligned}
$$

\section{Collaborative index}

CI is defined as the average number of authors per paper for a given set of articles (Lawani 1986). Mathematically, it is expressed as,

$$
C I_{\text {year }}=\sum_{j=1}^{k} \frac{j A j}{N}
$$

where $A j$ is the number of $\mathrm{j}$-authored articles produced in a discipline during a year, and $N=$ total number of articles in a year

$$
\begin{gathered}
C I_{(1976-1990, O U)}=\frac{\{(1 * 1)+(4 * 2)+(1 * 3)\}}{5} \\
C I_{(1976-1990, O U)}=2.400
\end{gathered}
$$




\section{Collaborative coefficient}

$\mathrm{CC}$ is based on the credit allocation method. Thus, if a paper has a single author, the paper receives a credit of 1.00 , and in general, papers with $\mathrm{X}$ authors, receive $1 / \mathrm{X}$ credit (Ajiferuke et al., 1988). Therefore,

$$
C C_{\text {year }}=1-\frac{f 1+(1 / 2) f 2+\cdots+(1 / k) f k}{N}
$$

where $f 1$ is the single-authored papers; $f 2$ is the papers with two authors; $f k$ is the number of k-authored papers; $N=$ total number of papers.

During 1976-1990, there was one single-authored paper, four articles by twoauthors, and one by three authors. Therefore,

$$
\begin{gathered}
C C_{(1976-1990, O U)}=1-\frac{1+(1 / 2) 4+(1 / 3) 1}{6} \\
C C_{(1976-1990, O U)}=0.445
\end{gathered}
$$

Acknowledgements This research was supported by University Grants Commission, New Delhi, India under the scheme Junior Research Fellowship in Sciences, Humanities and Social Sciences [1071/ (NET-DEC.2015)].

Author Contributions All authors contributed to the study conception and design. Material preparation, data collection and analysis were performed by Shubham Sharma. The first draft of the manuscript was written by Shubham Sharma and Usha Lenka commented on previous versions of the manuscript. All authors read and approved the final manuscript.

\section{Declarations}

Conflict of interest The authors declared no potential conflict of interest with respect to the authorship and/ or publication of this article.

\section{References}

Agrawal A, Muthulingam S (2015) Does organizational forgetting affect vendor quality performance? an empirical investigation. M\&SOM-Manuf Serv Oper Manag 17(3):350-367

Aguinis H, Cummings C, Ramani RS, Cummings TC (2020) An A is an A: the new bottom line for valuing academic research. Acad Manag Perspect 34(1):135-154

Akgün AE, Lynn GS, Byrne JC (2003) Organizational learning: a socio-cognitive framework. Hum Relat 56(7):839-868

Akgün AE, Lynn GS, Byrne JC (2006) Antecedents and consequences of unlearning in new product development teams. J Prod Innov Manag 23(1):73-88

Akgün AE, Byrne JC, Lynn GS, Keskin H (2007a) Organizational unlearning as changes in beliefs and routines in organizations. J Organ Chang Manag 20(6):794-812

Akgün AE, Byrne JC, Lynn GS, Keskin H (2007b) New product development in turbulent environments: impact of improvisation and unlearning on new product performance. J Eng Technol Manag 24(3):203-230 
Andrés A (2009) Measuring academic research: how to undertake a bibliometric study. Woodhead Publishing Limited, Cambridge

Antonacopoulou EP (2009) Impact and scholarship: unlearning and practising to co-create actionable knowledge. Manag Learn 40(4):421-430

Argote L (2013) Organizational learning: creating, retaining and transferring knowledge. Springer, Boston

Argyris C, Schön DA (1978) Organizational learning: a theory of action perspective. Addison-Wesley Publishing Company, Massachusetts

Argyris C, Schön DA (1996) Organizational learning II: theory, methods and practice. Addison-Wesley Publishing Company, Massachusetts

Azmi FT (2008) Mapping the learn-unlearn-relearn model: imperatives for strategic management. Eur Bus Rev 20(3):240-259

Baker WE, Sinkula JM (1999) The synergistic effect of market orientation and learning orientation on organizational performance. J Acad Mark Sci 27(4):411-427

Becker KL (2005) Individual and organisational unlearning: directions for future research. Int J Organ Behav 9(7):659-670

Becker KL (2008) Unlearning as a driver of sustainable change and innovation: three Australian case studies. Int J Technol Manag 42(1-2):89-106

Becker KL (2010) Facilitating unlearning during implementation of new technology. J Organ Chang Manag 23(3):251-268

Becker KL (2018) Knowledge management and unlearning/forgetting. In: Syed J, Murray PA, Hislop D, Mouzughi Y (eds) The Palgrave handbook of knowledge management. Palgrave Macmillan, Switzerland, pp 105-130

Becker KL, Hyland P, Acutt B (2006) Considering unlearning in HRD practices: an Australian study. J Eur Ind Train 30(8):608-621

Bettis RA, Prahalad CK (1995) The dominant logic: retrospective and extension. Strateg Manag J 16(1):5-14

Borgman CL, Furner J (2002) Scholarly communication and bibliometrics. Annu Rev Inform Sci Technol 36(1):2-72

Bouncken RB, Gast J, Kraus S, Bogers M (2015) Coopetition: a systematic review, synthesis, and future research directions. Rev Manag Sci 9(3):577-601

Brin S, Page L (1998) The anatomy of a large-scale hypertextual web search engine. Comput Netw ISDN Syst 30(1-7):107-117

Brook C, Pedler M, Abbott C, Burgoyne J (2016) On stopping doing those things that are not getting us to where we want to be: unlearning, wicked problems and critical action learning. Hum Relat 69(2):369-389

Callon M, Courtial JP, Laville F (1991) Co-word analysis as a tool for describing the network of interactions between basic and technological research: the case of polymer chemistry. Scientometrics 22(1):155-205

Carmona S, Grönlund A (1998) Learning from forgetting: an experiential study of two European car manufacturers. Manag Learn 29(1):21-38

Causholli M (2016) Evidence of organizational learning and organizational forgetting from financial statement audits. Audit-J Pract Theory 35(2):53-72

Cegarra-Navarro JG, Sánchez-Polo MT (2008) Linking the individual forgetting context with customer capital from a seller's perspective. J Oper Res Soc 59(12):1614-1623

Cegarra-Navarro JG, Wensley AK (2019) Promoting intentional unlearning through an unlearning cycle. J Organ Chang Manag 32(1):67-79

Cegarra-Navarro JG, Cepeda-Carrión G, Eldridge S (2011) Balancing technology and physician-patient knowledge through an unlearning context. Int J Inf Manag 31(5):420-427

Cegarra-Navarro JG, Eldridge S, Sánchez ALG (2012) How an unlearning context can help managers overcome the negative effects of counter-knowledge. J Manag Organ 18(2):231-246

Cegarra-Navarro JG, Eldridge S, Wensley AK (2014a) Counter-knowledge and realised absorptive capacity. Eur Manag J 32(2):165-176

Cegarra-Navarro JG, Wensley AK, Polo MTS (2014b) A conceptual framework for unlearning in a homecare setting. Knowl Manag Res Pract 12(4):375-386

Chokr NN (2009) Unlearning: or how not to be governed? Societas Imprint Academic, Exeter

Conner KR, Prahalad CK (1996) A resource-based theory of the firm: knowledge versus opportunism. Organ Sci 7(5):477-501 
Contu A, Grey C, Örtenblad A (2003) Against learning. Hum Relat 56(8):931-952

Conway E, Monks K (2011) Change from below: the role of middle managers in mediating paradoxical change. Hum Resour Manag J 21(2):190-203

Crossan MM, Lane HW, White RE (1999) An organizational learning framework: from intuition to institution. Acad Manag Rev 24(3):522-537

Davvetas V, Diamantopoulos A, Zaefarian G, Sichtmann C (2020) Ten basic questions about structural equations modeling you should know the answers to-but perhaps you don't. Ind Mark Manag 90:252-263

Delshab V, Boroujerdi SS (2018) Investigating the influence of unlearning on knowledge management in sport organizations. Kybernetes 47(10):2025-2040

Dewey J (1938) Experience and education. Macmillan, New York

Dimov D, Martin de Holan P, Milanov H (2012) Learning patterns in venture capital investing in new industries. Ind Corp Change 21(6):1389-1426

Ding Y, Yan E, Frazho A, Caverlee J (2009) PageRank for ranking authors in co-citation networks. J Am Soc Inf Sci Technol 60(11):2229-2243

Drucker PF (1999) Management challenges for the $21^{\text {st }}$ century. Harper Collins, New York

Durieux V, Gevenois PA (2010) Bibliometric indicators: quality measurements of scientific publication. Radiology 255(2):342-351

Easterby-Smith M, Lyles MA (2011) In praise of organizational forgetting. J Manag Inq 20(3):311-316

Easterby-Smith M, Crossan M, Nicolini D (2000) Organizational learning: debates past, present and future. J Manag Stud 37(6):783-796

Engeström Y (1991) Non Scolae sed vitae discimus: toward overcoming the encapsulation of school learning. Learn Instr 1(3):243-259

Escrig ED, Broch FFM, Alcamí RL, Gómez RC (2019) How to enhance radical innovation? the importance of organizational design and generative learning. Rev Manag Sci. https://doi.org/10.1007/ s11846-019-00326-7

Feldman MS, Pentland BT (2003) Reconceptualizing organizational routines as a source of flexibility and change. Adm Sci Q 48(1):94-118

Fernandez V, Sune A (2009) Organizational forgetting and its causes: an empirical research. J Organ Chang Manag 22(6):620-634

Ferreira MP, Santos JC, de Almeida MIR, Reis NR (2014) Mergers \& acquisitions research: a bibliometric study of top strategy and international business journals, 1980-2010. J Bus Res 67(12):2550-2558

Ferreira JJ, Fernandes CI, Kraus S (2019) Entrepreneurship research: mapping intellectual structures and research trends. Rev Manag Sci 13(1):181-205

Fiol CM, Lyles MA (1985) Organizational learning. Acad Manag Rev 10(4):803-813

Furrer O, Thomas H, Goussevskaia A (2008) The structure and evolution of the strategic management field: a content analysis of 26 years of strategic management research. Int J Manag Rev 10(1):1-23

García-Muiña FE, Pelechano-Barahona E, Navas-López JE (2009) Knowledge codification and technological innovation success: empirical evidence from Spanish biotech companies. Technol Forecast Soc Chang 76:141-153

Garfield E (1972) Citation analysis as a tool in journal evaluation. Science 178(4060):471-479

Gaviria-Marín M, Merigó JM, Baier-Fuentes H (2019) Knowledge management: a global examination based on bibliometric analysis. Technol Forecast Soc Chang 140:194-220

Gomes E, Barnes BR, Mahmood T (2016) A 22 year review of strategic alliance research in the leading management journals. Int Bus Rev 25(1):15-27

Griffiths DS, Winstanley D, Gabriel Y (2005) Learning shock: the trauma of return to formal learning. Manag Learn 36(3):275-297

Hambrick DC, Mason PA (1984) Upper echelons: the organization as a reflection of its top managers. Acad Manag Rev 9(2):193-206

Hamel G (1991) Competition for competence and interpartner learning within international strategic alliances. Strateg Manag J 12(S1):83-103

Hamel G, Prahalad CK (1994) Competing for the future. Harvard Business School Press, Boston

Hamel G, Zanini M (2018) The end of bureaucracy. Harv Bus Rev. https://hbr.org/2018/11/the-end-ofbureaucracy. Accessed 15 Apr 2020

Hamori M, Koyuncu B (2015) Experience matters? the impact of prior CEO experience on firm performance. Hum Resour Manag 54(1):23-44 
Hedberg BLT (1981) How organizations learn and unlearn. In: Nystrom PC, Starbuck WH (eds) Handbook of organizational design: adapting organizations to their environments. Oxford University Press, New York, pp 3-27

Hedberg BLT, Nystrom PC, Starbuck WH (1976) Camping on seesaws: prescriptions for a self-designing organization. Adm Sci Q 21(1):41-65

Hislop D, Bosley S, Coombs CR, Holland J (2014) The process of individual unlearning: a neglected topic in an under-researched field. Manag Learn 45(5):540-560

Howard GS, Day JD (1995) Individual productivity and impact in developmental psychology. Dev Rev 15(2):136-149

Howells J, Scholderer J (2016) Forget unlearning? how an empirically unwarranted concept from psychology was imported to flourish in management and organisation studies. Manag Learn 47(4):443-463

Hsu SW (2013) Alternative learning organization. In: Örtenblad A (ed) Handbook of research on the learning organization: adaptation and context, Edward Elgar Publishing, Cheltenham, pp 298-308

Huang D, Chen S, Zhang G, Ye J (2018) Organizational forgetting, absorptive capacity, and innovation performance. Manag Decis 56(1):87-104

Huber GP (1991) Organizational learning: the contributing processes and the literatures. Organ Sci 2(1):88-115

Imai K, Nonaka I, Takeuchi H (1985) Managing the new product development process: how Japanese companies learn and unlearn. In: Hayes R, Clark K, Lorenz C (eds) The uneasy alliance: managing the productivity-technology dilemma. Harvard Business School Press, Boston, pp 337-375

Inkpen AC (2008) Managing knowledge transfer in international alliances. Thunderbird Int Bus Rev 50(2):77-90

Kim HW, Kankanhalli A (2009) Investigating user resistance to information systems implementation: a status quo bias perspective. MIS Q 33(3):567-582

Kim I, Seo HL (2009) Depreciation and transfer of knowledge: an empirical exploration of a shipbuilding process. Int J Prod Res 47(7):1857-1876

Klammer A, Gueldenberg S (2019) Unlearning and forgetting in organizations: a systematic review of literature. J Knowl Manag 23(5):860-888

Klammer A, Grisold T, Gueldenberg S (2019) Introducing a 'stop-doing' culture: how to free your organization from rigidity. Bus Horiz 62(4):451-458

Klein JI (1989) Parenthetic learning in organizations: toward the unlearning of the unlearning model. J Manag Stud 26(3):291-308

Kraus S, Filser M, O’Dwyer M, Shaw E (2014) Social entrepreneurship: an exploratory citation analysis. Rev Manag Sci 8(2):275-292

Lawani S (1986) Some bibliometric correlates of quality in scientific research. Scientometrics 9(1-2):13-25

Lawrence DW (2008) What is lost when searching only one literature database for articles relevant to injury prevention and safety promotion? Inj Prev 14(6):401-404

Leal-Rodríguez AL, Eldridge S, Roldán JL, Leal-Millán AG, Ortega-Gutiérrez J (2015) Organizational unlearning, innovation outcomes, and performance: the moderating effect of firm size. J Bus Res 68(4):803-809

Lee LTS, Sukoco BM (2011) Reflexivity, stress, and unlearning in the new product development team: the moderating effect of procedural justice. R D Manag 41(4):410-423

Lei D, Slocum JW, Pitts RA (1999) Designing organizations for competitive advantage: the power of unlearning and learning. Organ Dyn 27(3):24-38

Levitt B, March JG (1988) Organizational learning. Annu Rev Sociol 14(1):319-338

Lewin K (1951) Field theory in social science. Harper \& Row, New York

Liu GY, Hu JM, Wang HL (2012) A co-word analysis of digital library field in China. Scientometrics 91(1):203-217

Locke K, Golden-Biddle K (1997) Constructing opportunities for contribution: structuring intertextual coherence and "problematizing" in organizational studies. Acad Manag J 40(5):1023-1062

López L, Sune A (2013) Turnover-induced forgetting and its impact on productivity. Br J Manag 24(1):38-53

Lundberg A, Westerman G (2020) The transformer CLO. Harv Bus Rev. https://hbr.org/2020/01/the-trans former-clo. Accessed 3 Sep 2020

Lyu C, Yang J, Zhang F, Teo TS, Guo W (2020) Antecedents and consequence of organizational unlearning: evidence from China. Ind Mark Manag 84:261-270 
March JG (1991) Exploration and exploitation in organizational learning. Organ Sci 2(1):71-87

Mariano S, Casey A (2015) Is organizational innovation always a good thing? Manag Learn 46(5):530-545

Marquis C, Tilcsik A (2013) Imprinting: toward a multilevel theory. Acad Manag Ann 7(1):195-245

Martelo-Landroguez S, Albort-Morant G, Leal-Rodríguez A, Ribeiro-Soriano B (2018) The effect of absorptive capacity on green customer capital under an organizational unlearning context. Sustainability 10(1):1-20

Martin de Holan P, Phillips N (2004a) Remembrance of things past? the dynamics of organizational forgetting. Manage Sci 50(11):1603-1613

Martin de Holan P, Phillips N (2004b) Organizational forgetting as strategy. Strateg Organ 2(4):423-433

Martin de Holan P, Phillips N, Lawrence TB (2004) Managing organizational forgetting. MIT Sloan Manag Rev 45(2):45-51

Martin de Holan P (2011) Agency in voluntary organizational forgetting. J Manag Inq 20(3):317-322

Mas-Tur A, Kraus S, Brandtner M, Ewert R, Kürsten W (2020) Advances in management research: a bibliometric overview of the Review of Managerial Science. Rev Manag Sci 14(5):933-958. https:// doi.org/10.1007/s11846-020-00406-Z

Matsuo M (2018) Goal orientation, critical reflection, and unlearning: an individual-level study. Hum Resour Dev Q 29(1):49-66

Matsuo M (2019) The unlearning of managerial skills: a qualitative study of executive officers. Eur Manag Rev 16(2):303-315

Meschi PX, Métais E (2013) Do firms forget about their past acquisitions? evidence from French acquisitions in the United States (1988-2006). J Manag 39(2):469-495

Miller KD, Martignoni D (2016) Organizational learning with forgetting: reconsidering the explorationexploitation tradeoff. Strateg Organ 14(1):53-72

Mishra D, Gunasekaran A, Childe SJ, Papadopoulos T, Dubey R, Wamba S (2016) Vision, applications and future challenges of Internet of Things: a bibliometric study of the recent literature. Ind Manag Data Syst 116(7):1331-1355

Newstrom JW (1983) The management of unlearning: exploding the "clean slate" fallacy. Train Dev J 37(8):36-39

Nooyi I, Govindarajan V (2020) Becoming a better corporate citizen: how PepsiCo moved toward a healthier future. Harv Bus Rev https://hbr.org/2020/03/becoming-a-better-corporate-citizen. Accessed 15 Apr 2020

Nystrom PC, Starbuck WH (1981) Handbook of organizational design: adapting organizations to their environments. Oxford University Press, New York

Nystrom PC, Starbuck WH (1984) To avoid organizational crises, unlearn. Organ Dyn 12(4):53-65

Post C, Sarala R, Gatrell C, Prescott JE (2020) Advancing theory with review articles. J Manag Stud 57(2):351-376

Pratt MG, Barnett CK (1997) Emotions and unlearning in Amway recruiting techniques: promoting change through "safe" ambivalence. Manag Learn 28(1):65-88

Raghuram S, Hill NS, Gibbs JL, Maruping LM (2019) Virtual work: bridging research clusters. Acad Manag Ann 13(1):308-341

Rebernik M, Širec K (2007) Fostering innovation by unlearning tacit knowledge. Kybernetes 36(3/4):406-419

Rhaiem K, Amara N (2019) Learning from innovation failures: a systematic review of the literature and research agenda. Rev Manag Sci. https://doi.org/10.1007/s11846-019-00339-2

Ronda-Pupo GA, Guerras-Martin LÁ (2012) Dynamics of the evolution of the strategy concept 1962-2008: a co-word analysis. Strateg Manag J 33(2):162-188

Rushmer R, Davies HTO (2004) Unlearning in health care. Qual Saf Health Care 13(2):10-15

Sandberg B, Aarikka-Stenroos L (2014) What makes it so difficult? a systematic review on barriers to radical innovation. Ind Mark Manag 43(8):1293-1305

Scheiner CW, Baccarella CV, Feller N, Voigt KI, Bessant J (2016) Organisational and individual unlearning in identification and evaluation of technologies. Int J Innov Manag 20(2):1650017

Senanayake U, Piraveenan M, Zomaya A (2015) The pagerank-index: going beyond citation counts in quantifying scientific impact of researchers. PLoS ONE 10(8):e0134794

Serenko A (2013) Meta-analysis of scientometric research of knowledge management: discovering the identity of the discipline. J Knowl Manag 17(5):773-812

Serenko A, Bontis N, Booker L, Sadeddin K, Hardie T (2010) A scientometric analysis of knowledge management and intellectual capital academic literature (1994-2008). J Knowl Manag 14(1):3-23 
Sergeeva A, Andreeva T (2016) Knowledge sharing research: bringing context back in. J Manag Inq 25(3):240-261

Sharma S, Lenka U (2019) Exploring linkages between unlearning and relearning in organizations. Learn Organ 26(5):500-517

Shaw RB, Perkins DN (1991) Teaching organizations to learn. Org Dev J 9(4):1-12

Sheaffer Z, Mano-Negrin R (2003) Executives' orientations as indicators of crisis management policies and practices. J Manag Stud 40(2):573-606

Sinha PN, Jaskiewicz P, Gibb J, Combs JG (2020) Managing history: how New Zealand's Gallagher Group used rhetorical narratives to reprioritize and modify imprinted strategic guideposts. Strateg Manag J 41(3):557-589

Sinkula JM (2002) Market-based success, organizational routines, and unlearning. J Bus Ind Mark 17(4):253-269

Small H (1973) Co-citation in the scientific literature: a new measure of the relationship between two documents. J Am Soc Inf Sci 24(4):265-269

Snihur Y (2018) Responding to business model innovation: organizational unlearning and firm failure. Learn Organ 25(3): 190-198

Starbuck WH (1983) Organizations as action generators. Am Sociol Rev 48(1):91-102

Starbuck WH (1996) Unlearning ineffective or obsolete technologies. Int J Technol Manag 11(7-8):725-737

Starbuck WH (2017) Organizational learning and unlearning. Learn. Organ 24(1):30-38

Starbuck WH, Hedberg BLT (1977) Saving an organization from a stagnating environment. In: Thorelli H (ed) Strategy+ structure $=$ performance the strategic planning imperative. IU Press, Indiana, pp 249-258

Starbuck WH, Hedberg BLT (2003) How organizations learn from success and failure. In: Dierkes M, Antal AB, Child J, Nonaka I (eds) Handbook of organizational learning and knowledge. Oxford University Press, New York, pp 327-350

Staw BM, Sandelands LE, Dutton JE (1981) Threat rigidity effects in organizational behavior: a multilevel analysis. Adm Sci Q 26(4):501-524

Subramanyam K (1983) Bibliometric studies of research collaboration: a review. J Inf Sci 6(1):33-38

Sydow J, Schreyögg G, Koch J (2009) Organizational path dependence: opening the black box. Acad Manage Rev 34(4):689-709

Szulanski G (1996) Exploring internal stickiness: impediments to the transfer of best practice within the firm. Strateg Manage J 17(S2):27-43

Takeuchi H, Nonaka I (1986) The new new product development game. Harv Bus Rev 64(1):137-146

Thompson P (2007) How much did the liberty shipbuilders forget? Manage Sci 53(6):908-918

Thorelli HB (1977) Strategy+ structure=performance: the strategic planning imperative. UI Press, Indiana

Toffler A (1971) Future shock. Bantam Books, New York

Tranfield D, Denyer D, Smart P (2003) Towards a methodology for developing evidence-informed management knowledge by means of systematic review. Br J Manag 14(3):207-222

Tripsas M, Gavetti G (2000) Capabilities, cognition, and inertia: evidence from digital imaging. Strateg Manag J 21:1147-1161

Tsang EWK (2001) Managerial learning in foreign-invested enterprises of China. Manag Int Rev 41(1):29-51

Tsang EWK (2008) Transferring knowledge to acquisition joint ventures: an organizational unlearning perspective. Manag Learn 39(1):5-20

Tsang EWK (2016) How existing organizational practices affect the transfer of practices to international joint ventures. Manag Int Rev 56(4):565-595

Tsang EWK (2017) How the concept of organizational unlearning contributes to studies of learning organizations: a personal reflection. Learn Organ 24(1):39-48

Tsang EWK, Zahra SA (2008) Organizational unlearning. Hum Relat 61(10):1435-1462

Turc E, Baumard P (2007) Can organizations really unlearn? In: McInerney CR, Day RE (eds) Rethinking knowledge management: from knowledge objects to knowledge processes. Springer, New York, pp 125-146

van Eck N, Waltman L (2010) Software survey: VOSviewer, a computer program for bibliometric mapping. Scientometrics 84(2):523-538

Vinkler P (1988) An attempt of surveying and classifying bibliometric indicators for scientometric purposes. Scientometrics 13(5-6):239-259

Wang J (2013) Citation time window choice for research impact evaluation. Scientometrics 94(3):851-872

Wang X, Xi Y, Xie J, Zhao Y (2017) Organizational unlearning and knowledge transfer in cross-border M\&A: the roles of routine and knowledge compatibility. J Knowl Manag 21(6):1580-1595 
Wang X, Qi Y, Zhao Y (2019) Individual unlearning, organizational unlearning and strategic flexibility: the down-up change perspective. Balt J Manag 14(1):2-18

Watson RJD, Richardson PH (1999) Accessing the literature on outcome studies in group psychotherapy: the sensitivity and precision of Medline and PsycINFO bibliographic database searching. Br J Med Psychol 72:127-134

Weick KE, Westley F (1996) Organizational learning: affirming an oxymoron. In: Clegg SR, Hardy C, Nord WR (eds) Handbook of organizational studies. Sage, California, pp 440-458

Wieland S, Dickersin K (2005) Selective exposure reporting and Medline indexing limited the search sensitivity for observational studies of the adverse effects of oral contraceptives. J Clin Epidemiol 58(6):560-567

Wilkins AL, Bristow NJ (1987) For successful organization culture, honor your past. Acad Manag Exec 1(3):221-228

Wu L, Wang D, Evans JA (2019) Large teams develop and small teams disrupt science and technology. Nature 566(7744):378-382

Xi JM, Kraus S, Filser M, Kellermanns FW (2015) Mapping the field of family business research: past trends and future directions. Int Entrep Manag J 11(1):113-132

Yang KP, Chou C, Chiu YJ (2014) How unlearning affects radical innovation: the dynamics of social capital and slack resources. Technol Forecast Soc Chang 87:152-163

Yildiz HE, Fey CF (2010) Compatibility and unlearning in knowledge transfer in mergers and acquisitions. Scand J Manag 26(4):448-456

Zahra SA, Abdelgawad SG, Tsang EW (2011) Emerging multinationals venturing into developed economies: implications for learning, unlearning, and entrepreneurial capability. J Manag Inq 20(3):323-330

Zeng J, Glaister KW, Darwish T (2019) Processes underlying MNE subsidiary absorptive capacity: evidence from emerging markets. Manag Int Rev 59(6):949-979

Zhao Y, Lu Y, Wang X (2013) Organizational unlearning and organizational relearning: a dynamic process of knowledge management. J Knowl Manag 17(6):902-912

Publisher's Note Springer Nature remains neutral with regard to jurisdictional claims in published maps and institutional affiliations. 